\title{
Genetic and nongenetic studies of schizophrenia
}

\author{
Citation for published version (APA):
}

Grech, A. (2011). Genetic and nongenetic studies of schizophrenia. [Doctoral Thesis, Maastricht University]. Datawyse / Universitaire Pers Maastricht. https://doi.org/10.26481/dis.20111207ag

Document status and date:

Published: 01/01/2011

DOI:

10.26481/dis.20111207ag

Document Version:

Publisher's PDF, also known as Version of record

\section{Please check the document version of this publication:}

- A submitted manuscript is the version of the article upon submission and before peer-review. There can be important differences between the submitted version and the official published version of record.

People interested in the research are advised to contact the author for the final version of the publication, or visit the DOI to the publisher's website.

- The final author version and the galley proof are versions of the publication after peer review.

- The final published version features the final layout of the paper including the volume, issue and page numbers.

Link to publication

\footnotetext{
General rights rights.

- You may freely distribute the URL identifying the publication in the public portal. please follow below link for the End User Agreement:

www.umlib.nl/taverne-license

Take down policy

If you believe that this document breaches copyright please contact us at:

repository@maastrichtuniversity.nl

providing details and we will investigate your claim.
}

Copyright and moral rights for the publications made accessible in the public portal are retained by the authors and/or other copyright owners and it is a condition of accessing publications that users recognise and abide by the legal requirements associated with these

- Users may download and print one copy of any publication from the public portal for the purpose of private study or research.

- You may not further distribute the material or use it for any profit-making activity or commercial gain

If the publication is distributed under the terms of Article $25 \mathrm{fa}$ of the Dutch Copyright Act, indicated by the "Taverne" license above, 
GENETIC AND NONGENETIC STUDIES

OF SCHIZOPHRENIA 
(c) Copyright Anton Grech, Gozo, Malta 2011

\section{ISBN 9789461590855}

Production: Datawyse | Universitaire Pers Maastricht

All rights reserved. No part of this publication may be reproduced, stored in a retrieval system, or transmitted, in any form or by any means, electronic, mechanical, photocopying, recording, or otherwise, without the prior permission in writing from the proprietor. 


\title{
GENETIC AND NONGENETIC STUDIES OF SCHIZOPHRENIA
}

\author{
ACADEMIC DISSERTATION \\ to obtain the degree of Doctor at Maastricht University, \\ on the authority of the Rector Magnificus, \\ Prof. dr. G.P.M.F. Mols \\ in accordance with the decision of the Board of Deans, \\ to be defended in public on \\ Wednesday, 7th December 2011, at 10.00 hrs. a.m. \\ by
}

ANTON GRECH

Born Malta on 16 November 1967

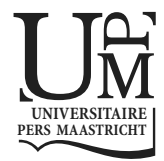




\section{Promotor}

Prof. Jim van Os

\section{Assessment committee}

Prof. dr. I. Myin-Germeys, chair

Dr. Ph.A.E.G. Delespaul

Prof. dr. P.B. Jones, Cambridge, UK

Prof. dr. R. Murray, London, UK

Prof. dr. M.W. de Vries 


\section{Table of contents}

$\begin{array}{lll}\text { Chapter } 1 & \text { Introduction } & 7\end{array}$

Chapter 2 Brain volumes in familial and non-familial schizophrenic 29 probands and their unaffected relatives

Chapter 3 Normal Cerebral Asymmetry in Familial and Non-familial Schizophrenic Probands and their Unaffected Relatives

Chapter 4 The relationship between volumetric brain changes and cognitive function: A family study on schizophrenia

Chapter 5 Maternal Exposure to Influenza and Paranoid Schizophrenia

Chapter 6 Socioeconomic status and population density risk factors for psychosis? A prospective incidence of the Maltese Islands

Chapter 7 Cannabis Use and Outcome of Recent Onset Pychosis

Chapter 8 Cannabis Use and Age of Admission to a Psychiatric Unit for First Episode of Psychosis; a Whole Population Based Study 

Chapter 1

Introduction 
Schizophrenia, the 'heartland of psychiatry', has been studied extensively especially what might be its aetiology. However the causes of schizophrenia are still mostly unknown and the extent of the role of the genetic and non genetic factors in this aetiology has yet to be established. Not only is the extent of these factors yet unknown, but there are still ongoing studies to establish what exactly are these genes and non genetic factors.

There are several approaches of how to study these possible aetiological factors of schizophrenia. One of the approaches as the regards the genetic factors is by means of family studies. Epidemiological studies, assessing the association between schizophrenia and presumed causal factors, are another way of studying the non genetic factors. Both approaches of study have been used in the studies for this Phd dissertation. The family studies have focused on structural brain abnormalities and neuropsychological deficits, as possible endophenotypic markers. The epidemiological studies were on the possible causal factors cannabis, prenatal exposure to influenza, urbanicity and socio-economic status.

\section{Genetic Studies}

It is accepted now that schizophrenia, like a large number of other illnesses, has a tendency to run in families. Emil Kraeplin, in 1919, had observed this in 'dementia praecox', the forerunner of schizophrenia (Kraeplin, 1919).

A scientific approach to assess if, and if positive to what extent, Schizophrenia or any of its traits aggregates in families is the 'Family Studies'. In family studies, the rate of schizophrenia (or the rate of a trait of schizophrenia), is examined in the relatives of patients with schizophrenia, and it is compared to the rate of schizophrenia (or to the rate of a trait of schizophrenia) in the general population or a control group. Gottesman pooled the results of about forty European family studies done between 1920 and 1987 (Gottesman, 1991). These studies showed that the lifetime risk of developing schizophrenia in relatives of patients with schizophrenia, increased with the degree of genetic relatedness to the patient with schizophrenia. Thus while the risk of third degree relatives was $2 \%$, for an individual where both parent and sibling have schizophrenia, the risk of developing schizophrenia was $17 \%$. Most of these studies were performed before the advent of clear defined criteria of schizophrenia, but similar studies using operationalized diagnostic criteria of schizophrenia have shown similar trends (Gershon et al., 1988; Kendler et al., 1993; Maier et al., 1993).

Problems in the genetic studies of schizophrenia include the fact that there is a long and complex pathway between genes and the phenotype (schizophrenia). The phenotype is diagnosed purely qualitatively (clinically), and there are no biological tests to confirm diagnosis. Also, the human brain is a very complex organ. It is not 
like other organs with a small number of common cellular types. Neurons are frequently distinct from one another in their cellular processes and in their local and regional networks. Considering these complexities, together with the likelihood of a continuous genetic liability of schizophrenia within the general population, genetic studies can be underpowered if they study only the phenotype of patients with schizophrenia versus to those not affected with schizophrenia. As a possible solution to this, research focused on 'Endophenotypes' (Gottesman \& Gould, 2003; Wickham \& Murray, 1997), that are quantitative markers of neurobiological or cognitive dysfunction. Since endophenotypes are measured quantitavely and represent effects more proximal to the genetic sequence than schizophrenia itself, their heritability may be simpler and more amenable to research.

Endophenotypes should ideally fulfill six criteria to be useful in genetic studies (Gershon\& Goldin, 1986; Leboyer et al., 1998). They should:

1. Be heritable themselves,

2. Be associated with the illness in the general population,

3. Be state independent, i.e. be manifest whether or not the illness is active,

4. Co-segregate with the illness within families, i.e. the illness is more prevalent among relatives who manifest the marker than among those relatives who do not,

5. Be measurable in both affected and unaffected subjects,

6. Be found more frequently among the biological relatives of patients than in healthy controls.

Some of these criteria are too strict for psychotic illness. But a very important criterion for endophenotypes is the latter one, i.e. that it must be found more frequently among the biological relatives of patients than in healthy controls. The best way to elicit this when looking for endophenotypes of an illness is to assess first degree relatives of patients with the illness. Ideally one should study the unaffected twins of monozygotic pairs when one of them has schizophrenia since they share exactly the same genetic sequence. Because of the logistic problems to have large samples of such twins, a more widely used approach is to examine the first degree relatives of patients. Such a study is the Maudsley Family Study of Psychosis (McDonald, 2008). Furthermore, this study also tried to broaden the likely genetic load of first degree relatives studied by making a distinction between families where only one member had schizophrenia and families where more than one member had schizophrenia. This approach does not exclude the possibility that in families where only one member of the family is affected by schizophrenia the other unaffected family members can have abnormalities that are potential endophenotypic markers resulting from susceptibility genes for the illness. But it assumes that such markers would be more prominent among relatives of families where more than one individual is affected by schizophrenia. This study also took into consideration the concept of 
'presumed obligate carriers', which are individuals unaffected by schizophrenia, but since they were members of families with individuals affected by schizophrenia and one of their offspring had schizophrenia, they appeared the ones that were transmit the genetic risk of schizophrenia to their affected offspring.

Putative endophenotypic markers for schizophrenia include structural brain abnormalities and neuropsychological deficits.

The presence of structural brain abnormalities in schizophrenia has been documented significantly over the last three decades (Gur et al., 2007). Contrasting ideas about the cause of these structural brain changes state that they might be a non specific effect of the illness/treatment or that they predate the onset of the illness. If they predate the onset of the schizophrenia, then these structural brain changes may be markers of vulnerability to schizophrenia, and thus possible endophenotypic markers.

One of the structural brain changes associated in some studies with schizophrenia is the loss of normal fronto-occipital asymmetry that is present in non affected individuals (De Lisi et al., 1997). Crow postulated that the reported loss of cerebral asymmetry in schizophrenia is related to a failure to establish cerebral dominance and is most likely under genetic control (Crow, 1997). Thus, this loss of asymmetry was studied as a possible marker for genetic risk of schizophrenia (Sharma et al., 1999). That patients with schizophrenia have enlarged ventricles is an accepted finding in schizophrenia research (Gur et al., 2007). It has thus also been studied as a possible endophenotypic marker (Sharma et al., 1998). Since it has been postulated that perinatal hypoxia can play a role in the cause of the structural brain changes in schizophrenia (Murray et al., 1985) in our study we have included the possible role of perinatal obstetric complications in this scenario.

Patients with schizophrenia have neuropsychological impairments (Palmer et al., 2009), and it has been shown that neuropsychological impairments are also present in their first degree relatives (Toulopoulou et al., 2003a, 2003b). Studies have tried to elicit if the type of relationship between the structural brain changes and cognitive function in patients with schizophrenia is different or not from that found in normal circumstances. The quality of this relationship is less studied in first degree relatives of patients with schizophrenia, and is another important area of study within the context of looking for the possible endophenotypic markers for this illness. 


\section{Nongenetic Studies}

\section{Prenatal Exposure to Influenza}

It has been postulated that various events occurring during pregnancy could influence the brain development of a fetus in such a way that the risk of development of schizophrenia increases. Such events include infections, and one that has been studied extensively is exposure to the influenza virus.

There were several epidemiological studies, as Table 2 shows, that showed a positive association between prenatal exposure to influenza and development of schizophrenia in adult life. All the studies in Table 2 showed that the association occurred when the exposure to influenza was in the $2^{\text {nd }}$ trimester. Three of these studies found that this association was mostly in female schizophrenic patients (Adams et al., 1993, Kunugi et al., 1995, Izumoto et al., 1996). One of the main problems of these studies was how the presence of exposure to influenza was determined. Exposure was considered to be present if during the gestation period there was an influenza epidemic, independently of the fact if the mother had actually an influenza infection or not.

\section{TABLE 2}

Studies showing a positive relationship between prenatal exposure to influenza during the second trimester and development of schizophrenia

\begin{tabular}{llll}
\hline Author & $\begin{array}{l}\text { Location } \\
\text { of study }\end{array}$ & $\begin{array}{l}\text { Sample } \\
\text { size }\end{array}$ & Exposure \\
\hline Watson et al., (1984) & USA & 3,246 & Seasonal Influenza \\
Mednick et al., (1988) & Finland & 1,781 & $\begin{array}{l}\text { 1957 A2 Epidemic } \\
\text { Barr et al., (1990) }\end{array}$ \\
Denmark & 7,239 & Epidemics between 1911 and 1950 \\
O'Callaghan (1991) & England & 339 & 1957 A2 Epidemic \\
Adams et al., (1993) & Scotland & 16,960 & Influenza outbreaks from 1911 to 1960 \\
& England & 22,021 & \\
McGrath and Castle (1995) & Australia & 378,606 & Influenza outbreaks in 1954, 1957 and 1959. \\
Kunugi et al., (1995) & Japan & 1,284 & 1957 A/B mixed and A2 epidemic \\
Takei et al., (1996) & Denmark & 9,462 & Outbreaks from 1915 to 1970 \\
Izumoto et al., (1999) & Japan & 941 & 1957 A2 epidemic \\
Limosin et al., (2003) & France & 974 & Influenza epidemics from 1949 to 1981 \\
\hline
\end{tabular}

The studies shown in Table 3 did not find an association between prenatal exposure to influenza and development of schizophrenia. The design of these studies was similar to those of Table 2. 
TABLE 3

Studies not showing a positive relationship between prenatal exposure to influenza and development of schizophrenia

\begin{tabular}{|c|c|c|c|}
\hline Author & $\begin{array}{l}\text { Location } \\
\text { of study }\end{array}$ & $\begin{array}{l}\text { Sample } \\
\text { size }\end{array}$ & Exposure \\
\hline Kendell et al., (1989) & Scotland & 18,476 & $\begin{array}{l}\text { 1919-1919 and } 1957 \text { influenza A epidemics in Edin- } \\
\text { burgh, Scotland }\end{array}$ \\
\hline Selten and Slaets, (1994) & Netherlands & 4,634 & 1957 influenza A2 epidemic in the Netherlands \\
\hline Susser et al., (1994) & Netherlands & 1,371 & 1957 influenza A2 epidemic in the Netherlands \\
\hline Cannon et al., (1996) & Ireland & 570 & 1957 influenza A2 epidemic in Ireland \\
\hline Morgan et al., (1997) & Australia & 1,852 & Six epidemics from 1950 to 1960 in Australia \\
\hline Selten et al., (1998) & Netherlands & 1,538 & $\begin{array}{l}1957 \text { influenza A2 epidemic in Antillean and Surinam- } \\
\text { ese immigrants in the Netherlands }\end{array}$ \\
\hline Mino et al., (2000) & Japan & 2,715 & 1957-58, 1962 and 1965 influenza epidemics in Japan \\
\hline
\end{tabular}

As the above two tables show, a significant number of ecological studies on the prenatal exposure to influenza and schizophrenia were based on the mothers' exposure to influenza during the 1957 pandemic in several countries. Selten et al (2009) have conducted a meta-analysis of the relevant studies to examine whether birth during the 9-month period after the pandemic of 1957 was a risk factor for schizophrenia. The analysis collapsed the studies into three groups: a group for studies conducted in the United States, Europe and Australia, a separated group for studies conducted in Japan since the epidemic came in 2 waves, and a group for studies who examined the risk for schizophrenia among subjects born to mothers who were pregnant during the pandemic and reported having had influenza. In none of these three groups was found a significantly increased risk for schizophrenia due to 1957 influenza pandemic, and the authors concluded that the evidence to support the maternal influenza hypothesis was insufficient.

\section{Urbanicity and Social Class}

In 1939, Faris and Dunham (Faris \& Dunham 1939) published a classic ecological study on psychosis in Chicago. In this work they studied the distribution of psychosis within different environments and their social organization. In this study they found that the least socially organized inner urban zones had higher rates of schizophrenia. This finding was replicated in studies done in other cities in the United States during the same era (Schroeder, 1942). These studies initiated epidemiological research into the possible association between urbanicity and schizophrenia, the vast majority of these studies showing an increased rate of psychosis in relation to urbanicity.

These studies consisted of assessing rates of psychosis according to urbanicity. These studies have defined the exposure to an urban environment either by com- 
paring schizophrenia in urban to rural/non urban areas, or more commonly by defining areas of urbanicity according to increase in population density. The latter had the advantage of allowing for a dose response result.

Four studies defined urbanicity by using the urban vs. rural/ non urban/ non city dichotomy. One of these studies (Thornicroft et al., 1993) did not find an association between schizophrenia and urbanicity, and the three other studies have found a higher incidence of schizophrenia in the urban area (Takei et al., 1995, Allardyce et al., 2001, Kirkbride et al., 2006).

The study that showed the strongest association in a dose-response relationship was done by Eaton et al (2000). Subjects were taken from the Danish Medical Birth Register and Danish Psychiatric Case Register, and studied persons born 1973 or later, and who entered a Danish psychiatric hospital before 1994. The controls were drawn from a $10 \%$ sample of the Medical Birth Register. Exposure was defined into five categories, i.e.: capital, capital suburb, large city, small city, rural area. The risk of hospitalization for schizophrenia was 4.20 times higher (95\% Cl=2.4-7.4) for those born in Copenhagen versus those born in rural areas of Denmark, and a linear relationship was demonstrated between urbanization of birthplace and risk. Other studies have also shown a dose-response relation between exposure to urban environment and risk of psychosis (Eaton et al., 1974, Marcelis et al., 1998, Schelin et al., 2000, Sundquist et al., 2004).

It has been suggested that a possible reason for the studies showing elevated rates of schizophrenia in urban areas is due to patients with schizophrenia moving ('drifting') to these areas. To investigate this, studies focused on exposure prior to the onset of illness. Marcelis et al (1999) performed a population-based birth cohort study in which all individuals born between 1972 and 1978 were followed up through the Dutch National Psychiatric Case Register for first admission for schizophrenia until 1995 (maximum age 23 years). Exposure status was defined by a combination of place of birth and place of residence at the time of illness onset, and exposure to schizophrenia was examined in four different exposure groups using various combinations of exposure when born and at residence. The greatest risk for schizophrenia was found among those exposed at birth and not around the time of onset of illness. There were several other studies that that examined exposure to urbanicity at time of birth, and these studies are summarized in Table 4. Overall, these studies reported that this exposure resulted in an approximate doubling in risk of psychosis in adulthood. 


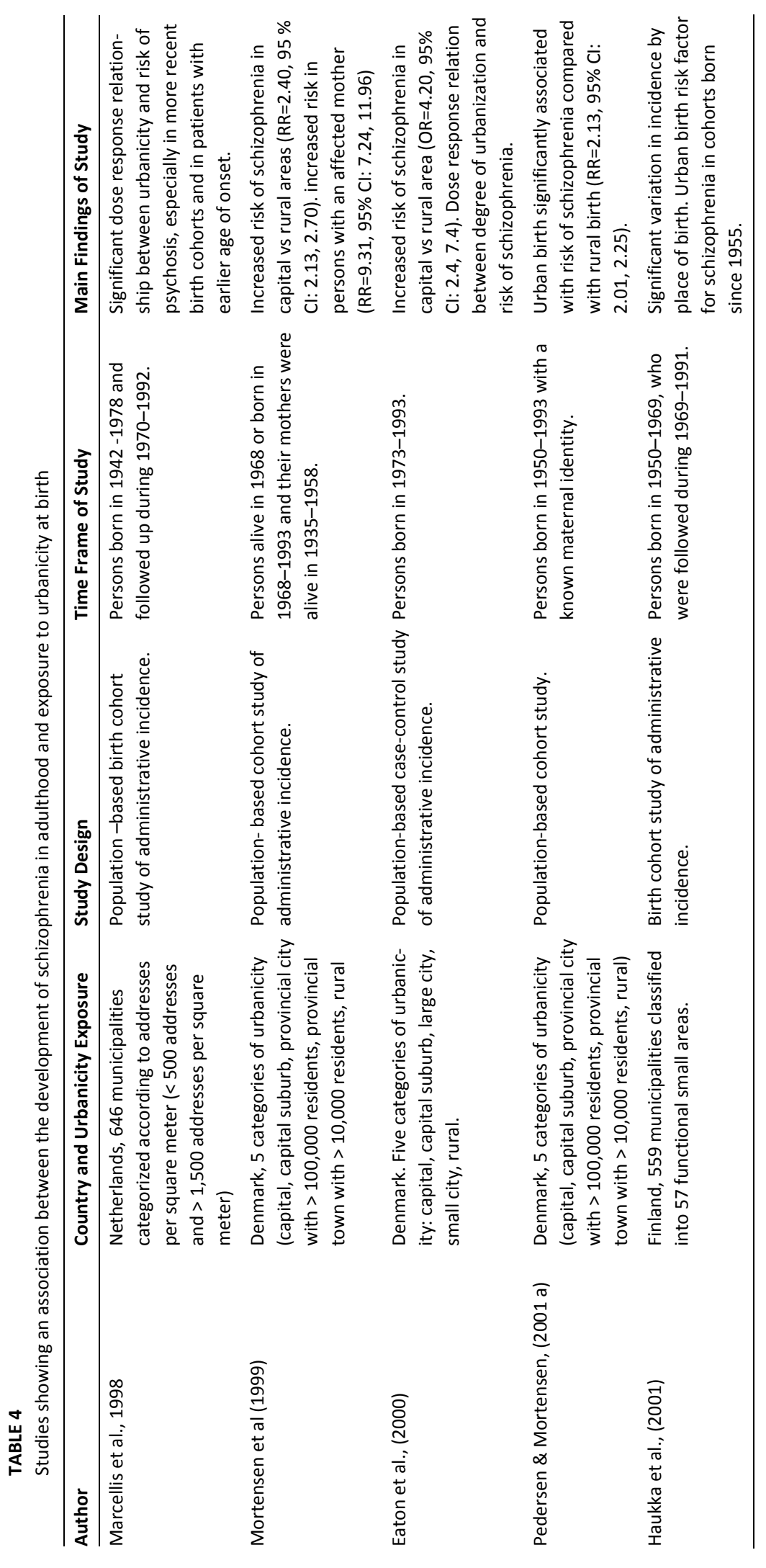




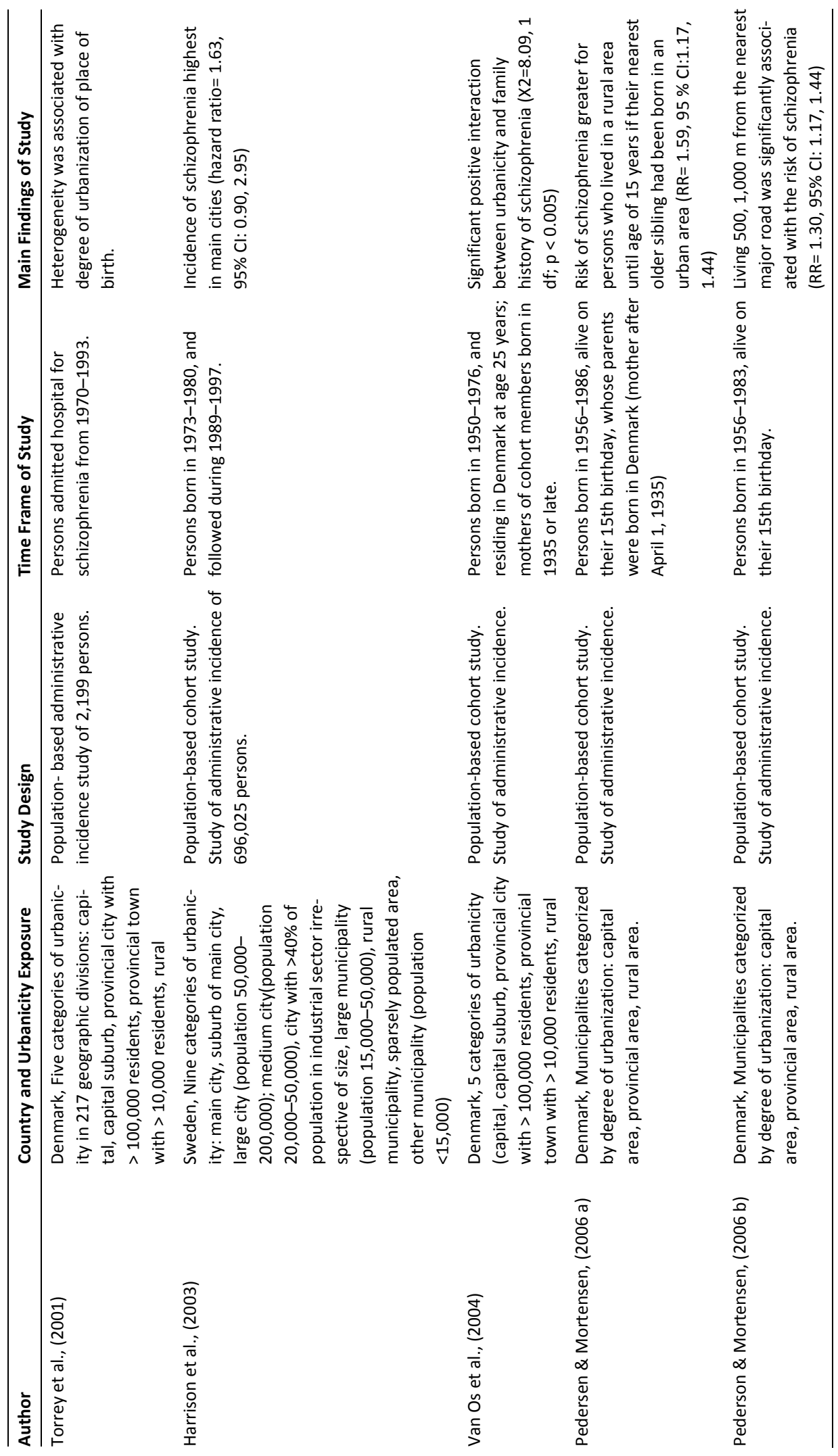


An important study conducted by Pedersen et al (2001b) has also shown that the association between urbanicity and schizophrenia before its onset, is not due to a selective drift to urban areas in those at genetic risk for psychosis. This study was a longitudinal study to discriminate the effect of urbanicity at birth from the effect of urbanicity during upbringing. It showed that moving from a rural area to an urban area increased the risk of developing schizophrenia, and vice versa. Individuals living in a higher degree of urbanization than 5 years earlier had a 1.40 fold $(95 \%$ confidence interval, 1.28-1.51) increased risk, while individuals living in a lower degree of urbanization than 5 years earlier had a 0.82 fold (95\%confidence interval $0.77-$ 0.88 ) decreased risk for schizophrenia.

Another very significant contribution that classic study 'Mental Disorders in Urban Areas' of Faris and Dunham mentioned above (Faris et al., 1939) did to the research into the understanding of schizophrenia, was that it has stimulated research into the association between social class and psychosis. Throughout the twentieth century, studies have found that having schizophrenia is associated with lower social class (Susser et al., 2006). Eventually this resulted into the debate if association found between lower social class and schizophrenia was a cause or a consequence of schizophrenia (Goldberg \& Morrison, 1963). This is because there are two mechanisms by which this association could be explained. The first possibility is that lower social class is associated with the incidence (onset) of schizophrenia, i.e. being of lower social class is an aetiological factor in the development of schizophrenia. The other possibility is that one of the results of having schizophrenia could be of becoming part of a lower social class category. This could happen by one of the two processes labeled as 'selection' and 'drift'. 'Selection' is a process that occurs from one generation to the next, in which individuals are selected into various social positions before and during the prodromal phase of schizophrenia. 'Drift' occurs in the same generation, and it is the process by which individuals with schizophrenia, after onset of their illness, ultimately occupy various social positions (March et al., 2008).

In a classical study, Goldberg et al., (1963) examined the association of social class at birth with that after the development of schizophrenia. Social class at birth was assessed by the parental occupation at that time. This study showed that there was no difference between the social classes of patients with schizophrenia at birth when compared with that of the general population. This study was in support of the theory that patients with schizophrenia 'drift' into lower social class. Recent population cohort studies that use paternal occupation as indicator of social class conducted and that were conducted in Scandinavia and United Kingdom have supported this finding. (Jones et al., 1994; Mäkikyrö et al.; 1997, Wicks et al., 2005).

Dohrenwend et al., (1992) used ethnic status as a measure of social status. They chose ethnic status because it is present at birth and thus cannot be an effect of the disorder, whereas socioeconomic status depends on educational and occupational 
attainment. They studied 4,914 young Israeli born adults of different ethnic origin, and compared those of the 'advantaged ethnic group' (European origin) to those of a 'disadvantaged ethnic group' (North African origin). In this study they included diagnosis of schizophrenia, major depression, antisocial personality disorder and substance use disorder. They found, that contrary to affective disorder, schizophrenia rates are higher in subjects of European background (the 'advantaged ethnic group'). Thus they concluded that the association between schizophrenia and social class was due to persons with schizophrenia moving to a lower socioeconomic status.

\section{Cannabis}

The major psychoactive ingredient of cannabis is tetrahydrocannabinol (THC). Its structure was elucidated by Raphael Mechoulam and colleagues in the 1960's (Mechoulam et al., 2000). Cannabis is in the medical world a controversial subject. Controversy exists if it should be considered a beneficial or harmful substance. It has been promoted as valuable to people with chronic pain, and to control spasticity in multiple sclerosis (Pacher et al., 2006). But the repeated studies showing an association between cannabis and psychosis are on the other hand a source of concern.

Cannabis is the illicit drug most commonly abused by patients with psychosis. This does not only reflect the widespread use of cannabis in the general population. In case- control studies, patients with schizophrenia are more likely to use cannabis than other psychiatric patients or normal controls (Schneier and Siris, 1987; Smith and Huckler, 1994; Warner et al., 1994). Grech at al., (1998) compared psychotic patients from two different cultural settings, London and Malta. Use of all illicit drugs (including cannabis) was much more widespread in London than Malta. Both in London and Malta, psychotic patients used illicit substances more than controls. A particularly strong association between cannabis abuse and psychosis was shown by the fact that Odds Ratio for cannabis abuse in patients over controls was greater in both centres than the Odds Ratio for substance abuse in general and for any other type of substance.

But controversy exists about what is the reason for this association between cannabis and psychosis, since there is more than one possibility.

Some researchers consider the higher consumption of cannabis by psychotic patients as an attempt to relieve distressing symptoms of their illness, or the adverse side-effects of antipsychotic medications (Peralta \& Cuesta 1992; Khantzian 1997).

But, prospective epidemiological studies have also suggested that cannabis is an independent risk factor for the development of schizophrenia. For example, an association between self reported use of cannabis in adolescence and subsequent 
use of schizophrenia was reported from a study of Swedish conscripts (Andreason et al., 1987). This study consisted of a 15-year follow-up study of a cohort of 45,570 Swedish conscripts. In this cohort the relative risk for schizophrenia among high consumers of cannabis (use on more than fifty occasions) was 6.0 ( $95 \%$ confidence interval 4.0-8.9) compared with non-users. Persistence of the association after allowance for other psychiatric illness and social background indicated that cannabis is an independent risk factor for schizophrenia. This study was criticized because this result could have been due to the use of drugs other than cannabis, and because personality traits may have confounded the results. Thus, the same cohort was analyzed further to answer these queries (Zammit et al., 2002). This further analysis still showed that cannabis use was associated with increased risk of schizophrenia in a dose dependent fashion. This association remained when analysis included only subjects who had used only cannabis and no other drugs before conscription. Further analysis also showed that this association is not explained by personality traits relating to social integration. A 3 year longitudinal study held in Netherlands of 4384 individuals, has replicated, and extended these findings. It showed that cannabis use at baseline predicted an increased risk of developing psychotic symptoms at follow-up (van Os et al., 2002). This risk was in individuals who have not reported psychiatric symptoms at baseline, it was dose dependent on frequency of cannabis use at baseline, persisted after statistical allowance for the effects of other drug use, and was stronger for cases with more severe psychotic symptoms that were considered to need psychiatric care. Importantly, this study also showed that those who reported psychotic symptoms at baseline were more likely to develop schizophrenia if they used cannabis, than were individuals with no psychotic symptoms at baseline. There were other longitudinal studies that have also confirmed that cannabis use is an independent risk factor for developing schizophrenia (Arseneault et al., 2002, Fergusson et al., 2003, Henquet et al., 2005).

Research has also focused also on the possible alteration of psychotic illness (age of onset and outcome), by cannabis use. Since studies have indicated the very possible aetiological role of cannabis in the development of schizophrenia, one can hypothesize that cannabis use can hasten the onset of psychotic illness, and thus patients with schizophrenia who abuse cannabis have an earlier age of onset than those who do not. A population based study conducted in The Hague (Netherlands) on 133 patients with a first onset episode of schizophrenia, concluded that there was a strong association between use of cannabis and earlier age at first psychotic episode in male patients with schizophrenia (Veen et al., 2004). Three other studies conducted on patients with first episode of psychosis have replicated the finding of an association between cannabis use and an earlier age of onset of psychosis, and in two of these studies this was for both males and females (Gonzalez-Pinto, et al., 2008; Compton et al., 2009). Sugranyes et al (2009), conducted a study on 116 patients with first episode psychosis and subsequent diagnosis of schizophrenia (after 
a 12-month follow-up). Their findings showed that cannabis use was significantly associated with a decrease in age of first antipsychotic treatment, and that this correlated with frequency of cannabis use (Sugranyes et al., 2009).

TABLE 1

Studies on the influence of Cannabis on the outcome of psychosis

\begin{tabular}{|c|c|c|c|c|}
\hline Author & Location & $\begin{array}{l}\text { Sample } \\
\text { Size }\end{array}$ & $\begin{array}{l}\text { Length of } \\
\text { follow-up }\end{array}$ & Outcome \\
\hline $\begin{array}{l}\text { Martinez-Arevalo } \\
\text { et al. (1994) }\end{array}$ & $\begin{array}{l}\text { Madrid } \\
\text { (Spain) }\end{array}$ & 62 & 12 months & $\begin{array}{l}\text { Relapse of schizophrenia increased by } \\
\text { cannabis use, with evidence strongest } \\
\text { for continued use. }\end{array}$ \\
\hline $\begin{array}{l}\text { Linszen et al., } \\
\text { (1994) }\end{array}$ & (Netherlands) & 93 & 12 months & $\begin{array}{l}\text { Patients who abused cannabis had } \\
\text { significantly more and earlier psychotic } \\
\text { relapses. This association became } \\
\text { stronger when heavy (as compared to } \\
\text { milder) cannabis use was assessed. }\end{array}$ \\
\hline $\begin{array}{l}\text { Caspari } \\
\text { (1999) }\end{array}$ & $\begin{array}{l}\text { Hamburg } \\
\text { (Germany) }\end{array}$ & 27 & 69 months & $\begin{array}{l}\text { History of cannabis use had significantly } \\
\text { more hospitalizations, tended to have } \\
\text { worse psychological functioning, and } \\
\text { showed more thought disorder and } \\
\text { hostility. }\end{array}$ \\
\hline $\begin{array}{l}\text { Pencer et al. } \\
\text { (2005) }\end{array}$ & $\begin{array}{l}\text { Calgary } \\
\text { (Canada) }\end{array}$ & 138 & 24 months & $\begin{array}{l}\text { Adolescents with schizophrenia (com- } \\
\text { pared to adults with schizophrenia) } \\
\text { used more cannabis and had increased } \\
\text { number of relapses. }\end{array}$ \\
\hline $\begin{array}{l}\text { Stirling et al., } \\
(2005)\end{array}$ & $\begin{array}{l}\text { Manchester } \\
\text { (United Kingdom) }\end{array}$ & 69 & $\begin{array}{l}\text { Between } \\
120 \text { and } 144 \\
\text { months }\end{array}$ & $\begin{array}{l}\text { Cannabis use was not associated with } \\
\text { positive or negative symptoms at follow } \\
\text {-up. Cannabis users at follow-up had } \\
\text { 'sparing' of neurocognitive functions. }\end{array}$ \\
\hline $\begin{array}{l}\text { Hides et al., } \\
\text { (2006) }\end{array}$ & $\begin{array}{l}\text { Brisbane } \\
\text { (Australia) }\end{array}$ & 121 & 6 months & $\begin{array}{l}\text { A higher frequency of cannabis use was } \\
\text { predictive of psychotic relapse. (An } \\
\text { increase in psychotic symptoms was } \\
\text { predictive of relapse of cannabis use, } \\
\text { and medication adherence reduced } \\
\text { cannabis relapse risk) }\end{array}$ \\
\hline $\begin{array}{l}\text { Degenhardt et al., } \\
\text { (2007) }\end{array}$ & $\begin{array}{l}\text { Sydney } \\
\text { (Australia) }\end{array}$ & 101 & 10 months & $\begin{array}{l}\text { Cannabis use predicted a small but } \\
\text { statistically significant increase in symp- } \\
\text { toms of psychosis. (Symptoms of psy- } \\
\text { chosis did not predict cannabis use) }\end{array}$ \\
\hline $\begin{array}{l}\text { Gonzalez -Pinto } \\
\text { et al., (2009) }\end{array}$ & $\begin{array}{l}\text { Vitoria } \\
\text { (Spain) }\end{array}$ & 92 & 96 & $\begin{array}{l}\text { Patients who had cannabis use before } \\
\text { their first episode of psychosis and } \\
\text { stopped its use during follow-up exhib- } \\
\text { ited better long-term functional out- } \\
\text { come compared with patients who have } \\
\text { never used cannabis, or that have used } \\
\text { cannabis both before onset of first } \\
\text { psychotic episode and at follow up }\end{array}$ \\
\hline
\end{tabular}


In 1994, Martinez-Aerovalo et al. and Linszen et al., both published studies in which they followed for 12 months patients with psychosis. In both studies, patients who abused cannabis had a worse outcome than those who did not. Table 1 is a summary of the other follow-up studies (except the study to be presented in this thesis), on the influence of cannabis on the outcome of psychotic illness. The various studies used different outcome measures to assess different aspects of psychotic illness. Despite this, all studies, except the one done in Manchester by Stirling et al. (2005), showed a negative influence of cannabis on the outcome of psychotic illness.

\section{Genetic Studies in this Thesis}

As stated above, a way of getting more information on the genetic causes of schizophrenia is by means of Family Studies on Schizophrenia that assess 'Putative Endophenotypic Markers'. The latter include structural brain abnormalities and neuropsychological deficits. In the section of the thesis dealing with genetic studies of schizophrenia I am going to include three Family Studies on Schizophrenia in which brain structural abnormalities were studied. In one of these studies, neuropsychological deficits were also studied alongside brain structures. These three studies were part of the 'Maudsley Family Study of Psychosis', a large project with the ultimate aim of elucidating more information on the Endophenotypes of Schizophrenia (McDonald, 2008) whose rationale was explained above.

In all the three studies the Structural brain changes were assessed by means of Brain MRI's, that had their images analyzed using the software MEASURE (Barta et al., 1997).

The first two studies of the thesis examine structural brain changes found in patients with schizophrenia and their relatives. These two studies were designed to provide a gradient of genetic risk for schizophrenia in first degree relatives of probands with a diagnosis of schizophrenia. This was done by studying two sets of families. One set consisted of families, in which there was more than one member affected by schizophrenia. The non affected relatives in these families included parents that appeared to transmit the genetic risk to their children and were labeled as 'presumed obligate carriers'. The other set consisted of families with no other affected individual with schizophrenia. First degree relatives were then categorized according to reducing genetic risk as: presumed obligate carriers, relatives of probands in families multiply affected by schizophrenia, and relatives of probands in families where only one member was affected by schizophrenia.

The first of the two studies examined if the structural brain changes found in patients with schizophrenia and their relatives are due to genetic or obstetric complications. Brain structures studied were: whole brain, lateral ventricles, third ventricle, cerebellum and temporal lobes. We studied two sets of families. One set 
consisted of 35 probands with a diagnosis of schizophrenia of families multiply affected by schizophrenia, and 63 unaffected relatives (10 of the latter were parents considered 'presumed obligate carriers'). The other set consisted of families with no other affected individual with schizophrenia (31 schizophrenic probands, and 33 unaffected relatives). 68 controls were also used. Obstetric complications were obtained by a maternal interview using the Lewis-Murray Scale (Lewis et al., 1989). The second study focused on if the reported loss of the normal fronto-occipital asymmetry in patients with schizophrenia and in their non-affected relatives could be associated with genetic susceptibility. A measure of fronto-occipital torque was derived from the volumetric measurements of prefrontal, premotor, sensorimotor and occipitoparietal regions. Two sets of families were studied : 25 probands with schizophrenia from multiply affected families, 36 of their unaffected relatives (including 12 'presumed obligate carriers'), 34 probands from families with no another affected members, 42 of their unaffected relatives, and 76 controls.

Patients with schizophrenia and their relatives display structural brain changes proportional to the likelihood of carrying genes for schizophrenia (as shown by the first study of this thesis), and neuropsychological deficits have been found in patients with schizophrenia and to a lesser degree in their first degree relatives. These neuropsychological deficits can constitute a familial, probably genetic, risk for schizophrenia. To assess this further, in the third study of the thesis, we conducted a family study where we examined the correlation between structure and function of the brain, and if this correlation had particular characteristics in patients with schizophrenia or their relatives. We examined 56 patients with schizophrenia or schizoaffective disorder, 90 non psychotic relatives and 55 controls. Neuropsychological assessments were done by an extensive battery of tests, and the brain structures measured by MRI were for whole brain, prefrontal region, lateral ventricles, third ventricles, temporal lobes, hippocampi and cerebellum.

\section{Nongenetic studies in this thesis}

As shown in Tables 2 and 3, large epidemiological studies on the association between maternal exposure to influenza in the second trimester and schizophrenia have provided contradictory results. Since previous research has suggested that patients with schizophrenia who were exposed to influenza during their second trimester of gestation have more delusions of jealousy, delusions of reference and suspiciousness, we studied if the association between second trimester exposure to influenza and schizophrenia is particularly present for the Paranoid subtype. We studied 17,247 patients with an ICD diagnosis of schizophrenia in England and Wales that were born between 1923 and 1965. The number of deaths attributed to influenza was used as a proxy measure of the prevalence of influenza, and the exposure 
months (i.e. the fifth month prior to birth) were divided into quartiles of increasing exposure to influenza according to the frequency of these deaths. We studied if the proportion of persons with a diagnosis of paranoid schizophrenia would increase with an increase in the level of influenza exposure.

Since research has shown that urbanicity (Table 4) and lower socio-economic status are risk factors for schizophrenia, we tested if this is replicated in a whole population based study in the Maltese Islands in a prospective cross sectional study. All patients with first onset psychosis admitted to one of the psychiatric units in the Maltese islands during a one year period were included in the study. 115 patients fulfilled the inclusion criteria. The incidence of psychosis obtained for the whole of the Maltese Islands was then analyzed further by dividing the Maltese Islands into six districts with different population density and socio economic background, and incidence of psychosis for each of these districts was obtained.

As shown above, it is very possible that Cannabis has a role in the aetiology and illness alteration of schizophrenia; and its relationship to psychosis is the subject of two studies on nongenetic factors assessed in this thesis.

One study on cannabis and schizophrenia in this thesis was aimed to study if cannabis use can alter or not the course of psychosis. The study was a 4-year follow up study of a cohort of 119 patients in South London with psychosis who had onset within 5 years of index admission. The patients followed-up were divided into four groups according to duration of cannabis use, taking index admission as reference point. The four groups of cannabis use were:

1. No history of cannabis use prior to index admission or at follow-up assessment,

2. History of cannabis use at index admission but not at follow-up assessment,

3. No history of cannabis use prior to index admission but cannabis use at followup assessment, and

4. History of cannabis use prior to index admission and at follow-up assessment.

History of cannabis intake was done by means of semi-structured interviews with the probands. Follow-up clinical assessments were done blind to all index data. Positive symptoms and course of illness were assessed by means of a slightly modified version of the 'life chart' instrument from the Multi-Centre Study on the Course and Outcome of Schizophrenia (World Health Organization, 1992). Outcome of negative symptoms was measured by means of the lager Negative Symptom Rating Scale (lager et al., 1985).

The second study on cannabis and schizophrenia in this thesis was aimed to study if cannabis can hasten the age of onset of patients with psychosis, and thus implying that it has an aetiological role. This study was a one year prospective study that included all ICD-10 first episode psychosis patients admitted to a psychiatric hospital in the Maltese Islands that were 100. Age of admission to hospital was used 
as proxy for age of onset of psychosis. Use of cannabis prior to admission was ascertained by urine testing.

\section{References}

Adams, W., Kendell, R.E., Hare, E.H., Munk-Jorgensen, P., (1993) Epidemiological evidence that maternal influenza contributes to the aetiology of schizophrenia. An analysis of Scottish, English, and Danish data. Br J Psychiatry, 165 : 522-34

Allardyce, J., Boydell, J., Van Os, J., Morrison, G., Castle, D., Murray, R.M., McCreadie, R.G. (2001) Comparison of the incidence of schizophrenia in rural Dumfries and Galloway and urban Camberwell. Br J Psychiatry, 179: 335-9.

Andreason, N., Allebeck, P., Engstorm, A., Rydberg,U. (1987) Cannabis and schizophrenia. A longitudinal study of Swedish Conscripts. Lancet, 2: 1483-1486.

Arsenault, L., Cannon, M., Poulton, R., Murray, R., Caspi, A., Moffit, T.E., (2002) Cannabis use in adolescence and risk for adult psychosis: longitudinal prospective study. British Medical Journal, 325: 1212-1213.

Barr, C.E., Mednick, S.A., Munk-Jorgensen, P., (1990) Exposure to influenza epidemics during gestation and adult schizophrenia. A 40 year study. Arch Gen Psychiatry, 47: 869-74.

Barta,P.E., Dhingra,L., Royall,R., Schwart,(1997) Improving stereological estimates for volume of the structures identified in three-dimensional arrays of spatial data. J Neurosci Meth, 75:111-118.

Cannon, M., Cotter, D., Coffey, V.P., Sham, P.C., Takei, N., Larkin, C., Murray, R.M., O’Callaghan, E., (1996) Prenatal exposure to the 1957 influenza epidemic and adult schizophrenia: a follow-up study. $\mathrm{Br} \mathrm{J}$ Psychiatry, 168: 368-71.

Caspari, D. (1999) Cannabis and schizophrenia: results of a follow-up study. Eur Arch Psychiatry Clin Neurosci, 249(1): 45-49.

Compton, M.T., Kelley, M.E., Ramsay, E.C., Makenya, P., Goulding, S.M., Esterberg, M.L., Stewart,T., Walker,E.F., (2009) Association of Pre-Onset Cannabis, Alcohol, and Tobacco Use with Age at Onset of Prodrome and Age at Onset of Psychosis in First-Episode Patients. Am J Psychiatry, 166: 12511257.

Crow, T.J., (1997) Is schizophrenia the price that Homo sapiens pays for language? Schizophr Res, 28: 127-141.

Degenhardt, L., Tennant, C., Gilmour, S., Schofield, D., Nash, L., Hall, W., McKay, D., (2007) The temporal dynamics of relationships between cannabis, psychosis and depression among young adults with psychotic disorders: findings from a 10-month prospective study. Psychol Med,37: 1-8.

De Lisi, L.E., Sakuma,M., Kushner, M., Finer, D.L., Hoff, A.L., Crow, T.J., (1997) Anomalous cerebral asymmetry and language processing in schizophrenia. Schizophr Bull, 23: 255-271.

Dohrenwend, B.P., Levav, I., Shrout, P.E., Schwartz, S., Naveh, G., Link, B.G., Skodol, A.E., Stueve, A., (1992) Socioeconomic status and psychiatric disorders: the causation-selection issue. Science, 255: 946-952.

Eaton, W.W., (1974) Residence, social class and schizophrenia. J Health Soc Behav, 15: 289-99.

Eaton, W.W., Mortensen, P.B., Frydenber, M., (2000) Obstetric factors, urbanization and psychosis. Schizophr Res, 43:117-23.

Faris, R., Dunham,H., (1939) Mental disorders in urban areas. IL: University of Chicago Press.

Fergusson, D.M., Horwood, L.J., Swain-Campbell, N.R., (2003) Cannabis dependence and psychotic symptoms in young people. Psychol Med, 33: 15-21.

Fernandez-Egea, E., Sugranyes, G., Flamarique, I., Parellada, E., Baeza, I., Goti, J., \& Bernardo, M. (2009). Cannabis use and age of diagnosis of schizophrenia. European Psychiatry, 24(5), 282-286 
Gershon, E. S., Delisi, L. E., Hamovit, J., Nurnberger, J. I., Maxwell, M. E., Schreiber, J., Dauphinais, D., Dingman, C. W., \& Guroff, J. J. (1988). A Controlled Family Study of Chronic Psychoses - Schizophrenia and Schizoaffective Disorder. Archives of general psychiatry, 45(4), 328-336

Gershon, E.S., Goldin , L.R. (1986) Clinical methods in psychiatric genetics. I. Robustness of genetic marker investigative strategies. Acta Psychiatrica Scandinavica, 74: 113-118.

Goldberg,D. \& Morrison,S. (1963)Schizophrenia and social class. B J Psychiatry, 109: 785-802.

Gonzalez-Pinto, A., Vega,P., Ibanez, B., Mosquera, F., Barbeito,S., Gutierrez,M., Ruiz de Azua,S., Vieta,E., (2008) Impact of cannabis and other drugs on age of onset of psychosis. J Clin Psychiatry, 69(8): 1210-6.

Gonzalez-Pinto, A., Alberich, S., Barbeito, S., Gutierraz, M., Vega,P., Ibanez, B.,Karim Haidar, M., Vieta,E., Arang,C., (2009) Cannabis and First-Episode Psychosis: Different Long-term Outcomes Depending on Continued or Discontinued Use. Schizophrenia Bullettin 37, 631-639.

Gottesman, I.I. (1991) Schizophrenia Genesis: The Origins of Madness. New York: H Freeman \& Co.

Gottesman, I.I., Gould, T.D. (2003). The endophenotype concept in psychiatry: Etymology and strategic intentions. American Journal of Psychiatry,160: 636-645.

Grech, A., Takei,N., Murray, R., (1998) Comparison of cannabis use in psychotic patients and controls in London and Malta. Schizophr Res, 29: 22.

Gur, R.E., Keshavan, M.S, Lawrie, S.M. (2007) Deconstructing psychosis with human brain imaging. Schizophr Bull, 33 (4): 921-931.

Harrison, G., Fouskakis, D., Rasmussen, F., Tynelius, P., Sipos, A., Gunnell. D. (2003) Association between psychotic disorder and urban place of birth is not mediated by obstetric complications or childhood socio-economic position: a cohort study. Psychol Med,May;33(4):723-31.

Haukka ,J., Suvisaari, J., Varilo, T., Lönnqvist, J. (2001) Regional variation in the incidence of schizophrenia in Finland: a study of birth cohorts born from 1950 to 1969.Psychol Med, 31(6):1045-53.

Henquet, C., Krabbbendam, L., Spauwen, J., Kaplan, C., Lieb, R., Mittchen, H.U., Van Os, J., (2005) Prospective cohort study of cannabis use, predisposition for psychosis, and psychotic symptoms in young people. Br M Journal, 330: 11-14.

Hides, L., Dawe, S., Kavanagh, D.J.,Young, R.M., (2006) Psychotic symptoms and cannabis relapse in recent-onset psychosis. Br J Psychiatry,189: 137-143.

lager, A.C., Kirch,D.G., Wyatt, R.J., (1985) A negative symptom rating scale. Psychiatry Res, 16:27-36.

Izumoto, Y., Inoue, S., Yasuda, N., (1999) Schizophrenia and the influenza epidemics of 1957 in Japan. Biol Psychiatry, 46: 119-24.

Jones, P., Rodgers, B., Murray, R.M., Marmot,M M., (1994) Childhood developmental risk factors for adult schizophrenia in the British 1946 birth cohort. Lancet, 344: 1398-1402.

Kendell, R.E. \& Kemp, I.W., (1989) Maternal influenza in the etiology of schizophrenia. Arch Gen Psychiatry, 46: 878-82.

Kendler, K.S., McGuire, M., Gruenberg, A.M., O'Hare, A., Spellman, M., Walsh, D.(1993) The Roscommon Family Study. I. Methods, diagnosis of probands, and risk of schizophrenia in relatives. Arch Gen Psychiatry, 50(7): 527-40.

Khantzian, E.J., (1997) The self-medication hypothesis of substance use disorders: a reconsideration and recent applications. Harv Rev Psychiatry, 4: 231-44.

Kirkbride, J.B., Fearon, P., Morgan,C., Dazzan, P., Morgan, K., Tarrant, J., Lloyd, T., Holloway, J., Hutchinson,G., Leff, J.P., Mallett, R.M., Harrison, G.L., Murray, R.M., Jones, P.B. (2006) Heterogenity in incidence rates of schizophrenia and other psychotic disorders : findings from the 3-centre AESOP Study. Arch Gen Psychiatry, 63(3):250-8.

Kraeplin, E. (1919). Dementia praecox and paraphrenia (R.M. Barclay, trans) (p232). Edinburgh: E \& S Livingstone.

Kunugi, H., Nanko, S., Takei, N., Sait, K., Hayashi, N., Kazamasturi, H., (1995) Schizophrenia following in utero exposure to the 1957 influenza epidemics in Japan. A J Psychiatry, 152: 450-2.

Leboyer, M., Bellivier, F., Nosten-Bertrand, M., Jouvent, R., Pauls,D.,Mallet,J. (1998). Psychiatric genetics: Search for phenotypes. Trends in Neuroscience, 21,102-105. 
Lewis,S., Owen,M.J., Murray,R. (1989) Obstetric complications and schizophrenia: methodology and mechanisms.In Schultz,S.C., Taminga,C.A.,editors. Schizophrenia: a scientific focus. New York: New York University Press, p 56-68.

Limosin, F., Rouillon, F., Payan, C., Cohen, J.M., Strub, N., (2003) Prenatal exposure to influenza as a risk factor for adult schizophrenia. Acta Psychiatr Scand, 107: 331-5.

Linszen D.H., Dingemans P.M., Lenoir M.E., (1994) Cannabis abuse and the course of recent -onset schizophrenic disorders. Arch Gen Psychiatry, 51 (4), 273-279.

Maier, W., Lichtermann, D., Minges, J., Hallmayer, J., Heun, R., Benkert, O., Levinson, D.F. (1993) Continuity and discontinuity of affective disorders and schizophrenia. Results of a controlled family study. Arch Gen Psychiatry, 50(11):871-83.

Mäkikyrö ,T., Isohanni, M., Moring, J., Oja, H., Hakko, H., Jones. P., Rantakallio, P. (1997) Is a child's risk of early onset schizophrenia increased in the highest social class? Schizophr Res, 23: 245-252.

Marcelis, M., Navarro-Mateu, F., Murray, R., Selten, J.P., Van Os, J. (1998) Urbanization and psychosis: a study of 1942-1978 birth cohorts in The Netherlands. Psychol Med, 28(4):871-9.

Marcelis,M., Takei,N., Van Os,J. (1999) Urbanization and risk for schizophrenia: does the effect operate before or around the time of illness onset? Psychol Med, 29:1197-203.

March,D., Hatch,S.L., Morgan,C., Kirkbride,B.,Bresenahan,M.,Fearon,P.,Susser,E. (2008) Psychosisand Place. Epidemiol Rev, 30: 84-100.

Martinez-Arevalo, M.J., Calcedo-Ordonez, A., Varo-Prieto, J.R., (1994) Cannabis consumption as a prognostic factor in schizophrenia. Br J Psychiatry,164: 679-81.

McDonald, C. (2008). The Maudsley Family Study of Psychosis, A Quest for Intermediate Phenotypes. Maudsley Monograph.

McGrath, J. \& Castle, D (1995) Does influenza cause schizophrenia? A five year review. Aust NZ J Psychiatry, $29: 23-31$.

Mechoulam, R. \& Hanus, L.A., (2000) A historical overview of chemical research on cannabinoids. Chem. Phys. Lipids, 108: 1-13.

Mednick, S.A., Machon, R.A., Huttunen, M.O., Bonett, D., (1988) Adult schizophrenia following prenatal exposure to influenza epidemic. Arch Gen Psychiatry, 45 : 189-92.

Mino, Y., Oshima, I., Tsuda,T., Okagami,K., (2000) No relationship between schizophrenic birth and influenza epidemics in Japan. J Psychiatr Res, 34:133-138

Morgan, V., Castle, D., Page,A., Fazio, S., Gurrin, L., Burton,P., Montgomery,P., Jablensky,A. (1997) Influenza epidemics and incidence of schizophrenia, affective disorders, and mental retardation in Western Austalia: no evidence of a major effect. Schizophr Res, 26: 25-39.

Mortensen, P.B., Pedersen, C.B., Westergaard, T., Wohlfahrt, J., Ewald, H., Mors, O., Andersen, P.K., Melbye, M. (1999). Effects of family history and place and season of birth on the risk of schizophrenia. N Engl J Med., Feb 25; 340(8): 603-8.

Murray, R.M., Lewis, S., Revely, A.M., (1985) Towards an aetiological classification of schizophrenia. Lancet, 1: 1023-1026.

O'Callaghan, E., Sham,P., Takei,N., Glover, G., Murray, R.M., (1991) Schizophrenia after prenatal exposure to 1957 A2 influenza epidemic. Lancet, 337: 1248-50.

Palmer,B.W., Dawes, S.E., Heaton,R.K., (2009) What do we know about neuropsychological aspects of schizophrenia? Neuropsycol Rev, 19 (3): 365-384.

Pacher, P., Batkai, S., Kunos,G., (2006) The endocannabinoid system as an emerging target of pharmacotherapy. Pharmachol. Rev 58: 389-462.

Peralta, V. \& Cuesta M.J., (1992) Influence of cannabis abuse on schizophrenic psychopathology. Acta Psychiatrica Scandinavica, 85: 127-30.

Pedersen,C.B., Mortensen,P.B., (2001a) Family history, place and season of birth as risk factors for schizophrenia in Denmark: a replication and reanalysis. Br J Psychiatry, 179: 46-52.

Pedersen,C.B., Mortensen,P.B., (2001b) Evidence of a dose-response relationship between urbanicity during upbringing and schizophrenia risk. Arch Gen Psychiatry, 58:1039-46. 
Pedersen,C.B., Mortensen,P.B., (2006a) Are the cause(s) responsible for the urban-rural differences in schizophrenia rooted in families or individuals? (2006) Am J Epidemiol, 163:971-8.

Pedersen,C.B., Mortensen,P.B., (2006b) Urbanization and traffic related exposures as risk factors for schizophrenia. BMC Psychiatry, 6:1-7.

Pencer, A., Addington, J., Addington, D. (2005) Outcome of first episode of psychosis in adolescence: a 2year follow-up. Psychiatry Res, 133: 35-43.

Schelin,E., Munk-Jorgensen,P. Olesen,A.,Gerlach,H., (2000) Regional differences in schizophrenia incidence in Denmark. Acta Psychiatr Scand, 101:293-9.

Schneier, F., R., \& Siris, S.G., (1987) A review of psychoactive substance use and abuse in schizophrenia: patterns of drug choice. Journal of Nervous and Mental Disease. 175: 641-652.

Schroeder, C.W.,(1942) Mental disorders in cities. Am J Sociol, 48:40-7.

Selten,J.P., Frissen,A., Lensvelt-Mulders,G., Morgan,V.A. (2009) Schizophrenia and 1957 pandemic of influenza: meta-analysis. Schizophr Bull, 36(2):219-228.

Selten, J.P. \& Slaets, J.P., (1994) Evidence against maternal influenza as a risk factor for schizophrenia. $\mathrm{Br}$ J Psychiatry, 164: 674-6.

Selten, J.P., Slaets,J., Kahn, R., (1998) Prenatal exposure to influenza and schizophrenia in Surinamese and Dutch Antillean immigrants to the Netherlands. Schizophr Res,30: 101-103.

Sharma,T., Lancater, E., Lee,D., Lewis,S., Sigmundsson.,T., Takei,N., Gurling, H., Barta,P., Pearlson, G., Murray, R.M., (1998) Brain changes in schizophrenia, Volumetric MRI study of families multiply affected with schizophrenia. The Maudsley Family Study 5. Br J Psychiatry, 173: 132-138.

Sharma, T., Lancater, E., Sigmundsson, T., Lewis,S., Takei, N., Gurling,H., Barta, P., Pearlson, G., Murray, R.M., (1999) Lack of normal pattern of cerebral asymmetry in familial schizophrenic patients and their relatives- The Maudsley Family Study. Schizophr Res, 40:111-120.

Smith, J. \& Huckler, S. (1994); Schizophrenia and substance abuse. Br J Psychiatry,165: 13-21.

Stirling, J., Lewis, S., Hopkins, R., White, C., (2005). Cannabis use prior to first onset psychosis predicts spared neurocognition at 10-year follow-up. Schizophr Res,75: 135-137.

Sundquist,K.,Frank,G.,Sundquist,J., (2004) Urbanisation and incidence of psychosis and depression. Br J Psychiatry, 184:293-8.

Susser, E., Lin, S.P., Brown, A.S., Lumey, L.D., Erlenmeyer-Kimling, L., (1994) No relation between risk of schizophrenia and prenatal exposure to influenza in Holland. A J Psychiatry, 151: 922-4.

Susser, E., Schwartz, S., Morabia, A., Bromet,E.J. (2006) Psychiatric epidemiology: searching for the causes of mental disorders. Oxford University Press; New York

Takei, N., Sham,P. , O'Callaghan, E., (1995) Schizophrenia: increased risk associated with winter birth and city birth- a case-control study in 12 regions within England and Wales. J Epidemiol Community Health, 49: 106-7.

Takei, N., Mortensen, P. B., Klaening, U., Murray, R. M., Sham, P. C., OCallaghan, E., \& MunkJorgensen, P. (1996). Relationship between in utero exposure to influenza epidemics and risk of schizophrenia in Denmark. Biological Psychiatry, 40(9), 817-824

Thornicroft,G., Bisoffi,G., De Salvia,D., Tansella,M. (1993) Urban-rural differences in the associations between social deprivation and psychiatric service utilization in schizophrenia and all diagnoses: a case-register study in Northern Italy. Psychol Med,23:497-96.

Torrey, E.F., Mortensen, P.B., Pedersen, C.B., Wohlfahrt, J., Melbye, M. (2001) Risk factors and confounders in the geographical clustering of schizophrenia. Schizophr Res, 49(3):295-9.

Toulopoulou,T., Morris, R.G., Rabe-Hesketh, S., Murray, R.M., (2003a) Selectivity of verbal memory deficit in schizophrenic patients and their relatives. Am J Med Genet, 116B: 1-7.

Toulopoulou,T., Rabe-Hesketh, S., King, H., Murray, R.M., Morris, R.G.,(2003b) Episodic memory in schizophrenic patients and their relatives. Schizophr Res, 63:261-271.

van Os, J., Bak, M., Hanssen,M., Bijl, R.V.,de graaf, R., Verdoux, H., (2002) Cannabis use and psychosis: a longitudinal population based study. American Journal of Epidemiology, 156: 319-327.

van Os J, Pedersen CB, Mortensen PB. (2004). Confirmation of synergy between urbanicity and familial liability in the causation of psychosis. Am J Psychiatry, 161(12):2312-4 
Veen N.D., Selten J., van der Tweel,I., Feller,W.G., Hoek,H.W., Kahn,R.S., (2004) Cannabis Use and Age at Onset of Schizophrenia. Am J Psychiatry,161:501-506.

Warner ,R., Taylor, D., Wright, J., Sloat, A., Springett, G., Arnold,S., Weinberg, H. (1994) Substance use among the mentally ill: prevalence, reasons for use, and effects on illness. American Journal of Orthopsychiatry, 64: 30-39.

Watson, C.G., Kucala, T., Tileskjor, C., Jacobs, L. (1984) Schizophrenic birth seasonality in relation to the incidence of infectious diseases and temperature extremes, Arch Gen Psychiatry, 41: 85-90.

Wickham,H., Murray, R.M. (1997) Can biological markers identify endophenotypes predisposing to schizophrenia? International Review of Psychiatry, 9: 355-364.

Wicks, S., Hjern, A., Gunnell, D., Lewis, G., Dalman, S., (2005) Social adversity in childhood and risk of developing psychosis: a national cohort study. Am J Psychiatry, 162: 1652-1657.

World Health Organization (1992) WHO Coordinated Multicenter Study on the Course and Outcome of Schizophrenia. Geneva, WHO.

Zammit, S., Allebeck, P., Andreasen, S., Lundberg, I., Lewis, G., (2002) Self reported cannabis use as a risk factor for schizophrenia in Swedish conscripts of 1969: historical cohort study. British Medical Journal, 325: 1183-4. 

Chapter 2

Brain volumes in familial and non-familial schizophrenic probands and their unaffected relatives

McDonald, C., Grech, A., Touopoulou, T., Schulze, K., Chapple, B., Sham, P., Walshe, M., Sharma, T., Sigmundsson, T., Chitnis, X., \& Murray, R. M. (2002). Brain volumes in familial and non-familial schizophrenic probands and their unaffected relatives. American journal of medical genetics, 114(6), 616-625 
Structural brain abnormalities are consistently reported in schizophrenic subjects but the etiology of these abnormalities remains unclear. We tested the contribution of genetic predisposition and obstetric complications to the structural brain abnormalities found in schizophrenic probands and their relatives. MRI scans were carried out on 35 schizophrenic probands from families multiply affected with the disorder, and 63 of their unaffected relatives, including 10 parents who appeared to transmit genetic risk to their children; as well as 31 schizophrenic probands from families with no other affected members, 33 of their unaffected relatives; and finally 68 controls. Volumetric measurements of whole brain, lateral ventricles, third ventricle, cerebellum and temporal lobes were completed for each subject. The impact of obstetric complications on brain structure was assessed across the gradient of presumed genetic predisposition. Both groups of schizophrenic probands displayed enlargement of the lateral and third ventricles, and there was a gradient of ventricular enlargement amongst the unaffected relatives in proportion to their likelihood of carrying schizophrenic genes. Ventricular enlargement was largely confined to males in both probands and unaffected relatives. Obstetric complications were associated with ventricular enlargement only in the familial probands. Non-familial probands displayed reduced volume of the temporal lobes bilaterally. In families with several schizophrenic members, ventricular enlargement is a marker for genetic liability, particularly in males. Individuals inheriting the susceptibility to schizophrenia appear particularly prone to develop ventricular enlargement in response to obstetric complications. 


\section{Introduction}

MRI studies have identified a number of structural brain abnormalities associated with schizophrenia. Some of these are global, such as a prominent enlargement of lateral ventricles and a small reduction in cortical grey matter, whereas others are more regional such as reduced volume of medial temporal lobe structures (McCarley et al., 1999; Wright et al., 2001). A number of potential causes for these abnormalities have been suggested, including genes that impair neurodevelopment (Jones and Murray, 1991) environmental insults such as perinatal hypoxia (Murray et al., 1985) and secondary effects of disease progression or antipsychotic medication (Rapport et al., 1997; DeLisi, 1999). Identifying structural brain abnormalities under genetic control is of particular importance because these could represent endophenotypes of schizophrenia. Endophenotypes are objectively measured markers of an illness that are produced by predisposing genes that underline the clinical phenotype. In complex heterogenous disorders such as schizophrenia, endophenotypes are presumed to be more proximal to gene action and therefore could aid in the identification of susceptibility genes (Wickham and Murray, 1997; Freedman et al.,1999). Potential endophenotypes can be identified by studies that relate the trait in question with increased genetic risk for the disorder.

Our group previously examined 16 multiply affected ('familial') schizophrenic families, and showed that enlarged lateral ventricles may represent a morphological endophenotype of schizophrenia (Sharma et al.,1998). This "Maudsley Family Study" included a subset of unaffected relatives who appeared to transmit genetic risk to their affected children (presumed obligate carriers) and were more likely than the other unaffected relatives to share the morphological abnormality with the probands.

In the present study, we sought to explore morphological endeophenotypes of schizophrenia further by extending the study to: (1) include a larger sample of multiply affected families; (2) include a group of probands with no family history of schizophrenia ("non-familial") and their unaffected relatives; (3) include measurements of the third ventricle in the analysis; and (4) examine how obstetric complications influenced brain structure across the sample. We hypothesized that structural abnormalities that are related to susceptibility genes would not only be associated with schizophrenia, but would also be present to a lessening degree among first degree relatives who were at reducing levels of genetic risk, i.e. from presumed obligate carriers, to other relatives of familial probands, to relatives of non-familial cases. The design also permitted an examination of how a putative environmental cause of structural brain abnormalities in schizophrenia, obstetric complications, was related to morphological changes across groups of differing genetic risk. 


\section{Materials and methods}

\section{Subjects}

All subjects were Caucasian, aged 17 - 70 years, and their first language was English. Subjects were excluded if they had a history of head trauma resulting in loss of consciousness for more than a few minutes, substance or alcohol dependence in the 12 months before assessment, or a history of organic brain disease. The study was approved by the local ethical committee.

\section{Patients and Relatives}

The majority of the familial patients and their relatives included in the analysis were initially recruited and reported on by Sharma et al., (1998); each schizophrenic proband had at least one other first or second degree relative with schizophrenia. For the present study, a further seven of these families were recruited and assessed. The relatives included a group of parents who were classified as "presumed obligate carriers", on the basis that they appeared to be transmitting the liability for schizophrenia by virtue that 1) they also had a sib or parent affected, and 2) transmission of liability was unilineal within each of these families, i.e. family history of psychosis was absent from the presumed obligate carrier's spouse.

A non-familial sample of patients and their relatives was also recruited. These probands had no known first or second degree relative with a functional psychotic disorder, and an attempt was made to particularly recruit a substantial number of patients ( $n=17$ ) who had also been subject to significant pregnancy or birth complications, to maximize the likelihood that non-genetic factors were related to the etiology of schizophrenia in these families. The familial and non-familial families were recruited in the same way, i.e. from advertising through voluntary agencies and from referral from local and regional clinics.

\section{Controls}

Controls were recruited from the community via newspaper advertisements and from local staff. These controls reflected the characteristics of the total group of patients and relatives on the basis of age and gender. None of the controls had a personal history of a psychotic or schizophrenia spectrum disorder, nor any known family history of functional psychosis. The presence of other axis 1 psychiatric disorders was not an exclusion factor. 
Successful MRI cans were completed on 230 subjects. These comprised 35 probands with schizophrenia or schizoaffective disorder $(n=3)$ from multiply affected families, 10 presumed obligate carriers, 53 other familial relatives, 31 probands with schizophrenia or schizoaffective disorder $(n=4)$ with no family history of schizophrenia, 33 of their unaffected first degree relatives and 68 controls. MRI scans were completed on at least one first-degree relative of 52 of the probands. For all but three of the participating relatives, the proband from the same family was also scanned successfully.

\section{Clinical Assessments}

Probands, relatives and controls were assessed using the clinical assessments. Structured clinical interviews were carried out by two raters using the Schedule for Affective Disorders and Schizophrenia-Lifetime version (Spitzer and Endicott, 1978) from which RDC diagnoses were produced (Spitzer et al., 1978). Additional clinical information was also collected on the timing and nature of symptoms to allow DSMIIIR diagnoses to be made. Clinical information was supplemented with collateral histories from relatives and information from case notes where available. A comprehensive family history was taken from available informants using the Family History Research Diagnostic Criteria (Endicott et al.,1975) or, more recently, the Family Interview for Genetic Studies (Nurnberger et al., 1994) to accurately diagnose those relatives who were not assessed directly and ensure correct classification of the families.

Where available, history of pregnancy and birth complications was obtained by maternal interview using the Lewis-Murray Scale (Lewis et al.,1989). Subjects who were rated "definite" on the Lewis-Murray scale were considered to have had obstetric complications (OCs). Handedness was assessed using the Annett Scale (Annett, 1970).

\section{MRI Acquisition}

Magnetic resonance imaging (MRI) data were obtained on all subjects using a GE Signa $1.5 \mathrm{~T}$ scanner. For each subject, a set of $1.5 \mathrm{~mm}$ thick contiguous coronal MRI images extending through the entire brain was obtained using a 3D spoiled gradient recall echo sequence $(T E=5 \mathrm{~ms}, T R=35 \mathrm{msec}$, number of excitations $=1$, field of view $=20 \mathrm{~cm}$, acquisition matrix $256 \times 256$, flip angle $=35$ 9). The majority of participants $(n=148)$ were scanned on this protocol. The remaining subjects were scanned on a shorter protocol with the same resolution ( $T E=3.7 \mathrm{msec}$, TR $=14.7$ msec, number of excitations $=1$, field of view $=20 \mathrm{~cm}$, acquisition matrix $256 \times 256$, flip angle 20ㅇ) 


\section{MRI Data Analysis}

Images were analyzed using MEASURE software (version 0.8.3, Johns Hopkins University, Baltimore), an image analysis program that uses stereologically unbiased estimation of volume (Barta et al., 1997). A detailed description of the image anlaysis method has been given previously (Frangou et al., 1997). In brief, a grid is applied over the whole volume of the brain and the rater marks grid points falling into the structure of interest, taking into consideration all three orthogonal views. The MEASURE program calculates the volume of a structure by multiplying the number of marked grid points by the volume of an elementary cuboid.

The volumetric measurements of some of the structures has been described previously (Sharma et al., 1998). The following regions were measured on the additional subjects by trained operators who were blind to group affiliation: whole brain volume $(A G, K S)$, lateral ventricles, cerebellum and temporal lobes (CMcD, BC). The third ventricle was measured on all subjects by a single rater (KS) and was that bounded by the anterior commissure, the fornix, the stria medullaris, the pineal body, the superior and inferior colliculi, the midbrain and mamillary body, the thalamus and hypothalamus. Interrater reliabilities between individual raters, including the earlier raters of these structures, were calculated using the intraclass correlation carried out on 10 brain scans before rating of the images for the study. The ranges of these are as follows: whole brain volume $0.94-0.99$, right lateral ventricle $0.95-0.99$, left lateral ventricle $0.90-0.99$, third ventricle 0.90 , cerebellum $0.93-0.98$, right temporal lobe $0.92-0.98$, left temporal lobe $0.88-0.92$. Intrarater reliabilities were calculated using intraclass correlation on 10 scans rated at least 6 months apart and were in the range $0.95-0.99$ for all structures.

Scans were mixed and identified by number only, to ensure rater's blindness to group affiliation, before any measurements, head tilt was corrected by aligning each brain along the anterior-posterior commissure axis in the sagittal plane and long the inter-hemispheric fissure in the coronal and axial planes.

\section{Data Analysis}

One-way analysis of variance (with Bonferroni post hoc tests), Mann-Whitney U-test and Pearson's $x^{2}$ tests were used to analyze differences between the groups on demographic and clinical characteristics. The control group was considered sufficiently large to obtain adjustment factors for confounds and the volumetric measurements for each structure were initially adjusted using multiple linear regression to the control group mean for the following potential confounds: age, gender, height, handedness, and scanning protocol. Height was used as the independent variable to control for head size because it is a good predictor of general head size 
(Arndt et al., 1991; Andreason et al., 1994) and is independent of any disease specific processes. Values for the lateral and third ventricle volumes, whose distributions were skewed, were successfully logarithmically transformed before analysis.

Standard linear regression analyses with volume as the dependent variable were calculated for each of the structures separately, comparing each subject group against the control group. Because many of the observations both within and between groups were of individuals within families and this not independent from each other, we carried out regression analyses for clustered observations using a robust estimator for the variances of the regression coefficient estimates as implemented in STATA (version 6.0; Stata Corp; College Station, TX). All tests were twotailed and used a 0.05 level of significance.

\section{Results}

\section{Demographic and Clinical Characteristics}

The demographic characteristics of the sample are shown in Table I. The relatives groups were significantly older than the other groups because they included parents of the probands $(F=16.26, d f=5,224,0.001)$. The groups differed significantly in gender distribution, with an excess of males in both the patient groups $\left(x^{2}=19.1, \mathrm{df}\right.$ $=5, P=0.02)$ but not in proportion of left-handers $\left(x^{2}=6.6, d f=5, P=0.25\right)$. Nonfamilial patients were slightly taller than their relatives $(F=2.55, \mathrm{df}=5,224, \mathrm{P}=$ 0.03 ), presumably due to the higher proportion of males in the proband group. Familial patients had spent fewer years in full-time education than controls ( $F=$ $2.46, d f=5,219, P=0.03)$. There was no significant difference in mean age of first psychotic symptoms between familial and non-familial probands $(U=406.00, P=$ 0.59).

Of the 63 familial relatives. 14 had fulfilled criteria for an axis 1 DSMIIIR diagnosis other than schizophrenia or schizoaffective disorder at some stage of their lives; 10 for major depressive disorder, one for psychotic disorder NOS, one for social phobia, one for bulimia nervosa, and one for alcohol dependence. Of these 33 nonfamilial relatives, eight had a lifetime diagnosis of a major depressive disorder. Two of the 68 controls had a lifetime diagnosis of major depressive disorder. 
TABLE I

Demographic Characteristics and Rates of Obstetric Complications in Each Subject Group*

\begin{tabular}{|c|c|c|c|c|c|c|}
\hline & $\begin{array}{l}\text { Familial } \\
\text { probands } \\
(\mathrm{n}=35)\end{array}$ & $\begin{array}{l}\text { Non-familial } \\
\text { probands } \\
(\mathrm{n}=31)\end{array}$ & $\begin{array}{l}\text { Presumed } \\
\text { obligate carriers } \\
(n=10)\end{array}$ & $\begin{array}{l}\text { Other familial } \\
\text { relatives } \\
(n=53)\end{array}$ & $\begin{array}{l}\text { Non-familial } \\
\text { relatives } \\
(n=33)\end{array}$ & Controls \\
\hline Age (years) & $38.1(12.1)$ & $31.3(7.8)$ & $59.5(7.5)$ & $44.0(14.8)$ & $50.8(12.9)$ & $36.3(11.2)$ \\
\hline Age range & $23-70$ & $17-52$ & $50-70$ & $18-70$ & $21-67$ & $21-69$ \\
\hline Height $(\mathrm{cm})$ & $173.2(8.8)$ & $175.5(8.8)$ & $168.8(8.8)$ & $170.0(8.4)$ & $168.6(10.2)$ & 172. \\
\hline $\begin{array}{l}\text { Years of } \\
\text { education }\end{array}$ & $12.1(2.6)$ & $13.1(2.8)$ & $13.6(3.6)$ & $13.3(2.7)$ & $13.8(2.9)$ & $14.3(3.7)$ \\
\hline Age of onset & 21.9 (7.9) & $20.6(5.0)$ & $\mathrm{N} / \mathrm{A}$ & $\mathrm{N} / \mathrm{A}$ & $N / A$ & N/A \\
\hline $\begin{array}{l}\text { Male gender, } \\
\mathrm{n}(\%)\end{array}$ & 22 (62.9) & $23(74.2)$ & $5(50.0)$ & $22(41.5)$ & $13(39.4)$ & $31(45.6)$ \\
\hline $\begin{array}{l}\text { Left handed, } \\
\mathrm{n}(\%)\end{array}$ & $3(8.6)$ & $5(16.1)$ & $1(10.0)$ & $2(3.8)$ & $5(15.2)$ & $12(17.6)$ \\
\hline $\begin{array}{l}\text { Definite OC}, \\
\mathrm{n}(\%)\end{array}$ & $6(27.3)$ & $17(65.4)$ & $\mathrm{N} / \mathrm{A}$ & 7 (25.9) & $2(25.0)$ & $5(23.8)$ \\
\hline
\end{tabular}

* Values are Mean (SD) unless indicated.

* Definite' score on Lewis-Murray scale of obstetric complications - available on 104 subjects.

\section{MRI Measurements}

The mean adjusted volumes of each structure are given for each subject group in Table II and the results of the cluster regression analysis are given Table III.

TABLE II

Adjusted Regional Brain Volumes ( $\mathrm{ml})$ in each Subject group*

\begin{tabular}{|c|c|c|c|c|c|c|}
\hline Region & $\begin{array}{l}\text { Familial } \\
\text { probands } \\
(\mathrm{n}=35)\end{array}$ & $\begin{array}{l}\text { Non-familial } \\
\text { probands } \\
(n=31)\end{array}$ & $\begin{array}{l}\text { Presumed } \\
\text { obligate carriers } \\
(n=10)\end{array}$ & $\begin{array}{l}\text { Other familial } \\
\text { relatives } \\
(n=53)\end{array}$ & $\begin{array}{l}\text { Non-familial } \\
\text { relatives } \\
(n=33)\end{array}$ & $\begin{array}{l}\text { Controls } \\
(n-68)\end{array}$ \\
\hline Whole brain & $1000.8(113.7)$ & $1020.7(107.0)$ & $1023.3(123.1)$ & 1041.4(90.9) & $1064.8(77.5)$ & $1011.7(97.0)$ \\
\hline $\begin{array}{l}\text { Left lateral } \\
\text { ventricle }\end{array}$ & $11.7(8.0)$ & $11.1(5.0)$ & $11.4(5.1$ & $7.8(4.4)$ & $6.8(3.5)$ & $6.9(3.7)$ \\
\hline $\begin{array}{l}\text { Right lateral } \\
\text { ventricle }\end{array}$ & $9.2(6.4)$ & & $8)$ & 7.3 & 6.3 & $6.8(4.0)$ \\
\hline Third ventricle & $0.9(0.5)$ & $1.0(0.5)$ & $1.1(0.6)$ & $0.8(0.4)$ & $0.7(0.3)$ & $0.7(0.3)$ \\
\hline Cerebellum & 129.9 (13.5) & $128.1(16.1)$ & $134.2(13.0)$ & $131.9(10.1)$ & $133.9(14.4)$ & $130.0(12.9)$ \\
\hline $\begin{array}{l}\text { Left temporal } \\
\text { lobe }\end{array}$ & $73.8(10))$. & $67.9(8.3)$ & $76.1(9.8)$ & 76.2 10.2) & $71.3(6.4)$ & $73.2(10.0)$ \\
\hline $\begin{array}{l}\text { Right temporal } \\
\text { lobe }\end{array}$ & $72.3(12.8)$ & $67.9(8.0)$ & $74.4(8.5)$ & $76.3(9.5)$ & $73.3(5.9)$ & $72.8(10.5)$ \\
\hline
\end{tabular}

* Values are Mean (SD). Volumes are adjusted for age, gender, height, handedness, and scanning protocol. 


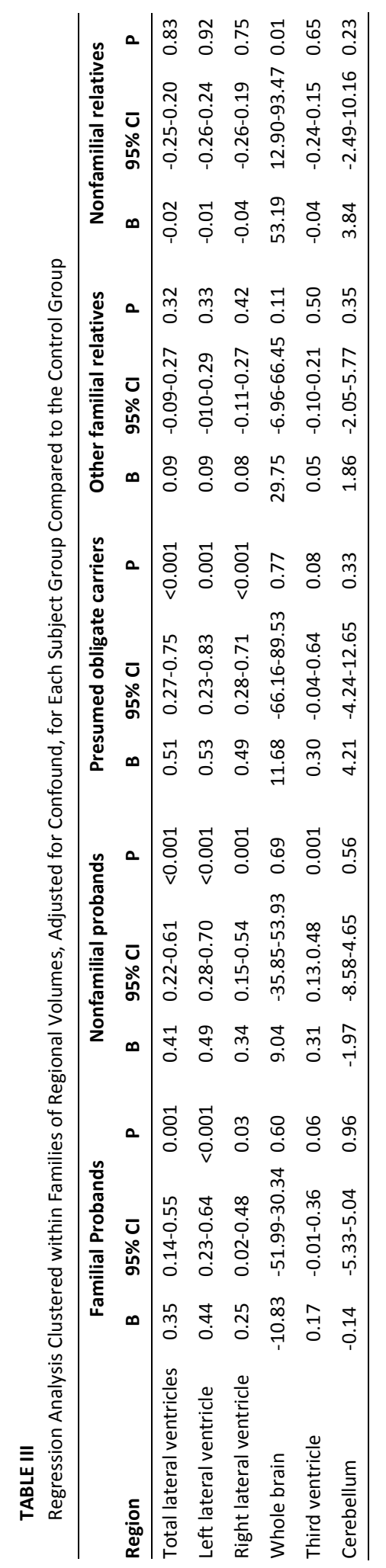




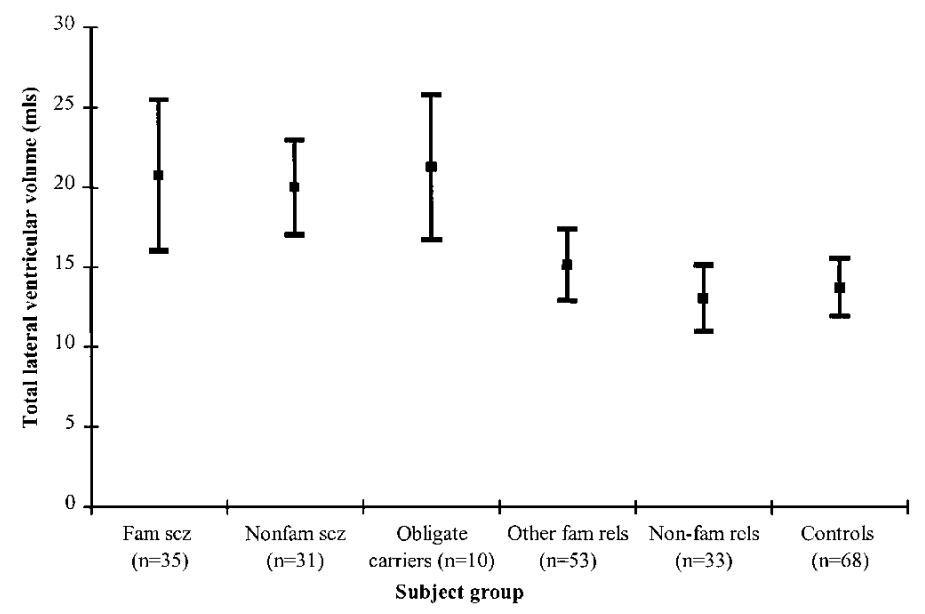

FIGURE 1

Mean $(95 \% \mathrm{Cl})$ total lateral ventricular volume, adjusted for confounds, of each subject group.

\section{Lateral Ventricular Volume}

There were significant differences in lateral ventricular volume measurements between the groups $\left(F(5,123)=8.08, P<0.001, R^{2}=0.12\right)$. Probands with both familial and non-familial schizophrenia had significantly enlarged lateral ventricular volumes bilaterally when compared to controls. Total lateral ventricular volume in probands with non-familial schizophrenia did not differ from that of probands with familial schizophrenia $(B=0.07, P=0.56,95 \% C l=-0.16-0.30)$.

There was a trend for the total group of relatives of the familial probands to have larger left lateral ventricles than controls $(B=0.16, P=0.08,95 \% \mathrm{Cl}=-0.02-0.35)$. The presumed obligate carrier group had significantly larger lateral ventricular volume than controls bilaterally. Non-familial relatives had similar lateral ventricular volumes to controls. Figure 1 shows the gradation of mean lateral ventricular volumes across the groups, with controls and non-familial relatives having the smallest ventricular volumes. Among the three relatives groups, there was a significant correlation between lateral ventricular volume enlargement and increasing putative genetic risk from non-familial relatives to other familial relatives to presumed obligate carriers (Spearman's $p=0.26, P=0.01$ ).

\section{Third Ventricular Volume}

There were significant differences in third ventricular volume measurements between the groups $\left(F(5,123)=3.83, P=0.003, R^{2}=0.08\right)$. Subjects with non-familial 
schizophrenia had significantly enlarged third ventricular volume compared to controls, and subjects with familial schizophrenia showed a strong trend for the same finding. Third ventricular volume did not differ significantly when probands with non-familial schizophrenia were compared directly to probands with familial schizophrenia $(\mathrm{B}=0.13, \mathrm{P}=0.26,95 \% \mathrm{Cl}=-00.10-0.36)$. Presumed obligate carriers also showed a trend for larger third ventricular volume compared to controls. There was a strong correlation in the volumes of lateral and third ventricles in the sample (Pearson correlation coefficient $=0.68, \mathrm{P}<0.001$ ), which was similar for each subgroup.

\section{Temporal Lobe Volume}

There were significant differences in left $\left(F(5,123)=2.81, P=0.02, R^{2}=0.07\right)$ and right $\left(F(5,123)=4.35, P=0.001, R^{2}=0.06\right)$ temporal lobe measurements between the groups. Probands with non familial schizophrenia had significantly smaller left and right temporal lobe volumes than controls; and smaller left $(B=-5.67, P=0.05$, $95 \% \mathrm{Cl}=-6.93-0.05)$ and right temporal lobe volumes $(\mathrm{B}=-5.67, \mathrm{P}=0.002,95 \% \mathrm{Cl}=-$ $9.00-2.34)$ when compared to their unaffected relatives. They also had significantly smaller left temporal lobe volume when compared directly to the familial proband group $(\mathrm{B}=-5.90, \mathrm{P}=0.009,95 \mathrm{Cl}=-10.22--1.57)$, although this comparison did not reach statistical significance for the right temporal lobe volume $(B=-4.42, P=0.11$, $95 \% \mathrm{Cl}=-9.86-1.03)$. Temporal lobe volume in the familial schizophrenic probands and in the relatives groups did not differ significantly from controls.

\section{Other Brain Structures}

There were significant differences in whole brain volume measurements between the groups $\left(F(5,123)=2.66, P=0.03, R^{2}=0.04\right)$. Whole brain volume did not differ significantly between either proband group and the control group but the group of non-familial relatives had a slightly larger whole brain volume than the control group. There were no differences in volumetric measurements of the cerebellum between any of the groups $\left(F(5,123)=0.73, P=0.60, R^{2}=0.02\right)$.

Because other axis disorders might be associated with neuroanatomical changes such as ventricular enlargement, we repeated each of the analyses after excluding those 21 relatives and controls who had fulfilled criteria for major depressive disorder or psychosis NOS at some stage of their lives. This reanalysis produced negligible differences in any of the regression coefficients or significance values reported (data not shown). 


\section{Gender}

Of particular note, there were strong group by gender interactions for lateral and third ventricular volume with males in each of the schizophrenic groups, and also the obligate carrier group, making the main contribution to lateral and third ventricular enlargement (Table IV). This effect is displayed for mean lateral ventricular volume in Figure 2. There was no gender by group interaction among non-familial probands for left temporal lobe volume $(\mathrm{B}=0.74,95 \% \mathrm{Cl}=-6.0-7.46, \mathrm{P}=0.83)$ or right temporal lobe volume $(\mathrm{B}=-1.12,95 \% \mathrm{Cl}=-7.93-5.68, \mathrm{P}=0.75)$. When male relatives were analyzed separately, there was a more prominent correlation between lateral ventricular volume enlargement and increasing genetic risk from nonfamilial relatives to presumed obligate carriers (Spearman's $p=0.39, P=0.01$ ) and a trend for a similar correlation with third ventricular enlargement (Spearman's $p=$ $0.30, P=0.06)$.

\section{Obstetric Complications}

We next assessed how a reported history of obstetric complications was related to the morphometric abnormalities in the sample. Data on obstetric complications were available on 104 subjects. Because it was difficult to obtain data on the relatives, particularly parents (e.g. presumed obligate carriers) whose own mothers had often died, the two relatives groups were collapsed for the purposes of this analysis. The rates of obstetric complications in each subgroup is shown in Table I. This smaller number of probands with familial and non-familial schizophrenia continued to demonstrate significantly enlarged left ventricular volume. Probands with nonfamilial schizophrenia also continued to show significantly enlarged right ventricular volume, third ventricular volume and reduction of the left $(\mathrm{B}=-7.39,95 \% \mathrm{Cl}=-$ 12.72- $-2.07, \mathrm{P}=0.007$ ) and right $\mathrm{B}=-5.83,95 \% \mathrm{Cl}=-11.65--0.01, \mathrm{P}=0.05$ ) temporal lobe volumes. The results of the main effects and of the interactions of obstetric complications with each subgroup (which were analyzed separately) upon ventricular volume are displayed in Table V.

A history of obstetric complications was not significantly associated with ventricular volume as a main effect. There was, however, a trend for an interaction between obstetric complications and a familial schizophrenia, which reached statistical significance for the right lateral ventricle: familial probands who had a history of obstetric complications having larger ventricles than those without, when compared to the control group. A similar pattern existed for the third ventricle, although this failed to reach statistical significance. These results are demonstrated for lateral ventricular volume in Figure 3. There was no significant impact of obstetric complications on temporal lobe volume as a main effect or in interaction with any of the 
sub-groups. Nor were there any significant three-way interactions between subject group, obstetric complications and gender.

\section{Discussion}

\section{Brain Abnormalities in Schizophrenic Probands and Their Relatives}

We (Sharma et al., 1998) demonstrated previously that a proportion of the schizophrenic probands from multiply affected families had enlarged lateral ventricles, and that among their relatives, presumed obligate carriers had significantly enlarged left lateral ventricles. In the present study, we confirmed the first finding in an enlarged group of familial probands, and we have also demonstrated that presumed obligate carriers have significantly enlarged lateral ventricles bilaterally. Furthermore, we demonstrated that, whilst non-familial schizophrenic probands also displayed enlarged lateral ventricles, the lateral ventricular size of their relatives did not differ at all from that of controls. Indeed, lateral ventricular enlargement among unaffected relatives significantly correlated with the likelihood of carrying predisposing genes for schizophrenia, lending further support to our previous suggestion (Sharma et al., 1998) that lateral ventricular enlargement is a biological marker for genetic liability to schizophrenia.

We also found a strong interaction with gender such that the ventricular enlargement was largely confined to males in the sample, not only for schizophrenic probands, but also for those relatives most likely to be gene carriers. Previous studies have reported male schizophrenic patients to display more prominent ventricular enlargement than females (Andreasen et al., 1990; Castle and Murray, 1991; Nopoulos met al., 1997), but to our knowledge, this is the first study that reports that ventricular enlargement in unaffected relatives of schizophrenics is largely confined to males. There were equal numbers of male and female obligate carriers, and that trait appears to be transmitted to males through either gender, i.e. transmission of this trait is not through a simple $X$-linked recessive mechanism. This raises the intriguing possibility that increased ventricular volume is an endophenotype for schizophrenia that is expressed predominantly in males, and points toward gene(s) that are differentially expressed in males and females. Information on obstetric complications was not available on any of the obligate carrier group and so it is possible that the males in this group had had more OCs; however, there was no evidence for a gender interaction with OC's for the group of subjects on whom these data were available. 
In general, studies demonstrate that probands with schizophrenia have larger ventricular volumes than their relatives, but there is some evidence from CT studies that unaffected sibs (Weinberger et al., 1981; DeLisi et al., 1986) share this abnormality to a lesser degree. Although most MRI studies do not find lateral ventricles to be significantly enlarged in relatives of schizophrenic patients (Cannon et al., 1998; Lawrie et al., 1999; Seidman et al., 1999; Staal et al., 2000), mild ventricular enlargement that falls short of significance is often noted. A striking finding from this present study is the manner in which lateral ventricular enlargement correlates with likelihood of carrying susceptibility genes amongst unaffected relatives, with relatives of non-familial probands not differing at all from controls, whereas obligate carriers have similar enlargement of ventricles to schizophrenic probands. Most other studies on relatives have not specifically examined multiply affected families and so the absence of this finding in these other studies does not contradict our results. Indeed evidence for an association between increasing ventricular enlargement in unaffected relatives with a stronger family history of schizophrenia is also reported by two studies of high risk subjects (Cannon et al., 1993; Lawrie et al., 1999).

There is considerable evidence that nongenetic factors, especially pregnancy and birth complications, contribute to enlarge lateral and third ventricles in schizophrenia (Reveley et al., 1984a; Schulsinger et al., 1984; Murray et al., 1985; Lewis et al., 1989; Suddath et al., 1990; McNeil et al., 2000). We also found some evidence for a contribution to ventricular enlargement in the sample from obstetric complications in our familial probands. No such effect was present for relatives or controls, indicating the subgroup likely to be richest in predisposing genes for schizophrenia, probands from multiply affected families, was also most likely to develop ventricular enlargement in response to obstetric complications. This evidence of a geneenvironment interaction echoes the reports by Cannon et al., $(1993,2002)$ who found that the effect of birth complications on ventricular enlargement increased with increasing likelihood of genetic risk.

The findings for lateral ventricular enlargement were generally reflected in those for third ventricular enlargement, and confirm our previous report of widening of the third ventricle in familial probands and presumed obligate carriers that was based on qualitative ratings (Sharma et al., 1997). Several studies have indentified third ventricular enlargement in patients (Fanon et al., 2000, Wright at el., 2000) and this finding has also been reported in unaffected first degree relatives of schizophrenic patients (Keshavan et al., 1997; Seidman et al., 1999; Staal et al., 2000; Lawrie et al., 2001). Given its high correlation with lateral ventricular enlargement in this sample, it seems likely that third ventricular enlargement may be part of a more widespread process. 
Non-familial relatives had a slight enlargement of whole brain volume, however, this result did not appear to reflect a broader pattern among the relatives groups and may be spurious given the number of statistical tests carried out. We found evidence for reduced volume of the temporal lobe in the non-familial probands in the sample. The value of the familial - non-familial distinction in schizophrenia is controversial (Lewis et al., 1987; Roy and Crowe, 1994), however, we contend that non-familial probands although unlikely to be pure phenocopies, are likely to represent a group with lesser genetic loading than those from multiply affected families, a suggestion supported by the lack of ventricular enlargement in their relatives. These data suggest that reduced temporal love volume in the non-familial probands may result from nongenetic factors.

\section{Methodological Issues}

Strengths of the study include the relatively large numbers of probands and relatives and that the various classes of unaffected relatives represented a likely gradient of genetic risk. We used a regression analysis for clustered observations that takes into account the non-independence of individuals within families, a factor ignored by some other family studies, despite evidence for a high degree of genetic control of brain structures such as ventricular size within families (Weinberger et al., 1981; Reveley et al., 1984b). Indeed the design of comparing probands to relatives evolved to reduce the large genetic variation of brain structures in the population rather than to search for morphometric endophenotypes and some such studies did not include an independent control group (Weinberger et al., 1981; Honer et al., 1994; Zorrilla et al., 1997; Silverman et al., 1998).

Several of the unaffected relatives in our sample had a lifetime diagnosis of depressive disorder. Affective disorder is commoner in the relatives of schizophrenic patients than controls and might be related to familial factors (Kendler and Gardner, 1997). Their inclusion, however, was not responsible for the morphometric abnormalities in the relatives groups because excluding subjects with a history of depressive illness produced negligible differences to our results.

The study, however, has several limitations. The six sub groups were not all well matched. This was inevitable for age given the study design because parents were included in the relatives groups. An advantage of this design is that parents, who have generally lived through the risk period of schizophrenia, can validly be considered in 'unaffected' relatives and it enables the study of those parents who are presumed obligate carriers of genetic risk. In common with other family studies that included parents as well as sibs (Honer et al., 1994; Seidman et al, 1999), we found that more female relatives took part in the assessment. These problems were com- 
pensated for by using a control group that spanned the age range in both genders and thus allowed tighter controlling for these confounds in the analysis without extrapolation.

The study sample was recruited deliberately on the basis of having multiply affected families and, for a proportion of the non-familial probands, a history of obstetric complications. Because it does not represent an epidemiological sample, this could reduce the generalizability of the results.

There was a small MRI protocol change during the study period. All scans, however, were completed on the same scanner at the same high resolution, and the protocol was controlled for in the analysis.

Identification of obstetric complications was retrospective and relied entirely on maternal recall. Although there is some evidence for the validity of maternal recall (O'Callaghan et al., 1990), other studies have reported discrepancies with birth records (Cantor-Graae et al., 1998; Buka et al., 2000).

Our studies provide further evidence that ventricular enlargement is a marker of genetic liability for schizophrenia, by finding increased ventricular enlargement associated with increasing genetic risk among the unaffected first degree relatives of schizophrenic patients. Ventricular enlargements in both probands and in unaffected relatives is largely contributed to by males, suggesting a gender specific activation of the critical gene(s). Environmental factors also influence ventricular enlargement and temporal lobe reduction in non-familial probands and there was evidence of a gene-environment interaction with those subjects at greatest likelihood of carrying susceptibility genes, familial probands, showing the greatest ventricular enlargement in response to obstetric complications. Thus the etiology of ventricular enlargement in schizophrenia, like the disorder itself, appears to be determined in a complex manner by genetic, environmental and gene-environment interaction mechanisms. Teasing apart such contributions to this quantitative trait could prove fruitful in more fully understanding the pathogenesis of schizophrenia.

\section{Acknowledgements}

Dr. McDonald is supported by the Wellcome Trust, and we also received support from the Stanley Foundation. We would like to thank all the families who participated in the study, the National Schizophrenia Fellowship for helping in the identification of families for the study, and the staff of the MR Unit, St. George's Hospital, London fort MRI scanning and data transfer. 


\section{References}

Andreasen NC, Ehrhardt JC, Swayze VW 2nd, Alliger RJ, Yuh WT, Cohen G, Ziebell S. 1990. Magnetic resonance imaging of the brain in schizophrenia. The pathophysiologic significance of structural abnorm- alities. Arch Gen Psychiatry 47:35 - 44.

Andreasen NC, Flashman L, Flaum M, Arndt S, Swayze V 2nd, O'Leary DS, Ehrhardt JC, Yuh WT. 1994. Regional brain abnormalities in schizophrenia measured with magnetic resonance imaging. JAMA 272:1763-1769.

Annett M. 1970. A classification of hand preference by association analysis. Br J Psychol 61:303-321.

Arndt S, Cohen G, Alliger RJ, Swayze VW 2nd, Andreasen NC. 1991. Problems with ratio and proportion measures of imaged cerebral structures. Psychiatry Res 40:79-89.

Barta PE, Dhingra L, Royall R, Schwartz E. 1997. Improving stereological estimates for the volume of the structures identified in three-dimensional arrays of spatial data. J Neurosci Meth 75:111 - 118.

Buka SL, Goldstein JM, Seidman LJ, Tsuang MT. 2000. Maternal recall of pregnancy history: accuracy and bias in schizophrenia research. Schizophr Bull 26:335 - 350.

Cannon TD, Mednick SA, Parnas J, Schulsinger F, Praestholm J, Vestergaard A. 1993. Developmental brain abnormalities in the off- spring of schizophrenic mothers. I. Contributions of genetic and perinatal factors. Arch Gen Psychiatry 50:551 - 564.

Cannon TD, van Erp TGM, Huttunen M, Lonnqvist J, Salonen O, Valanne L, Poutanen VP, StandertskjoldNordenstam CG, Gur RE, Yan M. 1998. Regional gray matter, white matter, and cerebrospinal fluid distribu- tions in schizophrenic patients, their siblings, and controls. Arch Gen Psychiatry 55:1084 1091.

Cannon TD, van Erp TG, Rosso IM, Huttunen M, Lonnqvist J, Pirkola T, Salonen O, Valanne L, Poutanen VP, Standertskjold-Nordenstam CG. 2002. Fetal hypoxia and structural brain abnormalities in schizophrenic patients, their siblings, and controls. Arch Gen Psychiatry 59:35 - 41.

Cantor-Graae E, Cardenal S, Ismail B, McNeil TF. 1998. Recall of obstetric events by mothers of schizophrenic patients. Psychol Med 28:1239-1243.

Castle DJ, Murray RM. 1991. The neurodevelopmental basis of sex differences in schizophrenia. Psychol Med 21:565 - 575.

DeLisi LE. 1999. Defining the course of brain structural change and plasticity in schizophrenia. Psychiatry Res 92:1-9.

DeLisi LE, Goldin LR, Hamovit JR, Maxwell ME, Kurtz D, Gershon ES. 1986. A family study of the association of increased ventricular size with schizophrenia. Arch Gen Psychiatry 43:148 - 153.

Endicott J, Andreasen NC, Spitzer RL. 1975. Family History Research Diagnostic Criteria. New York: New York State Psychiatric Institute, Biometrics Research Division.

Fannon D, Tennakoon L, O’Ceallaigh S, Doku V, Soni W, Chitnis X, Lowe J, Sumich A, Sharma T. 2000. Third ventricle enlargement and developmental delay in first-episode psychosis: preliminary findings. $\mathrm{Br} \mathrm{J}$ Psychiatry 177:354 - 359.

Frangou S, Sharma T, Sigmudsson T, Barta P, Pearlson G, Murray RM. 1997. The Maudsley Family Study IV. Normal planum temporale asymmetry in familial schizophrenia-A volumetric $\mathrm{MRI}$ study. $\mathrm{Br} \mathrm{J}$ Psychiatry 170:328 - 333.

Freedman R, Adler LE, Leonard S. 1999. Alternative phenotypes for the complex genetics of schizophrenia. Biol Psychiatry 45:551 - 558.

Honer WG, Bassett AS, Smith GN, Lapointe JS, Falkai P. 1994. Temporal lobe abnormalities in multigenerational families with schizophrenia. Biol Psychiatry 36:737 - 743.

Jones P, Murray RM. 1991. The genetics of schizophrenia is the genetics of neurodevelopment. $\mathrm{Br} \mathrm{J}$ Psychiatry 158:615 - 623.

Kendler KS, Gardner CO. 1997. The risk for psychiatric disorders in relatives of schizophrenic and control probands: a comparison of three independent studies. Psychol Med 27:411 - 419. 
Keshavan MS, Montrose DM, Pierri JN, Dick EL, Rosenberg D, Talagala L, Sweeney JA. 1997. Magnetic resonance imaging and spectroscopy in offspring at risk for schizophrenia: preliminary studies. Prog Neuro- psychopharmacol Biol Psychiatry 21:1285 - 1295.

Lawrie SM, Whalley H, Kestelman JN, Abukmeil SS, Byrne M, Hodges A, Rimmington JE, Best JJK, Owens DGC, Johnstone EC. 1999. Magnetic resonance imaging of brain in people at high risk of developing schizophrenia. Lancet 353:30 - 33.

Lawrie SM, Whalley HC, Abukmeil SS, Kestelman JN, Donnelly L, Miller P, Best JJ, Owens DG, Johnstone EC. 2001. Brain structure, genetic liability, and psychotic symptoms in subjects at high risk of developing schizophrenia. Biol Psychiatry 49:811 - 823.

Lewis S, Reveley A, Reveley M, Chitkara B, Murray RM. 1987. The familial/ sporadic distinction as a strategy in schizophrenia research. Br J Psychiatry 151:306 - 313.

Lewis SW, Owen MJ, Murray RM. 1989. Obstetric complications and schizophrenia: methodology and mechanisms. In: Schultz SC, Taminga CA, editors. Schizophrenia: a scientific focus. New York: New York University Press. p 56-68.

McCarley RW, Wible CG, Frumin M, Hirayasu Y, Levitt JJ, Fischer IA, Shenton ME. 1999. MRI anatomy of schizophrenia. Biol Psychiatry 45:1099 - 1119.

McNeil TF, Cantor-Graae E, Weinberger DR. 2000. Relationship of obstetric complications and differences in size of brain structures in monozygotic twin pairs discordant for schizophrenia. Am J Psychiatry 157:203 -212.

Murray RM, Lewis SW, Reveley AM. 1985. Towards an etiological classification of schizophrenia. Lancet $1: 1023-1026$.

Nopoulos P, Flaum M, Andreasen NC. 1997. Sex differences in brain morphology in schizophrenia. Am J Psychiatry 154:1648 - 1654.

Nurnberger JI, Blehar MC, Kaufmann CA, York-Cooler C, Simpson SG, Harkavy-Friedman J, Severe JB, Malaspina D, Reich T. 1994. Diagnostic interview for genetic studies. Rationale, unique features, and training. NIMH Genetics Initiative. Arch Gen Psychiatry 51:849 -859.

O'Callaghan E, Larkin C, Waddington JL. 1990. Obstetric complications in schizophrenia and the validity of maternal recall. Psychol Med 20:89-94.

Rapoport JL, Giedd J, Kumra S, Jacobsen L, Smith A, Lee P, Nelson J, Hamburger S. 1997. Childhood-onset schizophrenia. Progressive ventricular change during adolescence. Arch Gen Psychiatry 54:897 -903.

Reveley AM, Reveley MA, Murray RM. 1984a. Cerebral ventricular enlargement in non-genetic schizophrenia: a controlled twin study. Br J Psychiatry 144:89 - 93.

Reveley AM, Reveley MA, Chitkara B, Clifford C. 1984b. The genetic basis of cerebral ventricular volume. Psychiatry Res 13:261 - 266.

Roy M-A, Crowe R. 1994. Validity of the familial and sporadic subtypes of schizophrenia. Am J Psychiatry 151:805-814.

Schulsinger F, Parnas J, Petersen ET, Schulsinger H, Teasdale TW, Mednick SA, Moller L, Silverton L. 1984. Cerebral ventricular size in the offspring of schizophrenic mothers. A preliminary study. Arch Gen Psychiatry 41:602 - 606.

Seidman L, Faraone SV, Goldstein JM, Goodman JM, Kremen WS, Toomey R, Tourville J, Kennedy D, Makris N, Caviness VS, Tsuang MT. 1999. Thalamic and amygdala-hippocampal volume reductions in first-degree relatives of patients with schizophrenia: an MRI-based morphometric analysis. Biol Psychiatry 46:941 - 954 .

Sharma T, DuBoulay G, Lewis S, Sigmundsson T, Gurling H, Murray R. 1997. The Maudsley Family Study 1. Structural brain changes on magnetic resonance imaging in familial schizophrenia. Prog Neuropsychopharmacol Biol Psychiatry 21:1297 - 1315.

Sharma T, Lancaster E, Lee D, Lewis S, Sigmundsson T, Takei N, Gurling H, Barta P, Pearlson G, Murray RM. 1998. Brain changes in schizophrenia-Volumetric MRI study of families multiply affected with schizophrenia. The Maudsley Family Study 5. Br J Psychiatry 173:132 - 138. 
Silverman JM, Smith CJ, Guo SL, Mohs RC, Siever LJ, Davis KL. 1998.Lateral ventricular enlargement in schizophrenic probands and their siblings with schizophrenia-related disorders. Biol Psychiatry 43:97 -106 .

Spitzer RL, Endicott J. 1978. Schedule for affective disorders and schizophrenia. Lifetime version. New York: New York State Psychiatric Institute.

Spitzer RL, Endicott J, Robins E. 1978. Research Diagnostic Criteria (RDC) for a selected group of functional disorders. New York: New York State Psychiatric Institution, Biometrics Research Division.

Staal WG, Pol HEH, Schnack HG, Hoogendoorn MLC, Jellema K, Kahn RS.2000. Structural brain abnormalities in patients with schizophrenia and their healthy siblings. Am J Psychiatry 157:416 - 421.

Suddath RL, Christison GW, Torrey EF, Casonova MF, Weinberger DR 1990. Anatomical abnormalities in the brains of monozygotic twins discordant for schizophrenia. N Engl J Med 322:789 - 794.

Weinberger DR, DeLisi LE, Neophytides AN, Wyatt RJ. 1981. Familial aspects of CT scan abnormalities in chronic schizophrenic patients. Psychiatry Res 4:65 - 71.

Wickham H, Murray RM. 1997. Can biological markers identify endophenotypes predisposing to schizophrenia? Int Rev Psychiatry 9:355 - 364.

Wright IC, Rabe-Hesketh S, Woodruff PWR, David AS, Murray RM, Bullmore ET. 2000. Meta-analysis of regional brain volumes in schizophrenia. Am J Psychiatry 157:16 - 25.

Zorrilla LT, Cannon TD, Kronenberg S, Mednick SA, Schulsinger F, Parnas J, Praestholm J, Vestergaard A. 1997. Structural brain abnormalities in schizophrenia: a family study. Biol Psychiatry 42:1080 - 1086. 



\section{Chapter 3}

\section{Normal Cerebral Asymmetry in Familial and Non-familial Schizophrenic Probands and their Unaffected Relatives}

Chapple, B., Grech, A., Sham, P., Toulopoulou, T., Walshe, M., Schulze, K., Morgan, K., Murray, R. M., \& McDonald, C. (2004). Normal cerebral asymmetry in familial and non-familial schizophrenic probands and their unaffected relatives. Schizophrenia Research, 67(1), 33-40 


\begin{abstract}
Loss of normal frnoto-occipital cerebral asymmetry has been reported in patients with schizophrenia and also in their well relatives from multiply affected families, suggesting a relationship with susceptibility genes. We sought to confirm this relationship in a family study of patients with schizophrenia and their unaffected relatives of presumed differing genetic risk. MRI scans were carried out on 25 probands from families multiply affected with the disorder and 36 of their unaffected relatives, 34 probands from families with no other affected members, 42 of their unaffected relatives, and 76 controls. Volumetric measurements of prefrontal, promotor, sensorimotor and occipitoparietal regions were obtained from which a measure of fronto-occipital torque was derived. There were no significant differences in measurements of fronto-occipital torque between the subject groups. Both schizophrenic probands and their relatives displayed the normal pattern of cerebral asymmetry, with larger right than left frontal regions and a larger left than right occipitoparietal region. Our findings failed to confirm an association between loss of fronto-occipital torque and genetic liability for schizophrenia and also failed to replicate the previously reported association between loss/reversal of fronto-occipital asymmetry and schizophrenia.
\end{abstract}




\section{Introduction}

A number of structural asymmetries emerge during the normal development of the human brain. These include a longer Sylvian fissure and larger planum temporale on the left than the right, and a pattern of counterclockwise torque, where the right frontal lobe is larger than the left and the left occipital lobe is larger than the right (LeMay, 1976; Weinberger et al., 1982). Some studies have reported a reduced or even reversed pattern of these cerebral asymmetries in schizophrenia (Bilder et al., 1994; Bullmore et al., 1995; Falkai et al., 1995; DeLisi et al., 1997; Sharma et al., 1999).

The cause of any such abnormality of cerebral asymmetries in schizophrenia remains unclear. Since structural asymmetries are detectable by the third trimester (Weinberger et al., 1982; LeMay, 1984), any deviation might be expected to affect the developing brain of the foetus either through genetic mechanism or prenatal environmental influences. Crow has postulated that the reported loss of cerebral asymmetry in schizophrenia is related to a failure to establish cerebral dominance and is most likely under genetic control (Crow, 1997). A genetic contribution to the loss of fronto-occipital torque is supported by a report from our group of multiply affected families with schizophrena (Sharma et al., 1999). In this study, a familial pattern of reduced cerebral asymmetry was found, whereby schizophrenic probands had the greatest loss of assymmetry compared to controls, followed by their relatives who were at highest likelihood of carrying susceptibility genes and those relatives at lower likelihood of carrying such genes.

The aim of the present investigation was to replicate these findings in an independent group of families representing a wider range of likely genetic risk by including families both multiply and singly affected with schizophrenia. We hypothesized that, if reduced cerebral asymmetry is a marker of genetic risk for schizophrenia, there would be a pattern of loss/reversal of cerebral asymmetry in probands with schizophrenia which would be present to a diminishing extent in their unaffected relatives across a gradient of presumed reducing genetic risk. We have previously reported this pattern to be present for enlarged ventricular volume (McDonald et al.,2002).

\section{Method}

\subsection{Subjects}

All subjects were Caucasian, aged between 16 and 69 at the time of assessment and their first language was English. Subjects were excluded if they had a history of head 
trauma resulting in loss of consciousness for more than a few minutes, substance or alcohol dependence in the 12 months prior to assessment or a history of organic brain disease. The study was approved by the local ethical committee. A total of 213 subjects completed MRI scans successfully and were included in the study. There were no overlap between the subject who took part in this study and the sample previously reported by Sharma et al., (1999).

\subsection{Probands and relatives}

A total of 59 probands fulfilling DSM3R (APA, 1987) criteria for schizophrenia or schizo-affective disorder $(n=6)$ were included in the study. Probands were divided into two groups on the basis of family history: (a) 'familial', where the proband had at least one other first and/or second degree relative with schizophrenia $(n=25)$, and

(b) 'non-familial', where the proband had no known family history of schizophrenia or another functional psychotic disorder as far as their third degree relatives $(n=34)$. The recruitment of a proportion $(n=21)$ of these probands have been described previously (McDonald et al., 2002), consisting of 16 non-familial probands and 5 familial probands. A further 38 probands were recruited either by self-referral in response to advertisements through voluntary organizations or by direct referral from their clinicians.

A total of 36 nonpsychotic first-degree relatives of the familial probands also participated in the study. The familial relatives group included 12 parents who were classified as "presumed obligate carriers", on the basis that the appeared to be transmitting liability for schizophrenia to their affected child, by virtue that (a) they also had a sibling or parent affected and (b) transmission of liability was apparently unilineal, i.e. family history of psychosis was absent from the presumed obligate carrier's spouse. The remaining 24 "other familial relatives" were presumed to be more likely to carry susceptibility genes for schizophrenia than the relatives of the non-familial probands. Hence a decreasing gradient of presumed genetic risk was established amongst unaffected relatives from presumed obligate carriers, to other familial relatives, to non-familial relatives.

MRI scans were successfully measured on at least one first-degree relative of 47 of the probands. For all but six of the participating relatives, at lest one proband from the same family was also scanned successfully.

\subsection{Controls}

Seventy-six controls were recruited from the local community via newspaper advertisements and from local staff. Since the groups of relatives included parents and 
tended to be older than the proband groups, the controls were chosen to reflect the combined sample of probands and relatives on the basis of age, gender and parental social class distribution. None of the controls had a personal history of a functional psychotic or schizophrenia spectrum disorder, nor any known family history of functional psychosis. The presence of other psychiatric disorders was not an exclusion factor.

\subsection{Clinical assessments}

Patients, relatives, and controls were assessed using the same clinical scales in face to face interviews. Structured diagnostic interviews were performed using the Schedule for Affective Disorders and Schizophrenia-Lifetime version (Spitzer and Endicott, 1978) and additional information regarding the timing and nature of psychopathology was collected to enable DSM3R diagnoses to be made. For relatives not assessed directly, information regarding history of psychiatric illness was obtained from all reliable informants using the Family Interview for Genetic Studies (Nurnberger et al.,1994;) and from medical notes where available. The Schedule for Schizotypal Personality (Baron et al., 1981) was used to assess nonpsychotic relatives and controls fro schizotypal traits.

Socio-economic status based on details of parental occupation at birth of the subject was derived from Office of Population Censuses and Surveys Standard Occupational Classification (1991). Handedness was assessed using the Annett handedness scale (Annett, 1970).

\subsection{MRI data acquisition and analysis}

For each subject, a set of $1.5 \mathrm{~mm}$ thick contiguous coronal T1-weighted MRI images extending through the entire brain was obtained using a three-dimensional spoiled gradient recall echo sequence on a HE 1.5T scanner. 76 subjects were scanned on one scanner using the following protocol: $\mathrm{TE}=3.7 \mathrm{~ms}$, TR $=14.7 \mathrm{~ms}$, number of excitations $=1$, field of view $=20 \mathrm{~cm}$, acquisition matrix $256 \times 256$ and flip angle 20 degrees. The other 137 participants were scanned on another scanner using a slightly different protocol with TE $=2.3 \mathrm{~ms}, \mathrm{TR}=9.8 \mathrm{~ms}$ and filed of view $=22 \mathrm{~cm}$.

Images were analysed using MEASURE software (version 0.8 Johns Hopkins University Baltimore), an image analysis program that uses stereologically unbiased estimation of volume (Barta et al ., 1997). A grid is applied over the whole brain and the rater marks grid points falling into the structure of interest, taking into consideration all three orthogonal views. The grid-size used for cerebral measurements was 5 $X 5 X 5$, with every fifth pixel sampled in the sagittal, axial and coronal planes. 
Scans were mixed and identified by number only to ensure rater's blindness to group affiliation. Prior to any measurements, head tilt was corrected by aligning each brain along the anterior-posterio commissure axis in the sagittal plane and along the inter-hemispheric fissure in the coronal and axial planes.

Whole brain volume included cortical and sub-cortical grey matter and white matter, and excluded the cerebellum, ventricles and brainstem. Criteria for defining the cerebral regions in the sagittal plane were those employed by Bilder et al.,(1994) and Sharma et al. (1999). Four cerebral regions were defined for each hemisphere: (a) prefrontal, from the frontal pole to the section rostral to the rostrum of the corpus callosum; (b) premotor; from the rostrum of the corpus callosum to the most caudal section rostral to the rostral thalamus; (c) sensorimotor, from the rostral thalamus to the most caudal section through the splenium of the corpus collosum; and (d) occipitoparietal, from the splenium of the corpus collosum to the most caudal appearance of the occipital lobe. A figure demonstrating the delineation of the segments has been provided previously (Sharma et al., 1999).

Whole brain volume measurements were carried out by three raters ( $B C, A G$ and KS) and regional cerebral measurements were carried out by a single rater (BC), trained in this technique by an experienced MEASURE rater. Interrater reliability estimates based on a sample of 10 random brains calculated using the intraclass correlation coefficient ranged between 0.94 and 0.98 for whole brain volume and 0.91 and 0.99 for the eight cerebral regions,. Intra-rater reliability based upon a sample of 10 brains rated at least 6 months apart ranged from 0.98 to 0.99 for whole brain volume and 0.93 and 0.99 for the cerebral regions.

\subsection{Statistical analysis}

Pearson $v^{2}$ tests and one-way analysis of variance (ANOVA) were used to analyse differences in the demographic variables between the groups, conducted using SPSS, version 10. Since our variable of interest was a measure of cerebral asymmetry rather than the absolute values of the eight cerebral regions, we extracted a variable of fronto-occipital torque for each subject in the following manner. Initially an asymmetry index was calculated separately for each of the four cerebral regions, using the formula $(R-L) /(R+L) X 100$. A principal component factor analysis of these four indices was then performed without rotation in order to extract a single dimension of fronto-occipital torque using a data-driven statistical technique. Tests for the association of torqe with demograpghic variables were performed using the Student t-test for categorical variables and Pearson correlation coefficient for continuous variables. Multiple linear regression analyses with fronto-occipital torque as the dependent variable were performed, comparing each subject group against the 
control group and controlling for age, gender, height, whole brain volume, and scanner. Since many of the observations both within and between groups were of individuals within families and thus not independent from each other, we performed regression analyses for clustered observations using a robust estimator for the variances of the regression coefficient estimates as implemented in STATA (version 7.0). All tests were two-tailed and used a 0.05 level of significance.

\section{Results}

Analysis of the demographic variables (Table 1) revealed no significant differences between the groups in years of education $(F=1.42, d f=5,207) p=0.22)$, handedness $\left(X^{2}=1.98, d f=5, p=0.85\right)$ or parental social class $\left(X^{2}=3.16, d f=5, p=0.68\right)$. There were significant group differences in age $(F=14.63, d f=5,207, p<0.001)$, gender $\left(X^{2}=\right.$ 19.04, $d f=5, p=0.002)$ and height $(F=4.00, d f=5,207, p=0.002)$. Post hoc analysis using the Bonferroni test revealed the following age differences: nonfamilial relatives and presumed obligate carriers were significantly older than probands and controls, since they contained a number of parents, and non-familial probands were also significantly younger than other familial relatives. There was an excess of males in the proband groups and an excess of females in the relatives groups. With respect to height, the only significant group difference was that non-familial probands were taller than their relatives, which was contributed to by the larger proportion of males in the proband group.

TABLE 1

Demographic characteristics of each subject group

\begin{tabular}{|c|c|c|c|c|c|c|}
\hline Variable & $\begin{array}{l}\text { Familial } \\
\text { Probands } \\
(n=25)\end{array}$ & $\begin{array}{l}\text { Non-familial } \\
\text { Probands } \\
\text { (n-34) }\end{array}$ & $\begin{array}{l}\text { Presumed } \\
\text { obligate } \\
\text { Carriers } \\
((n=12)\end{array}$ & $\begin{array}{l}\text { Non-obligate } \\
\text { Familial } \\
\text { Relatives } \\
(\mathrm{n}=24)\end{array}$ & $\begin{array}{l}\text { Non-familial } \\
\text { Relatives } \\
(n=42)\end{array}$ & $\begin{array}{l}\text { Controls } \\
(n=76)\end{array}$ \\
\hline Mean age(S.D.) & $36.7(10.2)$ & $33.1(6.4)$ & $53.8(3.7)$ & $45.8(15.0)$ & $52.4(13.3)$ & $38.7(13.8)$ \\
\hline Age range & $24-55$ & $24-52$ & $49-63$ & $16-69$ & $17-69$ & $19-69$ \\
\hline Height in $\mathrm{cm}$ & $171.1(9.9)$ & $173.4(8.5)$ & 166.7(10.3) & $168.9(12.4)$ & $164.3(9.1)$ & $167.8(8.8)$ \\
\hline $\begin{array}{l}\text { Years of education } \\
\text { (S.D.) }\end{array}$ & $13.6(3.6)$ & $13.5(2.4)$ & $14.0(3.1)$ & $13.9(2.7)$ & $13.7(2.8)$ & $14.9(3.3)$. \\
\hline $\begin{array}{l}\text { Age of onset of psy- } \\
\text { chotic symptons }\end{array}$ & $22.3(5.6)$ & $20.7(3.9)$ & $\mathrm{N} / \mathrm{A}$ & N/A & N/A & N/A \\
\hline Gender (\% male) & $72.0(n=18)$ & $73.5(n=25)$ & $25.0(n=3)$ & $37.5(n=9)$ & $42.9(n=18)$ & $43.4(n=33)$ \\
\hline Handedness(\% left) & $8.0(n=2)$ & $17.6(n=6)$ & $8.3(n+1)$ & $8.3(n=2)$ & $14.3(n=6)$ & $13.2(n=10)$ \\
\hline $\begin{array}{l}\text { Parental social class } \\
\text { (\% or II) }\end{array}$ & $39.1(n=9)$ & $57.1(n=16)$ & $41.7(n=5)$ & $35.0(n=7)$ & $41.0(n=16)$ & $40.4(n=21)$ \\
\hline
\end{tabular}

(a) Recorded on 174 subjects 
TABLE 2

Mean asymmetry indices for each subject group and regression coefficients comparing the torque for each subject group to the controls, controlling for age, gender, height, whole brain volume and scanner, and clustering subjects within families

\begin{tabular}{lllllll}
\hline $\begin{array}{l}\text { Mean asymmetry } \\
\text { Index (S.D.) }\end{array}$ & $\begin{array}{l}\text { Familial pro- } \\
\text { bands }\end{array}$ & $\begin{array}{l}\text { Non-familial } \\
\text { probands }\end{array}$ & $\begin{array}{l}\text { Obligate } \\
\text { carriers }\end{array}$ & $\begin{array}{l}\text { Other } \\
\text { familial } \\
\text { relatives }\end{array}$ & $\begin{array}{l}\text { Non-familial Controls } \\
\text { relatives }\end{array}$ \\
\hline Prefrontal region & $3.02(4.44)$ & $2.59(4.70)$ & $1.40(2.77)$ & $3.72(4.07)$ & $2.24(3.56)$ & $1.86(3.78)$ \\
Premotor region & $0.76(1.49)$ & $-0.04(2.20)$ & $-0.12(2.11)$ & $0.88(2.00)$ & $0.01(2.03)$ & $0.58(1.76)$ \\
Sensorimotor region & $2.00(3.49)$ & $2.15(3.39)$ & $1.02(3.27)$ & $1.68(3.91)$ & $1.06(4.67)$ & $1.87(4.13)$ \\
Occipitoparietal region & $-2.46(3.58)$ & $-2.70(4.20)$ & $-0.82(2.91)$ & $-3.04(3.74)$ & $-2.47(3.62)$ & $-2.36(3.83)$ \\
$B$ & 0.11 & -0.06 & -0.26 & 0.28 & -0.07 & - \\
$95 \% \mathrm{Cl}$ & $-0.36-0.57$ & $-0.52-0.40$ & $-0.79-0.27$ & $-0.25-0.80$ & $-0.49-0.36$ & - \\
$p$ & 0.65 & 0.80 & 0.33 & 0.30 & 0.76 & - \\
\hline
\end{tabular}

Of the 78 relatives, 14 had fulfilled criteria for a DSM3R axis 1 diagnosis at some stage of their lives; 10 with major depressive disorder, 2 with panic disorder, 1 with anxiety disorder NOS and one with social phobia. Three relatives also fulfilled criteria for schizotypal personality disorder. Five of the control subjects had fulfilled criteria for major depressive disorder at some stage of their lives.

The principal components analysis of the asymmetry indices produced four components, the largest of which had an eigenvalue of 2.29 and explained $57.3 \%$ of the variance. This factor was loaded onto by the asymmetry indices as follows: prefrontal 0.84 , premotor 0.57 , sensorimotor 0.72 , occipitoparietal -0.86 and therefore represented fronto-occipital asymmetry. The standardized regression factor scores of this factor were produced for each subject and this variable was defined as "torque" in the subsequent analysis. This variable had a normal distribution (Kolmogorov - Smirnov $=0.05, d f=213, p=0.20$ ), and a higher score represented increasing asymmetry, whereas a lower score reflected loss or reversal of the normal pattern of fronto-occipital asymmetry. There was a trend for male patients in the sample to have higher torque scores, and thus more fronto-occipital asymmetry, than females ( $t=-1.79, d f=211, p=0.07$ ). There was no significant relationship between torque and age in the sample (Pearson correlation coefficient $-0.07, p=0.30$ ). There was no association between torque and left handedness $(t=0.19, d f=211, p=0.85$ ) or non-right handedness, i.e. left or mixed handed $(t=-0.49, d f=211, p=0.63$ ).

The mean asymmetry indices for each subject group and the results of the regression analysis of each subject group on torque are displayed in Table 2 . The overall model was non-significant $\left(F(10,134)=1.60, R^{2}=0.05, p=0.11\right)$ and there were no significant differences between the torque scores of any of the subgroups compared to the control group. A similar pattern of 'normal' cerebral asymmetry was present in each of the subject groups, where the frontal regions had a positive asymmetry 
index and the posterior region had a negative asymmetry index. When the familial and non-familial groups were combined into a single group of probands, there were no differences in the torque measurements of patients with schizophrenia compared to controls $(B=-0.01,95 \% C l=-0.38-0.36, p=0.94)$ or to the combined group of relatives $(B=0.08,95 \% \mathrm{Cl}=-0.50-0.66, p=0.78)$.

There were no gender by group interactions upon torque for either patients $(B=-$ $0.26,95 \% \mathrm{Cl}=-1.04-0.51, \mathrm{p}=0.50)$ or relatives $(\mathrm{B}=-0.13,95 \% \mathrm{Cl}=-0.77-0.51, p$ $=0.68)$. There was no significant effect upon torque of age of onset of psychotic symptoms among probands $(\mathrm{B}=-0.01,95 \% \mathrm{Cl}=-0.10-0.08, \mathrm{p}=0.77)$.

\section{Discussion}

In this study, we failed to replicate in an independent sample the findings of Sharma et al. (1999), which found loss of cerebral asymmetry in familial probands and those of their unaffected relatives most likely to be gene carriers. Indeed each subject group in our sample showed a broadly similar pattern of cerebral asymmetry to that reported in the general population., whereby the right frontal hemisphere regions were larger than the left, and the left occipital hemisphere region was larger than the right.

The association between disturbed fronto-occipital torque and schizophrenia remains a contentious issue in psychiatric research. Early CT reports of reversed asymmetry in schizophrenia, usually most prominent in the occipital region (Luchins et al., 1979; Tsai et al., 1983), were contradicted by a number of negative reports (Andreasen et al., 1982; Jernigan et al., 1982). However, these CT studies inevitably had methodological weaknesses including the use of linear or area measurements on selected slices and the failure to control for head tilt and brain size. MRI studies have the advantage of allowing volumetric assessments across the cortex and are inherently more reliable since they are based on more data, and can correct for head position. Some MRI studies have reported loss of the normal pattern of frontooccipital asymmetry in schizophrenia (Bilder et al., 1994, 1999;Sharma et al., 1999). The present study employed similar regions for measurement as those used by these studies, but found normal fronto-occipital asymmetry in schizophrenic probands from both multiply and singly affected families. There have been two other recent volumetric MRI studies using very similar methodology which have also failed to find loss of fronto-occipital asymmetry in samples of schizophrenic subjects compared to controls (Guerguerian and Lewine, 1998; Hadjulis et al., in press), which, together with our own, question the strength of the association of this structural anomaly with schizophrenia. The elusive nature of the relationship between re- 
duced fronto-occipital asymmetry and schizophrenia suggests that any effect size is small and further studies may elucidate whether the finding is associated with certain subgroups of patients.

Normal fronto-occipital asymmetry was also found in the unaffected relatives in our sample, who represented a gradient of likely genetic risk. Sharma et al. (1999) reported loss of asymmetry in the prefrontal, sensorimotor and occipitoparietal regions in their presumed obligate carrier group and that other non-obligate relatives had some loss of asymmetry in the occipitoparietal region only. Our failure to replicate this finding of loss of asymmetry, even in those presumed obligate carrier relatives who appeared to be transmitting genetic risk for the illness, casts doubt upon the conclusion of Sharma et al. (1999) that loss of cerebral asymmetry represents a marker of genetic liability for schizophrenia.

There are few methodological differences between the two studies that might explain their contradictory results. There was a difference in the manner in which controls were recruited. Whereas controls in the initial study (Sharma et al., 1999) were matched to the schizophrenic group only, in the present study the controls ere recruited to reflect the demographic characteristics of both patients with schizophrenia and their relatives and were therefore older with a larger age variance. However, it is unlikely that this methodological difference contributed to the differing results of the two studies, since there was no evidence that fronto-occipital asymmetry reduces with age. We extracted a single measure of torque from the eight regions measured, whereas Shrma et al., (1999) utilized a four-way MANCOVA with subsequent post hoc analysis. The advantages of using a single measure of torque, rather than eight regional measures, is that it simplified the analysis and allowed the use of a clustered regression technique to account for any nonindependence of measures within families, a factor ignored in the initial study. Other studies extracted a single value of torque by simply summing, whilst reversing negative signs, the asymmetry indices of the regions measured (Bilder et al., 1999; Guerguerian and Lewine; 1998; Hadjulis et al., in press). We used a principal components analysis to derive a data-driven factor which represented torque as it was positively loaded onto by the anterior regions and negatively loaded by the posterior region. When the regional data was analysed using MANCOVA as in the initial study (Sharma et al., 1999), there was no significant difference in hemispheric asymmetry between the subject groups (results available on request). It seems likely that the contradictory results between the two studies are related to variation of the trait in different samples of subject with schizophrenia rather than any methodological bias. 
General strengths of the study include the use of high-resolution images, a large ethnically homogenous sample and a gradient of likely genetic risk among the subjects. In addition, a single rater who was blind to subject status measured each cerebral region, with good inter- and intra-rater reliability.

However, the following limitations must be noted. The families who participated in the study represented a highly selected sample of volunteers who were recruited specifically because of the presence or absence of family history of psychosis; therefore the findings may not be generalizable. Studies adopting the familial/nonfamilial (or sporadic) strategy may misclassify patients (Roy and Crowe, 1994), especially since family size may differ or subjects have not lived through the risk period. We do not contend that patients with no family history of illness carry no genetic contribution to their illness, but rather that more densely affected families are more likely to carry susceptibility genes than those families with only one member affected. Indeed such a model of illness is supported by studies which find more extensive brain structural deviations among unaffected relatives from more densely affected families (McDonald et al., 2002; Seidman et al., 2002). Since neither schizophrenic group differed from the controls, this aspect of the design does not affect the negative result from this study.

Measurements were not rated blind to side. This might have introduced a possible bias due to previously reported fronto-occipital asymmetry. However, volumes were rated blind to group affiliation and any bias could not differentially influence ratings for particular subgroups of participants. Our finding of a strong trend for increased asymmetry in males is in keeping with previous reports in the literature of more accentuated asymmetries in males compared to females, which may be related to the influence of testosterone or cortical asymmetry (Bear et al.,1986; Wisniewski, 1998).

Loss of fronto-occipital torque is only one disturbance of normal structural cerebral asymmetry which has been reported to characterize schizophrenia. In our study, asymmetries of the temporal lobe were not examined, in particular the prominent asymmetry of the planum temporale or Sylvian fissure, which are the areas related to language function. However, some recent studies that measured volume, as distinct from surface area, of the planum temporale have failed to replicate studies claiming loss of normal asymmetry of this structure in schizophrenia (Frangou et al., 1997; Shapleske et al., 2001).

A range of disturbances of normal functional asymmetries have also been reported in schizophrenia such as those for hand performance, evoked potentials, regional cerebral blood flow and neuropsychological tasks (Gruzelier, 1999; Sommer et al., 
2001). Assessing whether these deviations in functional asymmetries also exist in the unaffected relatives of schizophrenic probands could be informative about their likely aetiology.

In summary, patients with schizophrenia from both multiply and singly affected families and their unaffected first degree relatives in this sample displayed the normal pattern of fronto-occipital asymmetry, thus questioning the link between deviations of this anatomical asymmetry and schizophrenia that have been reported in previous studies.

\section{Acknowledgements}

Dr. McDonald is supported by the Wellcome Trust, and we also received support from the Stanley Foundation. We would like to thank the National Schizophernia Fellowship for helping in the identification of families for the study, all the families who participated in the study, and the staff of the MR Units in St. George's Hospital, and Maudsley Hospital London, for MRI scanning.

\section{References}

Andreasen, N.C., Dennert, J.W., Olsen, S.A., Damasio, A.R., 1982 Hemispheric asymmetries and schizophrenia. Am. J. Psychiatry 139, $427-430$.

Annett, M., 1970. A classification of hand preference by association analysis. Br. J. Psychol. 61, $303-321$. APA, 1987. Diagnostic and Statistical Manual of Mental Disorders (DSM-III-R). American Psychiatric Press, Washington, DC. Baron, M. Asnis,L.Greun, R., 1981. The schedule for schizotypal personalities (SSP). A diagnostic interview for schizotypal features. Psychiatry Res. 4, $213-228$.

Barta, P.E., Dhingra, L., Royall, R., Schwartz, E., 1997. Improving stereological estimates for the volume of the structures identified in three-dimensional arrays of spatial data. J. Neurosci. Methods 75, $111-$ 118.

Bear, D., Schiff, D., Saver, J., Greenberg, M., Freeman, R., 1986. Quantitative analysis of cerebral asymmetries. Fronto-occipital correlation, sexual dimorphism and association with handedness. Arch. Neurol. 43, $598-603$.

Bilder, R.M., Wu, H., Bogerts, B., Degreef, G., Ashtari, M., Alvir, J.M., Snyder, P.J., Lieberman, J.A., 1994. Absence of regional hemispheric volume asymmetries in first-episode schizophrenia. Am. J. Psychiatry $151,1437-1447$.

Bilder, R.M., Wu, H., Bogerts, B., Ashtari, M., Robinson, D. Woerner, M., Lieberman, J.A., Degree, G., 1999. Cerebral volume asymmetries in schizophrenia and mood disorders: a quantitative magnetic resonance imaging study. Int. J. Psychophy- siol. 34, 197 - 205.

Bullmore, E., Brammer, M., Harvey, I., Murray, R., Ron, M., 1995. Cerebral hemispheric asymmetry revisited: effects of handedness, gender and schizophrenia measured by radius of gyration in magnetic resonance images. Psychol. Med. 25, 349- 363.

Crow, T.J., 1997. Is schizophrenia the price that Homo sapiens pays for language? Schizophr. Res. 28, 127 $-141$.

DeLisi, L.E., Sakuma, M., Kushner, M., Finer, D.L., Hoff, A.L., Crow, T.J., 1997. Anomalous cerebral asymmetry and language processing in schizophrenia. Schizophr. Bull. 23, 255 - 271. 
Falkai, P., Bogerts, B., Schneider, T., Greve, B., Pfeiffer, U., Pilz, K., Gonsiorzcyk, C., Majtenyi, C., Ovary, I., 1995. Disturbed planum temporale asymmetry in schizophrenia. A quantitative post-mortem study. Schizophr. Res. 14, $161-176$.

Frangou, S., Sharma, T., Sigmudsson, T., Barta, P., Pearlson, G., Murray, R.M., 1997. The Maudsley Family Study IV. Normal planum temporale asymmetry in familia schizophrenia- a volumetric MRI study. $\mathrm{Br}$ J Psychiatry 170, 328- 333.

Gruzelier, J.H., 1999. Functional neuropsychophysiological asymmetry in schizophrenia: a review and reorientation. Schizophr. Bull. 25, $91-120$.

Guerguerian, R., Lewine, R.R., 1998. Brain torque and sex differences in schizophrenia. Schizophr. Res. 30, $175-181$.

Hadjulis, M., Pipe, R., Frangou, S. Normal cerebral volume asymmetries in early onset schizophrenia. Biol. Psychiatry (in press).

Office of Population Censuses and Surveys, 1991. Standard Occupational Classification, vol. 3. HMSO, London.

Jernigan, T.L., Zatz, L.M., Moses Jr., J.A., Cardellino, J.P., 1982. Computed tomography in schizophrenics and normal volunteers: II. Cranial asymmetry. Arch. Gen. Psychiatry $39771-773$.

LeMay, M., 1976. Morphological cerebral asymmetries of modern man, fossil man, and nonhuman primate. Ann. N.Y. Acad. Sci. 280, $349-366$.

LeMay, M., 1984. Radiological, developmental, and fossil asymmetries. In Geschwind, N., Galaburda, A.M. (Eds.), Cerebral Dominance: The Biological Foundations. Harvard Univ. Press, Cambridge, MA, pp. $26-42$.

Luchins, D.J., Weinberger, D.R., Wyatt, R.J. Schizophrenia: evidence of a subgroup with reversed cerebral asymmetry. Arch. Gen. Psychiatry 36, $1309-1311$.

McDonald, C., Grech, A., Toulopoulou, T., Schulze, K., Chapple, B., Sham, P.C., Walshe, M., Sharma, T., Sigmundsson, T., Chitnis, X., Murray, R.M., 2002. Brain volumes in familial and non- familial schizophrenic probands and their unaffected relatives. Am. J. Med. Genet. 114, 616-625.

Nurnberger, J.I., Blehar, M.C., Kaufmann, C.A., York-Cooler, C., Simpson, S.G., Harkavy- Friedman, J., Severe, J.B., Malaspina, D., Reich, T., 1994. Diagnostic interview for genetic studies. Rationale, unique features, and training. NIMH Genetics Initia- tive. Arch. Gen. Psychiatry 51, 849-859.

Roy, M.A., Crowe, R., 1994. Validity of the familial and sporadic subtypes of schizophrenia. Am. J. Psychiatry $151,805-814$.

Seidman, L.J., Faraone, S.V., Goldstein, J.M., Kremen, W.S., Horton, N.J., Makris, N., Toomey, R., Kennedy, D., Caviness, V.S., Tsuang, M.T., 2002. Left hippocampal volume as a vulnerability indicator for schizophrenia: a magnetic resonance imaging morphometric study of nonpsychotic first-degree relatives. Arch. Gen. Psychiatry 59, 839 - 849.

Shapleske, J., Rossell, S.L., Simmons, A., David, A.S., Woodruff, P.W., 2001. Are auditory hallucinations the consequence of abnormal cerebral lateralization? A morphometric MRI study of the sylvian fissure and planum temporale. Biol. Psychiatry 49, $685-693$.

Sharma, T., Lancaster, E., Sigmundsson, T., Lewis, S., Takei, N., Gurling, H., Barta, P., Pearlson, G., Murray, R.M., 1999. Lack of normal pattern of cerebral asymmetry in familial schizophrenic patients and their relatives-the Maudsley Family Study. Schizophr. Res. 40, 111 - 120.

Sommer, I., Ramsey, N., Kahn, R., Aleman, A., Bouma, A., 2001. Handedness, language lateralisation and anatomical asymmetry in schizophrenia: meta-analysis. Br. J. Psychiatry 178, $344-351$.

Spitzer, R.L., Endicott, J., 1978. Schedule for Affective Disorders and Schizophrenia-Lifetime Version. New York State Psychiat- ric Institute, New York.

Tsai, L.Y., Nasrallah, H.A., Jacoby, C.G., 1983. Hemispheric asymmetries on computed tomographic scans in schizophrenia and mania. A controlled study and a critical review. Arch. Gen. Psychiatry 40, 1286 1289.

Weinberger, D.R., Luchins, D.J., Morihisa, J., Wyatt, R.J., 1982. Asymmetrical volumes of the right and left frontal and occipital regions of the human brain. Ann. Neurol. 11, 97-100. 
Wisniewski, A.B., 1998. Sexually-dimorphic patterns of cortical asymmetry, and the role for sex steroid hormones in determining cortical patterns of lateralization. Psychoneuroendocrinology 23, 519 547. 


\section{Chapter 4}

\section{The relationship between volumetric brain changes and cognitive function: A family study on schizophrenia}

Toulopoulou, T., Grech, A., Morris, R. G., Schulze, K., McDonald, C., Chapple, B., Rabe-Hesketh, S., \& Murray, R. M. (2004). The relationship between volumetric brain changes and cognitive function: A family study on schizophrenia. Biological Psychiatry, 56(6), 447-453 
Background: We examined the cerebral correlates of intelligence, memory and executive processing in 56 patients with schizophrenia or schizoaffective disorder and 90 of their nonpsychotic relatives to establish whether the pattern of structurefunction relationships in these two groups was different from that in 55 control subjects.

Methods: Magnetic resonance imaging data were acquired, and volumetric measurements were made for whole brain, prefrontal region, lateral ventricle, temporal lobes and cerebellum.

Results: In the total sample, full intelligence quotient (IQ) and verbal IQ correlated with the volume of the whole brain and right hippocampus; the latter was also associated with performance IQ. Left hippocampal size was associated with verbal IQ and, in control subjects and nonpsychotic relatives only, with estimated full IQ. Delayed verbal memory was linked to cerebellar and inversely to left hippocampal volume. Discrepancies in the relationship pattern emerged in patients with schizophrenia between left hippocampus and measures of IQ and verbal memory.

Conclusions: The latter data indicate a loss of a normal structure-function relationship in schizophrenia and might reflect a functional compensation occurring secondary to early neurodevelopmental impairment.

Key Words: Cognition, executive processing, intelligence, intelligence quotient, magnetic resonance imaging, memory 
The presence of structural brain abnormalities and neuropsychological impairments is well established in schizophrenia (Davidson and Heinrichs 2003; Heinrichs and Zakzanis 1998; Wright et al 2000), and these abnormalities have been found to a lesser extent in the first-degree relatives of patients with schizophrenia (Baare et al 2001; Cannon et al 2000; Lawrie et al 1999; Staal et al 2000a, 2000b; Toulopoulou et al 2003a, 2003b). What is less firmly established is whether the pattern of correlations between brain structure and function in patients also deviates from normal. $A$ number of studies have attempted to identify the structural abnormalities that mediate the functional deficits in patients (Allen et al 2001; Bilder et al 1995; Sanfilipo et al 2002). For example, Sanfilipo et al 2002) found a different set of structural-functional relationships in patients with schizophrenia compared with control subjects, especially for the prefrontal and hippocampal regions, whereas Bilder et al (1995) found that reductions in anterior hippocampal formation were associated with worse performances on tasks thought to be sensitive to the integrity of the frontal lobe systems.

Few studies, however, have examined such relationships in the relatives of patients with schizophrenia (Goldberg et al 1994; O'Driscoll et al 2001; Seidman et al 2002). Of these, the study by Seidman et al (2002) focused on total cerebrum and hippocampus, and that of O'Driscoll et al (2001) focused on amygdala and hippocampus; Goldberg et al (1994) examined hippocampal volumes and ventricular size. All three studies found associations between verbal memory and measures of hippocampus; Driscoll et al also reported that decreased volume of the amygdala was associated with poorer performance.

We recently found (McDonald et al 2002) that both patients with schizophrenia and their relatives display enlargements of the lateral and third ventricles and, in the case of relatives, these increases and proportional to the likelihood of carrying genes for schizophrenia. In other words, a subsample of the nonpsychotic relatives who seem to transmit genetic risk to their affected children (presumed obligate carriers) were more likely than the other unaffected relatives to show the same brain abnormalities as the probands. We also reported (Toulopoulou et al 2003a) that schizophrenic patients and their relatives show a selective deficit in verbal memory, implying that such impairment constitutes a familial, probably genetic, risk factor for schizophrenia.

In this article, we relate congnitive deficits to the underlying neuropathology of schizophrenia, as measured by magnetic resonance imaging (MRI), in a large sample of patients and their relatives and examine whether the pattern of functionstructure relationships in these two groups differs from that of control subjects. We examine performance on tasks assessing intelligence, memory, and executive processing in relation to the volumetric measures pertinent to these processes, including whole-brain volume, prefrontal cortex, temporal lobes, hippocampi, ventricles, and cerebellum. 


\section{Methods and Materials}

\section{Subjects}

The study was approved by the local research ethics committee, and all participants gave written informed consent. Participants were drawn from larger cohort of the Maudsley Family Study (Frangoou et al 1997a, 1997b; Griffiths et al 1998). The subjects who took part in the neuropsychological (Toulopoulou et al 2003a, 2003b) and MRI components of the study (McDonald et al 2002; Schulze et al 2003) are included in the present report.

A total of 201 of the 251 subjects who participated in the neuropsychological component of the Maudsley Family Study agreed and were suitable to undergo and MRI brain scan. Subjects were suitable for an MRI scan if they had no contraindication (e.g., metal fragments from previous injury) and could tolerate the confined space for the duration of the procedure without significant head movement. Fiftysix were patients (17 female, 39 male) with schizophrenia (n 51) or schizoaffective disorder ( $\mathrm{n}$ 5); 90 were nonpsychotic relatives (56 female, 34 male), of whom 52 were parents, 31 siblings, 4 adult offspring, and 3 second-degree relatives ( 2 aunts and 1 uncle); and 55 were normal control subjects (28 female, 27 male). The "second -degree relatives" were nonpsychotic relatives of second-degree to the proband, who had themselves first-degree relatives who suffered from schizophrenia but who did not participate in the neuropsychological component of the study. Fourteen of the patients included in this study had relatives who did not agree or who had a contraindication to undergoing a brain scan. The number of members that contributed in each family were as follows: 1 family had 9 members, 3 families had 6 members, 3 families had 5 members, 9 families has 4 members, 10 families had 3 members, 12 families had 2 members, and 14 families had 1 member contributing to this particular part of the study.

Every individual included in this report underwent an MRI scan and completed at least some neurocongnitive tests, if not all. In particular, 19 of the 201 individuals did not contribute to every single cognitive test, this was mainly because the assessment had to be discontinued owing to the tiredness experienced by the participant. The missing data on congnitive tests are totally random and are not systematic in any way. Families were referred from clinics and voluntary organizations across the United Kingdom. Control subjects were ascertained from pool of research participants obtained for previous studies conducted at the Institute of Psychiatry, from members of staff at the Bethlem and Maudsley Hospital Trust, and through advertisements in local press. A more detailed description of the sample can found elsewhere (Toulopoulou et al 2003a, 2003b).

All the patients met DSM- IV criteria for schizophrenia (American Psychiatric Association 1994) and were receiving antipsychotic medication at the time of the as- 
sessement. Among the the nonpsychotic relatives, five individuals had had a single episode of major depression, five had had recurrent depressive disorder, and one bulimia nervosa. These were lifetime diagnoses, and none of the relatives was unwell at the time of testing. Two of the control subjects had also a lifetime diagnosis of major depression. All participants had English as their primary language.

Exclusion criteria for all the participants were head trauma resulting in loss of consciousness, substance or alcohol dependence in the 12 months before assessment, organic brain disorder, English not the primary language, and the intelligence quotient (IQ) of less than 80. An additional exclusion criterion for relatives only was the presence of psychosis that did not meet DSM-IV criteria for schizophrenia or schizoaffective disorder. To be eligible for the study, control subjects had to be free of personal or family history of psychotic illness.

\section{Neuropsychological}

The neuropsychological battery has been described in detail previously (Toulopoulou et al 2003a, 2003b). Briefly, modality specific immediate and delayed recall was investigated with the Logical Memory and Visual Reproduction tests of the Wechsler Memory Scale (WMS; Wechsler and Stone 1945). The Associate Learning subtest of the WMS was used to access verbal learning. Current general intellectual function was assessed with the block design, object assembly, vocabulary, comprehension, and similarities, subtests of the Wechsler Adult Intelligence Scale-Revised (WAIS-R; Wechsler 1981). Executive functioning, was measured by administering tests of 1 ) spatial working memory and strategy formation, assessed with Executive Golf (Morris et al 1988; Owen et al 1990), a computerized procedure that involves searching around a set of specific locations on a computer screen and subsequently remembering not to return to successful positions; and 2) planning ability, measured with the three-dimensional, computerized Tower of London (Morris et al 1995,1988), which requires the subject to reproduce a target arrangement in a specific number of moves.

\section{MRI Data Acquisition and Analysis}

Magnetic resonance imaging data were acquired with a GE 1.5- Tesla scanner (General Electric Medical Systems, Milwaukee, Wisconsin) over a 4-year period. A set of 1.5-mm-thick, contiguous coronal MRI images extending through the entire brain were obtained with a three-dimensional spoiled gradient recall echo sequence, according to the following protocol: echo time (TE) $5 \mathrm{msec}$, repetition time (TR) 35 msec, number of excitations 1, field of view $20 \mathrm{~cm}$, acquisition matrix 256 256, and flip angle $35^{\circ}$; or a shorter one but with the same resolution: TE $3.7 \mathrm{msec}$, TR 14.7 msec, number of excitations 1 field of view $20 \mathrm{~cm}$, acquisition matrix 256256 and 
flip angle $20^{\circ}$. All subjects, irrespective of whether they were patients, relatives, or control subjects, were scanned interchangeably over the same period.

Images were analyzed with MEUSURE software (version 0.8, Johns Hopkins University, Baltimore, Maryland), an image-analysis program that uses stereologically unbiased estimation of volume (Barta et al 1997; Frangou et al 1997b). Briefly, a grid is applied over the whole brain, and grid points falling into the structure of interest are manually marked, taking into consideration all three orthogonal views. The MEASURE program calculates the volume of a structure by multiplying the number of marked grid points by the volume of an elementary cuboid. Before any measurements, head tilt was corrected by aligning each brain along the anteriorposterior commissure axis in the sagittal plane and along the interhemispheric fissure in the coronal and axial planes. All images were coded and rated blind to group affiliation.

Volumetric measurements were obtained for the whole-brain volume, prefrontal region, lateral ventricles, third ventricle, left/right (L/R) temporal lobes (this measurement included the hippocampus), L/R hippocampi, and cerebellum. The boundaries, grid settings, and reliability estimates for each structure have been described in detail previously (McDonald et al 2002; Schulze et al 2003; Sharma et al 1998). Briefly, we followed the criteria used by Delisi et al (1991) for measurement of regional brain volumes. The third ventricle was bounded by the anterior commissure, the fornix, the stria medullaris, the pineal body, the superior and inferior colliculi, the midbrain and mamillary body, the thalamus, and the hypothalamus. The hippocampus, in the coronal plane, was measured from the first slice in which the mamillary bodies were present until the first slice in which the fornix was clearly visible. The inferior boundary was the white matter of the parahippocampal gyrus and the superior boundary. The prefrontal region was defined from the frontal pole to the section rostral to the rostrum of the corpus callosum. All inter and intrarater reliability estimates were high, ranging from .86 to .99 .

The MRI and neuropsychological evaluations were done for the vast majority of the subjects on the same day. If that was not possible, the MRI and neuropsychological assessments were done within a few days or at most a few weeks of each other.

\section{Data Analysis}

The results of the volumetric analysis and the neuropsychological performance in a sample that substantially overlaps with the present one have already been published (McDonald et al 2002; Toulopoulou et al 2003a, 2003b) However, here we reran the analyses to include this particular group of research participants. Standard linear regression analyses were used with the volume of each of the structures or a neuropsychological measure as the dependent variable. The regression models 
included the predictors age, gender, and group (dummy variables for patients and relatives) to obtain estimates of differences in group means after adjusting for age and gender. Because many of the observations both within and between groups where of individuals within families and thus not independent from each other, we performed regression analyses for clustered observations, using a robust estimator for the variances of the regression coefficient estimates, as implemented in the STATA software program (version 8.0; Stata Corporation, College Station, Texas). All tests were two-tailed and used a .01 level of significance.

\section{Partial Correlations Assessing the Relationship Between Structure and Function}

All distributions of residuals were tested for deviations from normality and, when appropriate, the dependent variable was transformed according to the transformation method that was suitable in each case for achieving normalization of the residuals. The residuals of then visual reproduction, Tower of London, and Executive Golf tasks were not normally distributed and were transformed with either log or square root transformations. After the transformations, a regression analysis was used in the combined sample, with each neuropsychological score as the dependent variable and brain region, group membership, height, gender, and age as the predictors. Height was used as the independent variable to control for good size because it is good predictor of general head size (Andreasen et al 1994) and is independent of any disease-specific processes. Because age and gender can have an effect on neuropsychological performance and brain volume, age and gender were included in the model to control for the effects of these factors on the relationship between cognition and brain volumes. To examine whether there were any group differences in then relationship between brain structure and performance in neuropsychological tests, an interaction term was also included in the regression model. The regression analyses were mainly used 1 ) to examine whether there were any significant interaction effects; and 2) to obtain the partial correlations. Because it would have been inefficient to present results by group, instead of pooling across groups, when there is no evidence that the relationship differs between groups, partial correlational analyses - to obtain the partial or pooled within-group correlations - were performed in the entire sample with the coefficient from the regression analyses. In contrast a separate partial correlation for each group was estimated when an interaction effect was present that suggested a differential structure-function relationship between groups. The reason we converted the regression coefficients to partial correlations was to allow their magnitude to be interpreted more easily, because when interpreting regression coefficients, the reader must understand the units in which both the dependent and independent variables were measured.

Additional analysis examining how the partial correlations change when wholebrain volume, handedness, verbal memory, and IQ are controlled for were also 
performed on some of the observed significant partial correlations. We know, for example, that performance in specific tasks, such as memory and executive function, is related to general intellectual level and that the size of hippocampus is related to whole-brain volume. Similarly because visual stimuli can be encoded in a verbal format, performance in tests assessing visual memory can be influenced by the ability to recall verbal information. Furthermore, we know that handedness, an index of hemispheric dominance, can have an effect in the conventional left-verbal, right-visual relationships. We examined, therefore, how the partial correlations change when these factors are controlled for in those correlations between structure and function that turned out to be significant.

Inferences were based on robust standard errors for clustered data (The sandwich estimator, see eg. Williams 2000), to take into account of the clustering of individuals in families. Because the data analysis involved multiple statistical comparisons that inevitably increased the probability of falsely declaring non significant differences significant, significance is reported at the $1 \%$ level; however, as always, owing to the large number of tests, caution should be exercised when interpreting the results. All partial correlation analyses were conducted with the STATA program (version 7.0).

\section{Results}

\section{Demographic and Clinical Characteristics}

The demographic characteristics of the sample are shown in Table 1.

TABLE 1

Demographic Characteristics and General Intellectual Function Levels for Patients, Relatives, and Normal Control Subjects

\begin{tabular}{llll}
\hline & $\begin{array}{l}\text { Schizophrenic } \\
\text { Patients (a) }\end{array}$ & Relatives (b) & $\begin{array}{l}\text { Control } \\
\text { Subjects }\end{array}$ \\
\hline No. of Subjects & 56 & 90 & 55 \\
Age (y) & $32.8(7.7)$ & $50.2(15.5)$ & $38.8(14.1)$ \\
Range & $17-53$ & $18-85$ & $21-77$ \\
& $F=5.9, p=.02(\mathrm{c})$ & $F=11.5, p<.001(\mathrm{c})$ & \\
Sex (\% Female) & 30.3 & 62.2 & 50.9 \\
Education (y) & $13.0(2.6)$ & $13.5(2.8)$ & $13.8(3.5)$ \\
& $F=.80, p=.16(\mathrm{c})$ & $F=.32, p=.54(\mathrm{c})$ & $109.4(15.0)$ \\
Full IQ & $94.3(17.4)$ & $107.6(19.2)$ & \\
& $t=4.7, p<.001(\mathrm{~d})$ & $t=.52, p=.60(\mathrm{~d})$ & \\
\hline
\end{tabular}

Data are presented as mean (SD).

(a) $F$ or $t$ and $p$ values for patients vs. control subjects; (b) $F$ or $t$ and $p$ values for relatives vs. control subjects; (c)Based on analysis of variance; (d)Based on regression analyses with robust standard errors for clustered data 


\section{Brain Volumetric Measures and Neuropsychological Performance in Patients and Relatives Compared with Control Subjects}

As anticipated, overall results were similar to those we reported previously, based on a sample that substantially overlaps with the present one. In terms of the MRI, patients displayed enlargement of third ventricle $(B=.20,95 \%$ confidence interval $[\mathrm{Cl}]=.04, .37, p=.01)$ showed nonsignificant trends for reductions in the left temporal lobes $(B=-3.7,95 \% C l=-7.65, .25, p=.06)$ and left hippocampi $(B=-0.9,95 \%$ $\mathrm{Cl}=-.20, .01, p=.08)$. Regarding neuropsychological performance, patience performed worse control subjects on all measures considered, including estimated full IQ $(\mathrm{B}=-16.0,95 \% \mathrm{Cl}=-22.48,-9.62, p<.0001)$, verbal $\mathrm{IQ}(\mathrm{B}=-15.8,95 \% \mathrm{Cl}=-21.8,-$ $9.75, p<.0001)$, performance IQ ( $\mathrm{B}=-13.4,95 \% \mathrm{Cl}=-20.7,-6.172, p<.0001)$, immediate and delayed recall of verbal memory (immediate recall: $\mathrm{B}=-4.5,95 \% \mathrm{Cl}=-$ $5.99,-3.10, p<.0001$; delayed recall: $\mathrm{B}=-4.5,95 \% \mathrm{Cl}=-5.98,-2.98, p<.0001)$, immediate and delayed recall of visual memory (immediate recall: $\mathrm{B}=-3.03,95 \% \mathrm{Cl}$ $4.35,-1.7, p<.0001$; delayed recall: $\mathrm{B}=-3.3,95 \% \mathrm{Cl}=-4.7,-1.94, p<.0001)$, associate learning $(\mathrm{B}=-3.90,95 \% \mathrm{Cl}=-5.38,-2.43, p<.0001)$, planning $(\mathrm{B}=-.65,95 \% \mathrm{Cl}=$ $.25,1.05, p=.002)$, spatial working memory $(\mathrm{B}=2.5,95 \% \mathrm{Cl}=1.4,3.6, p<.0001)$, and strategy $(\mathrm{B}=1.7,95 \% \mathrm{Cl}=.97,2.3, p<.0001)$. Relatives performed significantly worse on immediate recall of verbal memory $(\mathrm{B}=-1.7,95 \% \mathrm{Cl}=-3.01,-.4, p=.01)$ and showed a non significant trend for delayed recall of verbal memory $(B=-1.3$, $95 \% \mathrm{Cl}=-2.70, .05, p=.06)$ and strategy formation $(\mathrm{B}=.7,95 \% \mathrm{Cl}=.04,1.4, p=.04)$.

\section{Relationship Between Regional and WhOole-Brain Volume and Neuropsychological Measures}

The partial correlations and $p$ values (adjusted for group membership, age, gender, and height) between neuropsychological domains and brain volumes for the combined sample are given in the Table 2(only the significant correlations are shown). If the relationship between brain volume and neuropsychological measure differed significantly between the three groups, the partial correlations and $p$ values for those groups in which these correlations were significant are shown in Table 3. 


\section{TABLE 2}

Age, Gender-, Group Membership-, and Height-Adjusted Partial Correlations with Robust Standard Errors and $p$ Values Between MRI and Neuropsychological Measures in the Combined Sample.

\begin{tabular}{|c|c|c|c|c|c|c|c|c|c|c|c|}
\hline & FIQ & VIQ & PIQ & LMi & LMd & VRi & VRd & $\mathbf{A L}$ & TLacc & EGe & EGs \\
\hline Whole-Brain Volume & $.28, .005$ & $.28, .004$ & & & & & & & & & \\
\hline \multicolumn{12}{|l|}{ Prefrontal Cortex } \\
\hline Right Temporal Lobe & & & & & & & & & & $-26, .009$ & \\
\hline \multicolumn{12}{|l|}{ Left Temporal Lobe } \\
\hline Right Hippocampus & $.31,001$ & $.26, .008$ & $.28, .005$ & & & & & & & $\mathrm{a}$ & \\
\hline Left Hippocampus & a & $.26, .008$ & a & & $-27, .006$ & a & a & & & & \\
\hline Lateral Ventricles & & & & & & & & & & a & \\
\hline \multicolumn{12}{|l|}{ Third Ventricle } \\
\hline Cerebellum & & & & & $.25, .01$ & a & a & & & & \\
\hline
\end{tabular}

Values are partial correlations $(r), p$ values, MRI, magnetic resonance imaging, FIQ, VIQ, PIQ, estimated full-scale intelligence quotient $(I Q)$, verbal $I Q$, and performance $I Q$, respectively; $L M i$, logical memory, immediate recall; LMd, logical memory, delayed recall, VRi, visual reproduction, immediate recall, VRd, visual reproduction, delayed recall, Al, associate learning, TLacc, Tower of London, accuracy (number of moves); EGe, Executive Golf, between-search errors; EGs, Executive Golf, strategy. a : The relationship between brain volume and neuropsychological measure differs significantly between the three groups. See Table 3 for partial correlations and $p$ values per group.

\section{TABLE 3}

Age-, Gender-, and Height-Adjusted Partial Correlations with Robust Standard Errors and $p$ Values Between MRI and Neuropsychological Measures per Group when the relationship Between Brain Volume and Neuropsychological Measure Differs Significantly Between the Three Groups.

\begin{tabular}{llllll}
\hline & FIQ & PIQ & VRi & VRd & EGe \\
\hline Left Hippocampus & $.36<.001 \mathrm{REL}$ & $.37,<.001 \mathrm{n} \mathrm{REL}$ & $.25, .009$ & REL & $.35,<.001 \mathrm{REL}$ \\
& $.35, .001 \mathrm{CON}$ & & & & $-.22, .02 \mathrm{REL}$ \\
Right Hippocampus & & & & & $.26, .008 \mathrm{SCH}$ \\
& & & & & \\
Lateral Ventricles & & & $.25, .01 \mathrm{REL}$ & $32, .001 \mathrm{REL}$ & \\
Cerebellum & & & & & \\
\hline
\end{tabular}

Values are partial correlations $(r), p$ values, MRI, magnetic resonance imaging; FIG, PIQ, estimated fullscale intelligence quotient (IQ) and performance IQ, respectively; VRi, visual reproduction, immediate recall; VRd, visual reproduction, delayed recall, EGe, Executive Golf, between-search errors, REL, relatives; $\mathrm{SCH}$, schizophrenic patients; $\mathrm{CON}$, control subjects.

\section{Correlation with IQ}

In the total sample, estimated full-scale IQ and verbal IQ correclated with wholebrain volume (full-scale IQ $r=.28, p=.005$; verbal IQ $r=.28, p=.004$ ) and right hippocampal volume (full-scale IQ $r=.31, p=.001$; verbal IQ $r=.26, p=.008$ ). The latter was also associated with performance IQ $(r=.28, p=.005)$. Further analyses of the specific measures of IQ contributing to the correlation with the right hippocampus showed that three of the five measures used to estimate current IQ were correlated 
with the right hippocampus (block design: $r=.25, p=.01$; object assembly: $r=.26, p$ $=.007$; comprehension: $r=.29, p=.003$; similarities: $r=.23, p=.02$; vocabulary: $=$ $.22, p=.02)$.

Left hippocampal size was associated with verbal IQ $(r=.26, p=.008)$ and, in control subjects and relatives only, with the estimated full-scale IQ (control subjects: $r=.35$, $p<.001$; relatives: $r=.36, p<.001$ ). All measures used to calculate verbal IQ contributed to the association between verbal IQ and left hippocampal volume (similarities: $r=29, p=.003$; comprehension: $r=.28, p=.004$; vocabulary: $r=.26, p=$ .009). The nonpsychotic relatives also showed an association between left hippocampal volume and performance IQ $(r=.37, p<.001)$, with both WAIS-R subtests, which contributed to the performance IQ, showing a correlation with the left hippocampus (block design: $r=.45, p<.0001$; objects assembly: $r=.29, p=.004$ ).

\section{Correlations with Verbal and Visual Memory}

Delayed recall of verbal memory was linked to the cerebellum $(r=25, p=.01)$ and inversely to the left hippocampus $(r=-.27, p=.006)$. Further analyses suggested that the latter correlation might be due to the effect of patients only (patients: $r=-$ $.22, p=.02$; relatives: $r=-.14, p-.17$; control subjects: $r=-.15, p=.14$ ). Immediate and delayed recall of visual memory was associated in relatives only with left hippocampal volume (immediate recall: $r=.25, p=.009$; delayed recall $: r=.35, p<.001$ ) and the cerebellum (immediate recall: $r=.25, p=.01$; delayed recall; $r=.32, p=$ .001). The latter correlation was due to the effect of verbal memory and IQ (correcting for verbal memory score in immediate recall: $r=.11, p=.29$; delayed recall: $r=$ $.21, p=.03$; correcting for IQ in immediate recall: $r=.17, p=.10$; delayed recall: $r=$ $0.24, p=.02$ ). The correlation between visual memory and left hippocampus survived corrections for differences in handedness (immediate recall: $r=.25, p=.009$; delayed recall: $r=.35, p<.0001$ ) and whole-brain volume (immediate recall: $r=.26$, $p=.27$; delayed recall: $r=.35, p<.0001$ ) but became non significant when IQ was used as a covariate in the analyses (immediate recall: $r=.11, p=.28$; delayed recall: $r$ $=.17, p<.09)$.

\section{Correlations with the Executive Measures}

The right temporal lobe volume was correlated with spatial working memory ( $r=$ $.26, p=.009$ ), as indexed by the number of errors; this suggests that the smaller the right temporal lobes, the more errors were made. The correlation, however, lost its strength after covarying for use of a self-generated search strategy that earlier reports suggested might affect performance on this sort of task by substantially reduc- 
ing the load on memory systems, making the task substantially easier to perform ( $r=$ $-.22, p=.03)$.

Between-search errors were also associated in patients only with the size of the lateral ventricles $(r=.26, p=.008)$, indicating that the poorer the performance, the larger the lateral ventricles. No other correlations between the executive measures and volume of brain structures were found.

\section{Discussion}

\section{Structure-Function Relationships Observed in the Combined Sample}

Our results support previous studies in showing a relationship between brain volume and intelligence in healthy individuals (Andersen et al 1993; Posthuma et al 2002; Tan et al 1999; Wickett et al 2000) and extend the finding to schizophrenic patients and their healthy relatives. We found a small but significant relationship between estimated full-scale and verbal IQ with whole volume, suggesting as noted previously (Andreasen et al 1993), that although brain size is not everything, it does nonetheless explain some of the variance in IQ. Our study shows that this is true not only for healthy individuals but also for people who suffer from schizophrenia.

We also found, as did Andreasen et al (1993), a relationship between IQ and the hippocampus. All measures of $I Q$, including estimated full-scale, performance, and verbal IQ, correlated with the right hippocampal volume. In addition, verbal IQ was also associated with the left hippocampal volume. Most of the subtests that we selected to derive the IQ scores correlated with hippocampal volume, hence confirming its involvement in several congnitive processes. Consistent with this, Bedwell et al (1999) found an association between decreases in hippocampal volumes and a smaller increment in the information raw score of the WAIS among adolescents with childhood-onset schizophrenia; this could reflect an inability o acquire new knowledge.

In addition, we found an association between delayed recall of verbal memory and the volume of the cerebellum, adding to reports that the cerebellum acts as a modulator of cognitive function (Allin et at 2001; Cabeza et al 2002; Desmond 2001; Justus and Ivry 2001). It has been implicated in the pathophysiology of several psychiatric disorders, including schizophrenia (Andreasen et al 1998; Rapoport 2001), though MRI data are inconsistent. We did not find cerebellar volume changes in our patients (McDonald et al 2002), nor did we find a differential relationship between cerebellum and memory in the schizophrenia sample relative to the other two groups. 
Consistent with reports on neurosurgical patients with either frontal lobe or temporal lobe excisions or patients who had undergone amygdalo-hippocampectomy (Owen et al 1996), we found an association between the number of errors made in the spatial working memory task and the size of the right temporal lobes, with smaller temporal volumes predicting more errors. The Executive Golf task involves searching through a set of specific locations and remembering not to return to successful positions. Thus, it provides a measure of on-line processing of spatial information and explores the extent to which implementation of strategic algorithms facilitates task performance. To explore the extent to which strategy impairment might have contributed to the correlation between spatial working memory and temporal lobes, we repeated the analyses with the strategy scores as the convariate in the analyses. The results suggested a loss of strength and of statistical significance in the correlation, consistent with previous reports that other regions might be more important in mediating strategy generation.

\section{Differential Structure-Function Relationships in Patients with Schizophrenia}

Although the relationship between structure and function is similar in many measures for patients and control subjects, there are instances in which patients with schizophrenia seem to differ from the norm. Consistently, we found correlations between left hippocampal volume and estimated full-scale IQ and performance IQ in relatives and control subjects (control subjects showed a trend with the performance IQ) but not in the patient group. This suggests a dissociation in schizophrenia between left hippocampus and the subtests that were used to estimate IQ.

Delayed recall of verbal memory was also correlated, but inversely, to left hippocampus in the whole sample. Further analyses suggested that this did not reach the statistical significance set for this study. It is possible that the effect , might be due to an early dynamic interplay between obstetric complication, hippocampal volume, and memory function. For example, we have previously, reported (Schulze et al 2003) hippocampal volume reductions in a sample overlapping with this patient group that was linked to obstetric complications. It is possible that, owing to the plasticity of the developing brain, these reductions have had a knock-on effect on the organization and allocation of brain function. In general, findings of relationship between hippocampal volume and memory in schizophrenia are inconsistent, with most studies failing to show a positive relationship (Weiss and Heckers 2001); some of those that do find such a relationship use more refined measures that discriminate between anterior and posterior hippocampus (Goldberg et al 1994; O'Driscoll et al 2001). It is possible, therefore, that if we had separated anterior and posterior hippocampus, we might have found a different pattern of relationships.

Between-search errors also correlated in the patient group only with lateral ventricular size. Loss of a normal structure-function relationship, as seems to be the 
case in at least this sample of schizophrenia patients, might indicate compensatory mechanisms whereby certain areas are recruited to subserve functions normally associated with a specific brain region. This could have occurred, as indicated above, as a result of an early brain insult and would be compatible with a wide range of evidence suggesting a neurodevelopmental component in the etiology of schizophrenia (Murray and Lewis 1987; Weinberger 1987). Nonetheless, age-related reallocation or shift of certain aspects of cognitive function to different brain networks, suggesting a dynamic nature of functional change that can occur at any point throughout life, is also possible (Hazlett et al 1998). Therefore, we cannot determinate with certainty, on the basis of the results of this study, when the loss of the relationship has occurred. Because the dissociation does not extend to relatives, we must presume that the changed pattern is related to the pathophysiology of schizophrenia per se.

\section{Differential Structure-Function Relationships in the Relatives of Patients with Schizophrenia}

Our results also suggest an association for the relatives only between visual memory, (immediate and delayed recall) and left hippocampus and cerebellum. These correlations are nullified when intelligence and, in the case of cerebellum, intelligence and verbal memory are considered as covariates in the analyses. These results are consistent with the hypothesis that the relatives use different pathways to process visual information, perhaps reflecting a variation in encoding strategy. Such encoding strategy might involve the processing of visual information more verbally relative to the other two groups. This hypothesis could explain why the association between visual memory and cerebellum is cancelled when verbal memory is used as a convariate in the analyses.

In summary, we examined the pattern of correlations between structure and function in a group of schizophrenia patients, in nonpsychotic relatives, an in control subjects and found a number of similar patterns across the three groups; however, discrepancies in the relationship pattern emerged in patients with schizophrenia between left hippocampus and measures of IQ and verbal memory. The latter discrepancies are consistent with the hypothesis of dissociation in pathologic processes underlying structural and cognitive abnormalities for at least these measures.

Financial support was given by the Stanley Medical Research Institute.

\section{References}

Allen DN, Goldstein G, Weiner C (2001): Differential neuropsychological patterns of frontal- and temporal-lobe dysfunction in patients with schizophrenia. Schizophr Res 48:7-15 
Allin M, Matsumoto H,Santhouse AM, Nosarti C, Alasady MHS, Steward AL, et al (2001): Cognitive and motor function and the size of the cerebellum in adolescents born very pre-term. Brain 124:60-66

American Psychiatric Association (1994): Diagnostic and Statistical Manual of Mental Disorders, $4^{\text {th }}$ ed. Washington, DC: American Psychiatric Association

Andreason NC, FLashman L, Flaum M, Arndt S, SwayzeV, Oleary DS, et al (1994): Regional brain abnormalities in schizophrenia measured with magnetic-resonance-imaging. JAMA 272:1763-1769.

Andreason NC, Flaum M, Swayze V, Oleary DS Alliger R, Cohen G, et al (1993): Intelligence and brain structure in normal individuals. Am J Psychiatry 150:130-134.

Andreason NC, Paradiso S, O'Leary DS (1998): "Cognitive dysmetria" as an integrative theory of schizophrenia: A dysfunction in cortical subcortical-cerebellar circuitry? Schizophr Bull 24:203-218.

Baare WFC, van Oel CJ, Pol HEH, Schnack HG, Durston S, Sitskoorn MM, et al (2001): Volumes of brain structures in twins discordant for schizophrenia. Arch Gen Psychiatry 58:33-40.

Barta PE, Powers RE: Aylward EH, Chase GA, Harris GJ, Rabins PV, et al (1997): Quantitative MRI volume changes in late onset schizophrenia and Alzhaimer's disease compared to normal controls. Psychiatry Res 68:65-75.

Bedwell JS, Keller B, Smith AK, Hamburger S, Kumra S, Rapoport JL (1999): Why does postpsychotic IQ decline in childhood-onset schizophrenia? Am J Psychiatry 156:1996-1997.

Bilder RM, Borgets B, Ashtari M, Wu HW, Alvir JM, Jody D, et al (1995): Anterior hippocampal volume reductions predict frontal-lobe dysfunction in first episode schizophrenia. Schiophr Res 17:47-58.

Cabeza R, Dolcos F, Graham R, Nyberg L (2002): Similarities and differences in the neural correlations of episodic memory retrieval and working memory. Neuroimage 16:317-330.

Canon TD, Huttunen MO, Lonnqvist J, Tuulio-Henriksson A, Pirkola Y, Glahn D, et al (2000)L The inheritance of neuropsychological dysfunction in twins discordant for schizophrenia. Am J Hum Genet 67:369-382.

Davidson LL, Heinrichs RM (2003): Quantification of frontal and temporal lobe brain-imaging findings in schizophrenia: A meta-analysis. Psychiatry Res 122:69-87.

Delisi LE, Hoff Al, Schwartz JE, Shields GW, Halthore SN, Gupta SM, et al (1991) Brain morphology in $1^{\text {st }}$ episode schizophrenic-like psychotic patients-a quantitative magnetic-resonance-imaging study. Biol Psychiatry 29:159-175.

Desmond JE (2001): Cerebellar involvement on cognitive function: Evidence from neuroimaging. Int Rev Psychiatry 13:283-294.

Frangou S, Sharma T, Alarcon G, Sigmudsson T, Takeri N, Binnie C, et al (1997): The Maudsley family study. 2. Endogenous event-related potentials in familial schizophrenia Schizophr Res 23:45-53.

Frangou S, Sharma T, Sigmudsson T, Barta P, Pearlson G, Murray RM (1997): The Maudsley family Study. 4. Normal planum temporale asymmetry in familiar schizophrenia - a volumetric MRI study Br J Psychiatry 170:328-333.

Goldberg TE, Torrey Ef, Berman KF, Weinberger Dr (1994): Relations between neuropsychological performance and brain morphological and physiological measures in monozygotic twins discordant for schizophrenia. Psychiatry Res 55:51-61.

Griffiths TD, Sigmundsson T, Takei N, Frangou S, Birkett PB, Sharma T, et al (1998): Minor physical anomalies in familial and sporadic schizophrenia : The Maudsley family study. Journal of Neurology Neurosurgery and Psychiatry 64:56-60.

Halzett EA, Buchsbaum MS, Mohs RC, Spiegel-Cohen J, Wei TC, Azueta R, et al (1998): Age-related shift in brain region activity during successful memory performance. Neurobiol Aging 19:437-445.

Heinrichs RW, Zakzanis KK (1998): Neurocognitive deficit in schizophrenia: A quantitative review of the evidence. Neuropsychological 12:426-445.

Justus TC, Ivry RB (2001): The cognitive neuropsychological of the cerebellum. Int Rev Psychiatry 13:276282.

Lawrie SM, Whalley H, Kestelman JN, Abukmeil SS, Byrne M, Hodges A, et al (1999): Magnetic resonance imaging of brain in people at high risk of developing schizophrenia. Lancet 353:30-33. 
McDonald C, Grech A, Toulopoulou T, Schulze L, Chapple B, Sham P, et al (2002): Brain volumes in familial and non-familial schizophrenic probands and their unaffected relatives. Am J Med Genet 114:616625.

Morris RG, Downes JJ, Sahakian BJ, Evenden JL, Heald A, Robbins TW (1998): Planning and spatial working memory in Parkinson's disease. J Neurol Neurosurg Psychiatry 51:757-766.

Morris RG, Rushe T, Woodruffe PWR, Murray RM (1995): Problem-solving in schizophrenia: A specific deficit in planning ability. Schizophr Res 14:235-246.

Murray RM, Lewis Sw (1987): Is schizophrenia a neurodevelopment disorder? Br Med J 295:681-682.

O'Driscoll GA, Florencio PS, Gagnon D, Wolf AV, Benkelfat C, Mikula L, et al (2001): Amygdalahippocampal volume and verbal memory in first-degree relatives of schizophrenia patients. Psychiatry Res 107:75-85.

Owen AM, Downes JJ, Sahakian BJ, Polkey CE, Robbins TW (1990): Planning and spatial working memory following frontal-lobe lesions in man. Neuropsychologia 28:1021-1034.

Owen AM, Morris RG, Sahakian BJ, Polkey CE, Robbins TW (1996): Double dissociations of memory and executive functions in working memory tasks following frontal lobe excisions, temporal lobe excisions or amygdalo-hippocampectomy in man. Brain 119:1597-1615.

Posthuma D, De Gues EJC, Baare WFC, Pol HEH, Kahn RS, Boomsma Di (2002): The association between brain volume and intelligence is of genetic origin. Nat Neurosci 5:83-84.

Rapoport M (2001): The cerebellum in psychiatric disorders. Int Rev Psychiatry 13:295-301.

Sanfilipo M, Lafargue T, Rusinek H, Arena L, Loneragan C, Lautin A, et al (2002): Cognitive performance in schizophrenia: Relationship to regional brain volumes and psychiatric symptoms. Psychiatry Res 116:1-23.

Schulze K, Mc Donald C, Frangou S, Sham P, Grech A, Toulopoulou T, et al (2003): Hippocampal volume familial and nonfamilial schizophrenic probands and their unaffected relatives. Biol Psychiatry 53:562-570.

Seidman LJ, Faraone SV, Goldstein JM, Kremen WS, Horton NJ, Makris N, et al (2002): Left hippocampal volume as a vulnerability indicator for schizophrenia: A magnetic resonance imaging morphometric study of non-psychotic first-degree relatives. Arch Gen Psychiatry 59:839-849.

Sharma T, Lancaster E, Lee D, Lewis S, Sigmudsson T, Takei N, et al (1998): Brain changes in schizophrenia. Volumetric MRI study of families multiply affected with schizophrenia - The Maudsley Family Study 5. Br J Psychiatric 173:132-138.

Staal WG, Hijman R, Pol HEH, Kahn RS (2000) Neuropsychological dysfunctions in siblings discordant for schizophrenia. Psychiatry Res 95: 227-235.

Staal WG,. Pol HEH, Schnack HG, Hoogendoorm MLC, Jellema K, Kahan RS (2000): Structural brain abnormalities in patients with schizophrenia and their healthy siblings. Am J Psychiatry 157:416-421.

Tan U, Tan M, Polat P, Ceylan Y, Suma S, Okur A (1999): Magnetic resonance imaging brain size/ IQ relations in Turkish university students. Intelligence 27:83-92.

Toulopoulou T, Morris RG, Rabe-Hesketh S, Murray RM (2003a): Selectivity of verbal memory deficit in schizophrenic patients and their relatives. Am J Med Genet 116B:1-7.

Toulopoulou T, Rabe-Hesketh S, King H, Murray RM, Morris RG (2003b): Episodic memory in schizophrenic patients and their relatives. Schizophr Res 63:261-271.

Wechsler D (1981): Wechsler Adult Intelligence Scale-Revised Manual. New York: Psychological Corporation.

Wechsler D, Stone CP (1945): Manual for the Wechsler Memory Scale. New York: Psychological Corporation.

Weinberger DR (1987): Implications of normal brain-development for the pathogenesis of schizophrenia. Arch Gen Psychiatry 44:660-669.

Weiss AP, Heckers S (2001): Neuroimaging of declarative memory in schizophrenia. Scand J Psychol: 42:339-250.

Wickett JC, Vernon PA, Lee DH (2000): Relationships between factors of intelligence and brain volume. Pers Individual Differences 29:1095-1122. 
Williams RL (2000): A note on robust variance estimation for cluster-correlated data. Biometrics 56:645646.

Wright IC, Rabe-Hesketh S, Woodruff PWR, David AS, Murray RM, Bullmore ET (2000): Meta-analysis of regional brain volumes in schizophrenia. Am J.Psychiatry 157:16-25. 

Chapter 5

\section{Maternal Exposure to Influenza and Paranoid Schizophrenia}

Grech, A., Takei, N., \& Murray, R. M. (1997). Maternal exposure to influenza and paranoid schizophrenia. Schizophrenia Research, 26(2-3), 121-125 


\begin{abstract}
Previous research has suggested that schizophrenics exposed to influenza in the second trimester have more delusions of jealousy, delusions of reference and suspiciousness. We therefore hypothesized that the risk-increasing effect of in utero exposure to influenza would be particularly demonstrable in paranoid schizophrenia. We studied patients with an ICD diagnosis of schizophrenia in England and Wales who were born each month between 1923 and 1965 ( $N=17$ 247). Chi-square test for trend showed that an increase in influenza exposure level during the fifth month of gestation was accompanied by an increase in the proportion of patients with paranoid schizophrenia. However, logistic regression analysis including sex, seasonality and birth period in the model resulted in the loss of any significant association between in utero exposure to influenza and the development of paranoid schizophrenia, the loss of this significance being maily accounted for by birth period. Therefore, the association between the utero exposure to influenza and subsequent development of paranoid schizophrenia we hypothesized was not supported by our data.
\end{abstract}

Keywords: Schizophernia; Influenza,; Prenatal exposure; Paranoid schizophrenia 


\section{Introduction}

A majority of epidemiological studies from different countries in both hemispheres have reported a relationship between maternal exposure to influenza during gestation and the development of schizophrenia in the offspring. Ten studies have shown a positive association between prenatal exposure to influenza and schizophrenia, three have produced equivocal results, while three found no such association (reviewed by Wright et al., in press).Two recent studies have further shown that this relationship is stronger in more strictly defined schizophrenia. In a Danish study (Takei et al., 1996), the association was more conspicuous in those with narrowly defined schizophrenia, while national data from the Netherlands (Takei et al., 1995b) also demonstrated a more marked association with typical schizophrenia.

However, the latter two studies used a crude distinction between 'typical' and 'atypical' schizophrenics and did not examine further whether any specific subtype of schizophrenia was responsible for this association. The effect of prenatal exposure to influenza in the development of schizophrenia appears more readily detectable in females (Takei et al., 1993, 1994, 1995a). Furthermore, Machon et al. (1995) claimed that schizophrenics who were exposed to influenza in the second trimester have significantly more symptoms of delusions of jealousy, delusions of reference and suspiciousness, than do schizophrenics exposed to influenza in the first or third trimester. Taken with the evidence that female schizophrenics more frequently manifest a paranoid picture than males (Goldstein et al., 1990), these findings suggest that paranoid schizophrenia may be the subtype responsible for the association previously found between prenatal exposure to influenza and narrowly defined schizophrenia. Therefore, we decided to test the hypothesis that the risk increasing effect of in utero exposure to influenza is associated particularly with the paranoid schizophrenia subtype.

\section{Methods}

We obtained, from 12 Regional Health Authorities, information on individuals who were born in England and Wales between 1923 and 1965 and had a first admission to psychiatric hospital and subsequent discharge between 1976 and 1986 with an ICD-8 or ICD-9 (World Health Organisation, 1978) diagnosis of schizophrenia. The following authorities provided data for the following years: North West Thames (1976-1984), South East Thames (1976-1986), Oxford (1979-1986), South West (1982-1987), North West (1976-1986), Mersey (1976-1981), Trent (1979-1986), Yorkshire (1976, 1978, 1980-1984), North (1976-1985), West Midlands (19761982), East Anglia (1976-1981) and Wales (1976-1986). 
Data on the number of deaths from influenza per month was obtained from the Registrar General's Statistical Review of England and Wales from 1923 to 1965. Our own previous studies have used these data from 1938 onwards (Takei et al., 1993, 1994; Sham et al., 1992), but since we have recently obtained the data back to 1923 we have included the years 1923-1937 in the present study.

For this study, the year was defined to start in October and end in September of the following year, because the prevalence of influenza increases gradually in autumn, reaching a peak during the earlier months of the year and then decreases again through the spring and summer. The number of deaths attributed to influenza was used as a proxy measure of the prevalence of influenza, as these data were available and assumed to reflect the varying occurrence of influenza epidemics. The vulnerable risk period with regard to the exposure to influenza was defined as the fifth month prior to birth, according to previous studies which have shown that the risk of schizophrenia associated with prenatal exposure to influenza is particularly pronounced during the fifth month of gestation (i.e. midgestation) (Takei et al. , 1993, 1994, 1995a).

The number of deaths attributed to influenza for each month between October 1923 and September 1965 (504 months) were identified. Schizophrenic patients born 5 months after these influenza exposure months were therefore those born between March 1924 and February 1966. A total of 17,247 schizophrenic patients were born during this period. These patients were subdivided by diagnostic subtypes into two groups. One group consisted of all patients who had an ICD-8 or ICD9 diagnosis of paranoid schizophrenia $(n=2897)$. The second group included all the schizophrenics with a diagnosis of one of the other subtypes of schizophrenia or who had been diagnosed as schizophrenic without reference to a diagnostic subtype (non-paranoid schizophrenics; $n=14$ 350). The 504 influenza exposure months were divided into quartiles according to frequency distribution of the monthly number of deaths attributed to influenza. These quartiles were designated as: very low, low, high and very high exposure level.

Our prediction was that the proportion of paranoid schizophrenics would increase with an increase in the level of influenza exposure. If crude analysis showed that our prediction of an increase in paranoid schizophrenia was correct, then we wished to explore further whether this effect is influenced by gender. The possible effect-modification of sex arises because subtypes of schizophrenia have gender differences and, as mentioned above, the effect of influenza is more marked in females. Most influenza epidemics occur in autumn and winter, and schizophrenic births are more common in winter and spring (Torrey et al., 1997), raising the possibility that any effect of influenza noted could be confounded by a seasonal effect.

We considered only those patients who were discharged from hospital between 1976 and 1986, following their first psychiatric admission. To be included in the sample, a patient had to have his/her first admission to psychiatric hospital within a 
particular 11-year period of his/her life. For example, patients born in January 1960 were included in the sample only if their first psychiatric admission was between the ages of 16 and 26 years, and patients born in January 1940 were included in the sample only if their psychiatric admission was between the ages of 36 and 46 years. As these examples show, those born during the early years under study were included in the sample only if their first psychiatric admission was at an older age than those born during the later years. The onset of paranoid schizophrenia tends to be at an older age than in the other schizophrenia subtypes. It is thus possible that those born in the earlier part of study had a greater chance of being included in the sample if his/her schizophrenia was of the paranoid subtype rather than of another subtype. If the prevalence of influenza, as measured by the number of deaths from that infection, were higher during the earlier years of the study, an association between exposure to influenza and paranoid schizophrenia could arise from the birth period effect as a confounding factor, rather than from a genuine association between them.

Statistical analysis was performed using SPSS (Statistical Package for Social Sciences) for Windows V.6 All $p$ values presented are two-tailed.

\section{Results}

First we identified the proportion of paranoid schizophrenics in each quartile of the exposure level. This showed an increase in the proportion of paranoid schizophrenics with an increase in influenza exposure level: $13.5 \%$ for very low, $16.7 \%$ for low, $19.5 \%$ for high, and $19.0 \%$ for very high influenza exposure (see Table 1 ). Using the very low influenza exposure level as reference, the odds ratio (OR) of paranoid to non-paranoid schizophrenics associated with influenza exposure was then calculated for the other exposure levels. An increase in exposure level was accompanied by an increase in OR: OR was 1.28 for low influenza exposure, 1.55 for high influenza exposure and 1.50 for very high influenza exposure. Chi-square test for trend showed that this increase is statistically significant $\left(x^{2}=41.84\right.$, d.f. $\left.=1, p<0.00001\right)$ (Table 1); an increase in one exposure level corresponds to an increase of $15 \%$ for paranoid schizophrenia $(O R=1.15)$. 
TABLE 1

Distribution of paranoid-type schizophrenia in relation to prenatal exposure to influenza

\begin{tabular}{llllll}
\hline & \multicolumn{4}{l}{ Distribution according to influenza exposure level } & \\
& Very low & Low & High & Very high & Test for trend \\
\hline Paranoid & 723 & 739 & 705 & 730 & \\
schizophrenics (\%)a & $(13.5)$ & $(16.7)$ & $(19.5)$ & $(19.0)$ & \\
Non-paranoid & 4267 & 3695 & 2914 & 3113 & \\
schizophrenics (\%)a & $(86.5)$ & $(83.3)$ & $(80.5)$ & $(81.1)$ & \\
Odds ratio & $1 \mathrm{~b}$ & 1.28 & 1.55 & 1.50 & $\mathrm{p}<0.00001$ \\
\hline
\end{tabular}

a Column per cent.

b Reference.

We then performed further analysis using logistic regression to examine any effect modification by sex and season-of-birth after adjusting for birth period (as a potential confounding factor). The year was dichotomised (December-May, JuneNovember), and birth periods were divided into four categories: October 1923September 1933, October 1933-September 1944, October 1944-September 1955 and October 1955-September 1965. These factors, together with sex, were then included in the logistic regression in which paranoid versus non-paranoid schizophrenia was a dependent variable and influenza exposure with four levels was the independent variable.

Results of the logistic regression showed that when these factors (sex, seasonof-birth and birth period) were entered into the model, the statistically significant association found in the initial analysis between paranoid schizophrenia and level of exposure to influenza disappeared ( $O R=0.96$, likelihood ratio statistic $(L R S)=3.21$, d.f. $=1, p=0.07$ ). There was no evidence of an increase in the proportion of paranoid versus non-paranoid schizophrenics with an increase in influenza exposure level; the adjusted OR against the reference exposure level was 0.95 for low, 0.92 for high and 0.87 for the very high influenza exposure category. The disappearance of the significant association was found to be due exclusively to inclusion of the factor of birth period; the initial finding of an unadjusted OR of 1.15 for every one level increase in exposure category dropped to 0.95 when a factor of birth period was included, whereas it remained almost unchanged when factors of sex (1.15) and season-of-birth (1.19) were entered in to the model. This indicates that a factor of birth period was indeed a strong confounder for the association between exposure to influenza and paranoid schizophrenia.

Further analysis to assess the possible modifying effect of sex and season-ofbirth were carried out by including interactions of the influenza exposure variable and these two variables in the model. Neither interaction between sex and exposure to influenza (LRS $=0.95$, d.f. $=1, p=0.33$ ), nor interaction between season-ofbirth and influenza exposure (LRS $=0.95$, d.f. $=1, p<0.33$ ) was found to be signifi- 
cant. Additionally, no significant second-order interaction between sex, season-ofbirth and exposure to influenza (LRS $=0.021$, d.f. $=1, p=0.88$ ) was evident.

Since the non-paranoid schizophrenia group was likely to include those patients who were not assigned any schizophrenia subtype, it is probable that a number of these unclassified or unspecified schizophrenics were in fact of the paranoid subtype and their misclassification as non-paranoid would result in bias towards the null hypothesis. We therefore performed further analysis after removing the schizophrenics without a diagnostic subtype from the non-paranoid schizophrenics group. This decreased the sample by $59.65 \%$, to $n=6960$. However, the results with this confined sample were virtually the same as those obtained when the whole sample was used. Again, there was no evidence supporting the association of exposure to influenza with an increased proportion of paranoid schizophrenics when birth period was adequately controlled for; the unadjusted OR of 1.12 (LRS $=29.02$, d.f. $=1, p<0.001$ ) was reduced to 0.96 (95\% confidence limit; $0.91-1.01$ ).

\section{Discussion}

\subsection{Limitations}

The data used do not cover the whole of England and Wales, but around $80 \%$ of the population. In addition, some of the regional health authorities provided data for only some of the years between 1976 and 1986. However, it is highly unlikely that this caused any systematic bias in favour or against our hypothesis.

According to previous studies, especially our own studies (Takei et al., 1993, 1994, 1995a), the risk period of exposure to influenza was defined as the fifth month prior to birth. Assuming that all births had a full-term pregnancy, this month corresponds to the fifth month of gestation. However, this assumption is not true for all pregnancies, and misclassification of the exposure may have taken place in some unknown proportion of patients who were born either prematurely or postmaturely. This random misclassification may have biased our results towards the null hypothesis.

We used the number deaths attributed to influenza as a measure of the degree of exposure. This is an indirect measure and does not reflect precisely the likelihood with which mothers of schizophrenics in the study had been infected with influenza during the susceptible period. Furthermore, the current method of measuring exposure is subject to under-reporting since 'hidden influenza deaths' may vary by a factor between 1.8 and 8.9 in different epidemics (Curwen et al. , 1990). Thus, this may have also biased our results towards the null finding.

The effect of birth period could be mainly accounted for by the nature of our sample, in that each patient was included only if his/her first psychiatric admission was 
within a particular 11-year period. The nature of our study did not allow for further analysis to assess or remove this effect, and answers to this can be provided only by a study with a different sampling method.

\subsection{Implications}

It has previously been shown that there is a positive relationship between maternal exposure to influenza during the second trimester of pregnancy and the development of schizophrenia in the offspring (Wright et al. , in press). Other studies have suggested that this relationship is stronger for narrowly defined or typical schizophrenia, for schizophrenics with symptoms of delusions of jealousy, delusions of reference and suspiciousness, and for females. On the basis of these earlier observations, we hypothesised that the risk of in utero exposure to influenza is associated particularly with the paranoid subtype of schizophrenia. Initial crude analysis (unadjusted odds ratio) showed that there was a linearly increased proportion of paranoid schizophrenia with an increase in the level of in utero exposure to influenza. However, when sex, season-of-birth and birth period were included in logistic regression analysis such a relation vanished, mainly due to the confounding effect of birth period on the association. As a result, the association between in utero exposure to influenza and paranoid schizophrenia that we specifically hypothesised is not supported by our data.

\section{Acknowledgement}

We are grateful to the Stanley Foundation for their financial support; N.T. is a Stanley Research Fellow.

\section{References}

Curwen, M., Dunnell, K. Ashley. J., 1990. Hidden influenza deaths; 1989 90. Pop. Trends 61.31.33.

Goldstein, J.M. Santangelo, S.L. Simpson, J.C., Tsuang, M.T. 1990. The role of gender in identifying subtypes of schizophrenia; a latent class analytic approach. Schizophr. Bull. 16.263.275.

Machon, R.A., Mednick, S.A., Huttunen, M.O., 1995. Fetal viral infection and adult schizophrenia: empirical findings and interpretation. In Mednick, S.A., Hollister, J.M. (Eds.), Neural Development of Schizophrenia, Plenum Press, New York.

Sham, T., O'Callaghan E., Takei. N., Murray, G.K., Hare, E., Murray, R.M., 1992. Schizophrenia following per-natal exposure to influenza epidemics between 1939 and 1960. Br, J. Psychiatry 160, 461-466.

Takei, N., O'Callaghan, E. Sham, P.C., Glover, G. Murray, R.M., 1993. Does prenatal influenza divert susceptible females from later affective psychosis to schizophrenia? Acta Psychiatr. Scand. 88, 328-336.

Takei, N., Sham, P.,O'Callaghan., E. Murray, G.K., Glover, G. Murray, R.M., 1994. Prenatal exposure to influenza and the development of schizophrenia: is the effect confined to females? Am. J. Psychiatry 151.117.119. 
Takei, N., Murray, R.M., Sham, P., O’Callaghan, E.,1995a. Schizophrenia risk for women from in utero exposure to influenza. Am. J. Psychiatry 152. 150-151.

Takei N., Van Os, J., Murray, R.M., 1995b. Maternal exposure to influenza and risk of schizophrenia: a 22year study from the Netherlands. J. Psychiatr. Res. 29, 435-445.

Takei, N. Mortensen, P.B., Klaening. U., Murray, R.M., Sham, P., O’Callaghan, E., Munk-Jorgensen, P., 1996. Relationship between in utero exposure to influenza epidemics and risk of schizophrenia in Denmark. Biol. Psychiatry 40, 817-824.

Torrey, E.F., Miller, J., Rawlings. R., Yolkem, R.H., 1997. Seasonality of births in schizophrenia and bipolar disorder: a review of the literature (Abstract). Schizophr. Res. 24, 260.

World Health Organization, 1978, Mental Disorders: Glossary and Guide to Their Classification in accordance with the Ninth Revision of the International Classification of Diseases (ICD-9), WHO Geneva.

Wright, P., Takei, N., Murray, R.M., Sham, P., in press. Seasonality, influenza and schizophrenia. In: Susser, E. (Ed), Prenatal Factors for Schizophrenia. 



\section{Chapter 6}

Socioeconomic status and population density risk factors for psychosis? A prospective incidence of the Maltese Islands

Dr. Anton Grech (*) MD MSc (Lond) FRCPsych (UK),Dr. Nigel Camilleri (*) MD MRCPsych (Uk), DCP (Ire), Dr. Rachel Taylor East MD MSc (Lond), International Psychiatry, Vol 2, Number 3, July 2010, pp 69-71

$\left({ }^{*}\right)=$ contributed equally 


\section{Abstract}

Background: Studies on psychosis suggest that urbanicity and lower socio-economic status and migrant are risk factors for psychosis.

Aim: The aim of this study is to calculate the incidence of patients admitted suffering from psychosis in the Maltese Islands, and to examine statistical differences between various districts with a different level of urbanicity and socio-economic level.

Methods and Sample: This study is a one year prospective study that includes all ICD-10 psychosis patients admitted to one of the three psychiatric hospitals on the Maltese Islands ( $n=115)$.

Results: Incidence of hospital admissions due to psychosis was found to be 26.0 at risk per year per 100, 000 population. Incidence was highest in the Southern Harbour area (32.1, $\mathrm{Cl}=31.9-32.3)$, and lowest in the Western District (20.1, $\mathrm{Cl}=19.9-$ 20.2).

Incidence for non affective psychosis was 16 per year per 100,000 (95\% Cl,0.13$0.21)$, whilst that for affective psychosis was 7 per capita(95\% $\mathrm{Cl}, 0.05-0.1)$. Rates in men were almost double those in women.

After adjustment for age and sex, rates were elevated for irregular migrants (direct standardization age range $16-18$ years 49 and 19 years and over 660)

Conclusion: The incidence of hospital admissions due to psychosis in the Maltese Islands is within range when compared to other population studies. But the incidence of psychosis has varied with statistical difference between the districts of the Maltese Islands. The district with the lowest socio-economic groups seems to have the highest incidence of psychosis. The most densely populated district followed. Cultural factors and a small genetic pool could account for the relatively high incidence in the Gozo and Comino district. This has important implications for mental health service planning.

Declaration of Interest: None 


\section{Introduction}

Malta is an archipelago in the Mediterranean Sea. It has a population of approximately 407,810 people and is the $8^{\text {th }}$ most densely populated country in the world (1272 persons per $\mathrm{km} / \mathrm{sq}$ ) and most of all EU countries. The most densely populated town in Malta is Senglea 22,744 persons per sq/ km (situated in the Southern Harbour District). In comparison with the sister island Gozo which has a density of 422 persons per sq/km. Over $92 \%$ of the population lives in urban areas (3).

There are three National Health Service units that offer treatment for psychiatric patients. The largest is Mount Carmel Hospital, with 569 beds (3). Smaller units exist within two general hospitals: Mater Dei Hospital (main island) and in Gozo General Hospital (sister island Gozo).

A prospective study by Menezes et al., in a large metropolitan city in Brazil, among residents found that the incidence of psychosis was 15.8 per 100,000 person-years at risk (95\% Cl 14.3-17.6) (10). The incidence described in this study was overall lower than most other epidemiological studies. Another study carried out in Northern Ireland found a higher incidence of 33 at risk per year per 100,000 population (11).

Findings from the 3-centre AESOP study, an epidemiological study (UK), concluded that the incidence of all psychotic disorders was 34.8 per 100,000 person years $(95 \%$ $\mathrm{Cl}, 32.1-37.8)$. In this study it was suggested that environmental effects may interact together with genetic factors in the aetiology of psychosis. Kirkbride et al found that neighbourhood level effected the incidence of psychosis in that the incidence for the south-east of London (54.5 per capita) was double that of Nottingham (25.1 per capita) and Bristol (22.0 per capita)(7). The point prevalence and lifetime risk has been found to be similar in different countries (140-460 per 100,000), and is approximately $1 \%$ of the population (4).

There are a number of studies which assess the relationship between urbanization and psychosis. A longitudinal study carried out in the Netherlands of birth cohorts concluded that urban birth was linearly associated with schizophrenia. The effect of which appears to be increasing over successive generations (8). Another study concluded that individuals who were exposed to urbanisation at birth as opposed to those exposed to urbanisation at the time of onset of illness where at a higher risk of developing schizophrenia. (9) A follow up study of 4.4 million people in Sweden, concluded that urbanisation is associated with a $68-77 \%$ more risk of developing psychosis for both men and women (12). What contributes to urban stress include noise, the direct effect of pollution, health behaviours and social factors such as 
social fragmentation, social isolation and social inequality $(13,14)$. The incidence of schizophrenia increases consistently with increasing levels of urbanicity in a doseresponse fashion. This not only suggests statistical association but also causality (13).

Other researchers carrying out an incidence study in Northern Ireland and on birth cohorts in Finland believe that the increase in patients suffering from psychosis is likely due to socio-economic factors $(11,6)$.

The aim of this study was to find out the incidence of patients suffering from psychosis and requiring admission to hospital. We also intended to gain further epidemiological information looking specifically at population density and socio-economic status as well as ethnicity, and examine the differences between the six districts of the Maltese Islands.

Based on evidence from previous studies, we hypothesised that similarly an increased incidence of psychosis would be found in the lower socio-economic region, the more densely populated region and the group of irregular migrants.

\section{Subjects and Methods}

\subsection{Sample}

The study design used was a prospective cross-sectional study of the incidence of psychosis in patients requiring admission to hospital.

The inclusion criteria for this study were all new cases admitted to a psychiatric ward at any of the three government hospitals between $1^{\text {st }}$ May 2007 and $30^{\text {th }}$ April 2008, with a diagnosis of psychosis. Participations included persons of all age, sex and ethnical background.

\subsection{Clinical Assessment of the patient sample}

At admission the senior doctor established if this person suffered from a psychosis. After the patient was seen by the consultant psychiatrist and multidisciplinary team (MDT) the diagnosis was confirmed or dismissed. Only people with a diagnosis of psychosis by the MDT were included in the study. 


\subsection{Geographical Division of Regions in Malta}

Malta is divided into 6 regions namely; the southern harbour area, the northern harbour area, the south-east district, the western district, northern district and Gozo and Comino district (3). From this data the incidence was calculated and then compared statistically.

\subsection{Data Protection}

All patients were invited to participate in the study, and were free to decline. Informed consent was given. They were informed that all data collected would be anonymous and confidential and that this study would not negatively or positively effect the treatment they received in hospital.

This study was approved by the relevant hospital authorities.

\subsection{Statistics}

All data was imputed into Microsoft Excel and analysed using SPSS. Confidence intervals were calculated using the standard formula for rates. Gender and age specific direct standardisation of migrant data on native population data was carried out.

\section{Results}

This included a cohort of 115 people. $60.5 \%$ (67) of these were male, 38.5\% (44) were female. Satisfactory data was available on 111 patients $(96.5 \%)$. The mean age at index admission was 41.4 years $(95 \% \mathrm{Cl}=44.0-38.8)$. The ages ranged from 16 to 87 years.

The incidence of patients with psychosis requiring admission any hospital on the Maltese Islands was 26.0 per100, 000. The incidence of patients admitted to hospital diagnosed with a non affective psychosis (schizophrenia) was 15.4 per 100, 000 (95\% Cl: 0.13-0.21), whilst the incidence of affective psychosis was 7 per capita (95\% $\mathrm{Cl} 0.05-0.1$ ) and other types of psychosis (organic and drug induced) was 4 per capita (95\% $\mathrm{Cl} 0.02-0.06)$. The difference between each group is statically significant. 
TABLE 1

Number of patients admitted.

\begin{tabular}{llll}
\hline Diagnosis & New Case & Males & Females \\
\hline Organic Disorders delusions hallucinations or catatonic stupor & $4(3.6 \%)$ & $2(50 \%)$ & $2(50 \%)$ \\
Schizophrenia and Delusional disorders & $49(44.1 \%)$ & $27(55 \%)$ & $22(45 \%)$ \\
Acute and transient psychotic disorders & $18(16.2 \%)$ & $9(50 \%)$ & $9(50 \%)$ \\
Schizoaffective disorders & $3(2.7 \%)$ & $2(67)$ & $1(33 \%)$ \\
Psychotic disorder due to psychoactive substance use & $12(10.8 \%)$ & $11(91 \%)$ & $1(9 \%)$ \\
Bipolar Affective Disorder; current episode manic with psychotic & $12(10.8 \%)$ & $8(75 \%)$ & $4(25 \%)$ \\
symptoms. & & & $5(38 \%)$ \\
Severe depressive episode with psychotic symptoms. & $13(11.7 \%)$ & $8(62 \%)$ & 5 \\
\hline
\end{tabular}

The epidemiological results were further analysed, as per district in the Maltese Islands. The largest incidence of patients suffering from psychosis was found in the South Harbour District (32.1 per 100,000 person years at risk). The most densely populated area in Malta (the Northern Harbour Area) was found to have an incidence of 28.3 per 100,000 people of the population. These results were statistically different to the much lower incidence of the less densely populated districts. The sister island Gozo was found to have a relatively similar incidence to that of the mainland; 25.6 per 100,000 people, though still statistically different, as indicated by the confidence intervals in table 2 .

TABLE 2

\begin{tabular}{lll}
\hline District & $\mathrm{N}$ & Incidence $(95 \% \mathrm{Cl})$ \\
\hline Southern Harbour & 32 & $32.1(31.9-32.3)$ \\
Northern Harbour & 38 & $28.3(28.1-28.4)$ \\
Western & 8 & $20.1(19.9-20.2)$ \\
South-East & 10 & $20.9(20.8-21.1)$ \\
Northern & 11 & $22.4(22.2-22.6)$ \\
Gozo and Comino & 10 & $25.6(25.3-25.9)$ \\
Irregular Immigrants & 6 & Aprox. 400 (379.8-420.2) \\
Malta & Tot= 115 & $26.0(25.9-26.1)$
\end{tabular}

Another finding suggests that $6(5.2 \%)$ of the total of patients included in the study were irregular migrants. Data drawn on Malta National Statistics Office shows that in 2007 just over 1500 immigrants landed in Malta. The average stay for an irregular migrant is around 12 months. So an approximate estimate for the incidence of psychosis in irregular immigrants is 400 per 100,000 person years at risk. After adjustment for age and sex, rates for irregular migrants were found to be elevated. After direct standardisation the weighted cases for ages 16-18years was 49 . For those over 19 years if the Maltese population had the same risk of psychosis as the migrants we would have had 660 patients. 


\section{Discussion}

When comparing the results in this study to other epidemiological studies, it transpires that the incidence of psychosis in the Maltese population is within range when compared to that of other populations.

What was confirmed in our study was that incidence of psychosis statistically varied between the districts of the Maltese Islands. This highlights the importance of the role urbanization, socio-economic status and migration place in the aetiology of psychosis.

Sociological studies describe the western district, where incidence of psychosis was lowest, as the district with highest proportion of academic achievers. The southern harbour district, where there was the highest incidence of psychosis, has the highest number of residents in the lowest socio-economic group, with $41 \%$ of residents having no schooling (1). The northern harbour district has the highest population density, and the second highest incidence of psychosis.

The Gozo and Comino district has a much lower population density, yet the incidence is similar to that of Malta. This may be due to easier access to psychiatric services. However, it may be also be possible that people living in this small community may be more aware of stigma and discrimination, leading to people waiting longer before seeking medical attention. Symptoms may then be more severe, requiring hospitalisation. High expressed emotion which can take place in closely knit families and extended families, can also account for the above results. Another explanation may be the smaller genetic pool.

The incidence of psychosis in irregular immigrants was very high when compared to that of the Maltese population and that of other studies. Clinically one of the most consistent findings amongst immigrant ethnic groups in Western Europe is an increase in the incidence rate of psychosis. A recent meta-analysis study confirms that migration is a risk factor for schizophrenia that cannot be solely explained by selection. $(15,2)$.

\section{Limitations}

Our study used a population that were referred as in-patients to hospital thus excluding all those suffering from a form of psychotic illness and treated in the community. Since we do not have an urgent care and home management team available by the National Health Services on the Maltese islands, then we can confidently say 
that most patients suffering from a first episode of psychosis would be admitted to hospital. The authors bear in mind that this study may suffer from Ecological fallacy thus the sample population may not be truly representative of the target population. So results should be interpreted with care.

Another limitation of our study is that we did not include patients admitted to a private hospital. At the time the study was carried out, in the private sector, there were no admitting units specifically for psychotic patients.

Data was solely collected from medical files without actually interviewing the respective Multidisciplinary Team or patients themselves.

\section{Clinical Implications}

The results in this study support and highlight the facts that; incidence of psychosis is variable. Like in other countries, in Malta; urbanization, low socio economic status and immigration are potential risk factors and thus play a role in the aetiology of psychosis. Higher educational attainment may be a protective factor. Awareness of this by clinicians and service providers can lead to better provision and planning of services.

\section{Acknowledgments}

We would like to thank Dr. Neville Calleja MD MSc, for his input with statistical data.

\section{References}

1. Camilleri F. A day in her life, insights into the social and economic contribution of Maltese women, 2001. Commission for the Advancement of women, Ministry of Social Policy, Malta

2. Cantro-Grae E and Shelton JP. Schizophrenia and migration: a meta-analysis review. Am J of psychiatry 2005, 162,12-24.

3. Census of Population and Housing, 2006, Volume 1, National Office of Statistics Malta

4. ECA, Keith 91; National Co-morbidity Survey, Kendler, Arch Gen Psych, 1996; 53 1022-1031

5. Haukka J, Suvisaari J, Varilo T, Lonnquvist J. Regional variation in the incidence of schizophrenia in Finland: a study of birth cohorts born from 1950-1969, Psychological medicine, 2001; 31 (6): 10451053

6. Hickman M, Vickerman P, Macleod J, Kirkbride J, Jones PB. Cannabis and schizophrenia: model projections of the impact of the rise in cannabis use on historical and future trends in schizophrenia in England and Wales. Addiction, 2007; 102:4: 597-606

7. Kirkbride JB, Fearon P, Morgan C, Dazzan P, Morgan K, Tarrant J, Lloyd T, Holloway J, Hutchinson G, Leff JP, Mallett RM, Harrison GL, Murray RM, Jones PB. Heterogeneity in Incidence Rates of Schizophrenia and Other Psychotic Syndromes, 2006, Arch Gen Psychiatry Volume 63: 250-258 
8. Marcelis M, Navarro-Mateu F, Murry R, Seltes JP, Van OS J, Urbanization and psychosis: a study of 1942-1978 birth cohorts in The Netherlands. Psychological Medicine (1998) 28:871-879

9. Marcelis M, Takei N, Van OS J. Urbanisation and risk for schizophrenia: does the effect operate before or around the time of illness onset? Psychological Medicine (1999), 29:1197-1203

10. Menezes PR, Scazufca M, Busatto GF, Coutinho LMS, McGuire PK, Murray RM. Incidence of firstcontact psychosis in Sao Paulo, Brazil. The British J of Psychiatry, 2007; 191:102-6.

11. Northern Ireland Psychosis Study finds: Higher incidence than in recent studies men have higher rate of schizophrenia than women. No evidence of increase in psychosis in urban areas, Royal College of Psychiatrists, annual meeting June 2005, Edinburgh International Conference Centre.

12. Sundquist K, Frank G, Sundquist J. Urbanisation and incidence of psychosis and depression: follow-up study of 4.4million women and men in Sweden. Br J Psychiatry 2004 Apr; 184:293-8

13 Van Os J Does the urban environment cause psychosis? The Br J of Psychiatry (2004) 184:287-288

14 Van Os J, Driessen G, GuntherN, Delespaul P. Neighbourhood variation in incidence of schizophrenia. Evidence for person-environment interaction. British Journal of Psychiatry (2000) 176: 243-248

15. Veiling W, Susser E., Van Os J, Mackenbach JP, Selten JP, Hoek HW. Ethnic density of neighbourhoods and incidence of psychotic disorders among immigrants. Am J Psychiatry 2008 Jan;165(1):66-73 



\section{Chapter 7}

\section{Cannabis Use and Outcome of Recent Onset Psychosis}

Grech, A., Van Os, J., Jones, P. B., Lewis, S. W., \& Murray, R. M. (2005). Cannabis use and outcome of recent onset psychosis. European Psychiatry, 20(4), 349-353 


\section{Abstract}

Purpose: To test the hypothesis that recent onset psychotic patients who use cannabis will have psychotic symptoms that are more severe and more persistent than those who do not use cannabis.

Subjects and methods: We carried out a 4-year follow-up study of a cohort of 119 patients with recent onset of psychosis. The patients were divided into four groups according to duration of cannabis use, taking index admission and follow-up as reference points.

Results: Those subjects who persisted in the use of cannabis had more positive (but not negative) symptoms and a more continuous illness at follow-up.

Limitations: The main limitations of the study were: the relatively small sample size, and that the excess of male subjects and the presence of cannabis induced psychosis could have a confusing impact on the interpretation of the results.

Conclusion: It is possible that psychotic patients who use cannabis are at a greater risk of a more continuous illness with more positive symptoms than those who do not.

Keywords: Cannabis; Psychosis; Outcome 


\section{Introduction}

Next to alcohol and nicotine, cannabis is the drug most commonly used by people with psychosis; this is not surprising since its use is widespread in many countries (e.g. $[7,818]$ ). Additionally, many studies have reported a strong association between cannabis consumption and psychosis $[1,4,5,14,16,19,22,23]$. The reason for this association remain hotly debated. Several prospective epidemiological studies have suggested that cannabis is an independent risk factor for the development of schizophrenia $[1,2,26]$. However, other researchers explain the higher consumption of cannabis by psychotic patients as an attempt to relieve distressing symptoms of their illness or the adverse side-effects of antipsychotic medications [11,21].

Distinct from this controversy, it is important to establish whether the outcome for psychotic patients who use cannabis is worse than that for those who do not, and if this is so, whether the outlook can be improved by stopping the cannabis consumption. Three studies have addressed these questions. Linszen at al.[14] carried out a prospective 1-year study in which they compared outcome for cannabis-abusing schizophrenic outpatients with that of their non-abusing counterparts. Cannabis abuse, particularly if heavy, was associated with worsening of psychosis; indeed, many of the abusers reported an increase in their psychotic symptoms soon after taking cannabis. Caspari [3] followed-up 27 schizophrenic patients with a history of cannabis use for a mean of 69 months, and compared their outcome with that of schizophrenic patients without such a history; about half of the cannabis users ceased their consumption or switched to alcohol. Nevertheless, those with a history of cannabis use had significantly more hospitalizations, tended to have worse psychosocial functioning, and showed more thought disorder and hostility. Kovasznay et al. [12] reported similar findings from a 6 months follow-up study of patients suffering their first episode of schizophrenia; they concluded that further cannabis use "may exacerbate overall symptoms, as represented by the BPRS score, while showing little effect on the negative symptoms as represented by the SANS."

We therefore, set out to test the hypothesis that recent onset psychotic patients who continue to use cannabis have psychotic symptoms that are more severe and more persistent than those who do not use cannabis. We aimed to complement the previous work; in particular regarding the role of continued cannabis use over the follow-up period. 


\section{Subjects and methods}

\subsection{Sample}

This study is a part of a larger investigation, designed to establish the predictors of social and clinical outcome in psychosis. The study rationale has been described in detail elsewhere [27, 28]. Briefly, we followed up a cohort of 119 patients who were admitted to two South London Hospitals, with recent onset psychosis. Patients were considered to be suffering from psychosis, and thus included in the study, if they had at least one of the following: hallucinations in any modality, delusions or severe thought or speech disorder (e.g. incoherence, irrelevance, thought blocking, neologisms, incomprehensibility of speech, not simple retardation or acceleration). The other inclusion criteria were that patients should have clear consciousness and an age less than 60 years. All patients were interviewed within 3 days of their admission, and gave written informed consent to participate in the study. The 119 patients included in the study had an onset of functional psychosis within 5 years of the index admission, and at that admission had been interviewed regarding illicit drug and alcohol use.

\subsection{Baseline and clinical assessments}

At index admission, the patients were interviewed using the Present State Examination (PSE) [29]. The Operational Criteria Checklist for Psychotic Illness (OCCPI) [17] was completed for all patients, by using both PSE cross-sectional data and all available case-note material. The OCCPI was then analysed with the OPCRIT computer programme [17] to give a DSMIII R index diagnosis.

\subsection{Follow-up clinical assessments}

Follow-up clinical data were collected in interviews conducted by JvO, who was blind to all index data, including that related to cannabis use. These data were collected almost 4 years after index admission (Mean $=3.7$ years, S.D. $=2.5$ ). Positive symptoms and course illness were assessed by means of a slightly modified version of the 'life chart' instrument from the Multi-Centre Study on the Course and Outcome of Scizophrenia [30]. With respect to positive psychotic symptoms, the patients were categorized into two groups according to their 'usual severity of symptoms' during the follow-up period; (1) patients with no or mild positive symptoms and (2) patients with moderate and severe positive symptoms. The course of illness during the follow-up period was categorized into (1) continuous (no remission longer than 6 months) and, (2) other (had remission which lasted more than 6 months). The outcome measure used to assess negative symptoms was the lager 
Negative Symptom Rating Scale [10], and the patients were categorized into two categories, (1) Patients with Negative Symptoms of any severity and (2) Patients without Negative Symptoms.

\subsection{Cannabis consumption}

A semi-structured interview was used to collect information on alcohol and illicit drugs intake (including cannabis), both before the index admission and the time of the follow-up assessment. At index admission the interview consisted of standard questions on the lifelong history of alcohol and illicit drugs intake (age of onset, use in typical week, length of use, history of changes in intake) and recent changes in use. When appropriate the interviewer asked further more detailed questions, especially on changes in intake of alcohol and drugs prior to the admission. The interview at the follow-up assessment consisted of questions on the frequency and quantity of alcohol and illicit drugs intake since index admission, with emphasis on the last 3 months prior to the assessment. For the purpose of this study, a subject was considered to have a 'history of cannabis use prior to index admission'; if prior to the index admission he had a history of using cannabis frequently or regularly. 'Cannabis use at follow-up' was having used cannabis in the 3 months prior to the follow-up assessment. The patients were divided into four groups with different duration of use of cannabis taking index admission and follow-up as reference points;(1) no history of cannabis use prior index admission or at follow-up assessment, (2) history of cannabis use prior to index admission but not at follow-up assessment, (3) no history of cannabis use prior to index admission but cannabis use at follow-up assessment, and (4) history of cannabis use prior to index admission and at follow-up assessment.

\section{Results}

Adequate index and follow-up date on cannabis use were available for 98 (82.4\%) of the 119 patients. Sixty-five (66.3\%) of these were male, 32 (32.7\%) were of African/African-Caribbean origin, and their mean age at index admission was 25.4 years (S.D. = 5.5). There were no large or significant differences in the demographic variables between the 21 cases who were not included in the analyses due to inadequate data on cannabis use, and the 98 patients who were included.

The DSMIII R diagnoses of 97 patients were: schizophrenia $=41$ (41.8\%), schizoaffective disorder $=9(9.1 \%)$, schizophreniform disorder $=6(6.1 \%)$, affective psychoses $=$ $25(25.5 \%)$, delusional disorder $=9$ (9.2\%), and atypical psychosis $=7$ (7.1\%). Sixtyone $(62.2 \%)$ patients reported no history of cannabis use at index admission or at 
follow-up; 9 (9.2\%) patients reported history of cannabis use at index admission but no use at follow-up; 12 (12.2\%) patients reported cannabis use at follow-up but had no history of cannabis use at index admission and 16 (16.3\%) patients reported a history of cannabis use at index and cannabis use at follow-up.

Crude and adjusted (for age at index admission, ethnicity and sex) odds ratios were assessed to measure outcome for each group of cannabis use, taking the patients with no cannabis use as the reference category.

TABLE 1

Change on course of illness and in positive psychotic symptoms (Life Chart Instrument - WHO 1992) with respect to change in cannabis intake

\begin{tabular}{|c|c|c|c|c|}
\hline & $\begin{array}{l}\text { Patients with no } \\
\text { history of cannabis } \\
\text { use at index or at } \\
\text { follow-up }\end{array}$ & $\begin{array}{l}\text { Patients with history } \\
\text { of cannabis use at } \\
\text { index but no use at } \\
\text { follow-up }\end{array}$ & $\begin{array}{l}\text { Patients with no } \\
\text { history of cannabis } \\
\text { use at index and use } \\
\text { at follow-up }\end{array}$ & $\begin{array}{l}\text { Patients with } \\
\text { history of cannabis } \\
\text { use at index and } \\
\text { use at follow-up }\end{array}$ \\
\hline Total Number of Patients & 61 & 9 & 12 & 16 \\
\hline $\begin{array}{l}\text { Patients with continuous course } \\
\text { of illness }\end{array}$ & $20(32.8 \% 0$ & $4(44.4 \%)$ & $5(41.7 \%)$ & $10(62.5 \%)$ \\
\hline $\begin{array}{l}\text { Patients with no continuous } \\
\text { course of illness }\end{array}$ & $41(67.2 \%)$ & $5(55.6 \%)$ & $7(58.3 \%)$ & $6(37.5 \%)$ \\
\hline $\begin{array}{l}\text { Crude Odds Ratio for course of } \\
\text { illness }\end{array}$ & 1 & $1.64 \underline{a}$ & $1.46^{\mathrm{a}}$ & $3.42 b$ \\
\hline $\begin{array}{l}\text { Adjusted odds ratio* for course } \\
\text { of illness }(95 \% \mathrm{Cl})\end{array}$ & 1 & 1.68 a $(0.37-7.51)$ & $1.09 \mathrm{a}(0.28-4.27)$ & $2.82 \mathrm{a}(0.82-9.70)$ \\
\hline $\begin{array}{l}\text { Patients with moderate or severe } \\
\text { positive psychotic symptoms }\end{array}$ & $14(23.0 \%)$ & $3(33.3 \%)$ & $4(33.3 \%)$ & $9(56.3 \%)$ \\
\hline $\begin{array}{l}\text { Patients with mild or no positive } \\
\text { psychotic symptoms }\end{array}$ & $47(77.0 \%)$ & $6(66.7 \%)$ & $8(66.7 \%)$ & $7(43.8 \%)$ \\
\hline $\begin{array}{l}\text { Creude odds ratio for positive } \\
\text { psychotic symptoms }\end{array}$ & 1 & 1.68 a & $1.68 \mathrm{a}$ & $4.32 c$ \\
\hline $\begin{array}{l}\text { Adjusted odds ratio* for positive } \\
\text { psychotic symptoms }(95 \% \mathrm{Cl})\end{array}$ & 1 & $1.61 \mathrm{a}(0.35-7.58)$ & $1.32 \mathrm{a}(0.33-5.31)$ & $3.67 d(1.12-12.07)$ \\
\hline
\end{tabular}

* Odds ratio adjusted for : age at index admission, ethnicity and sex.

a Statistically non-significant, $\mathrm{p}=>0.05$

b Statiscally significant, $p=0.04$

c Statistically significant, $p=0.01$

d Statistcially signifcatn, $p=0.03$.

There was an association between increased cannabis use and more continuous course of psychotic illness. The statistical significance shown at the level of most cannabis use was lost after adjusting for age at index admission, ethnicity and sex. However, the trend for increase in continuity of illness was maintained (see Table 1). There was also an association between increase in cannabis use and the severity of positive psychotic symptoms during the follow-up period, with this association reaching statistical significance at the level of most cannabis use (see Table 1). After 
adjusting for age at index admission . ethnicity and sex, this association remained statistically significant.

There was no statistically significant association between increase in duration of cannabis intake and presence or absence of negative symptoms at follow-up (Table 2).

TABLE 2

Change in negative symptoms (larger Scale) with respect to change in duration of cannabis intake

\begin{tabular}{lllll}
\hline & $\begin{array}{l}\text { Patients with no } \\
\text { history of cannabis } \\
\text { use at index or at } \\
\text { follow-up }\end{array}$ & $\begin{array}{l}\text { Patients with } \\
\text { history of cannabis } \\
\text { use at index but } \\
\text { no use at follow-up }\end{array}$ & $\begin{array}{l}\text { Patients with no } \\
\text { history of cannabis } \\
\text { use at index and use } \\
\text { at follow-up }\end{array}$ & $\begin{array}{l}\text { Patients with } \\
\text { history of cannabis } \\
\text { use at index and } \\
\text { use at follow-up }\end{array}$ \\
\hline Total Number of Patients & 61 & 9 & 11 & 15 \\
Patients with negative symptoms & $31(50.8 \%)$ & $5(44.4 \%)$ & $6(54.5 \%)$ & $9(60.0 \%)$ \\
Patients with no negative symptoms & $30(49.2 \%$ & $5(55.6 \%)$ & $5(45.5 \%)$ & $6(40.0 \%)$ \\
Crude odds ratio & 1 & $0.77 \underline{a}$ & $1.16 \underline{a}$ & 1.45 a \\
Adjusted odds ratio* for course of & 1 & $0.63 \underline{a}(0.29-2.86)$ & 0.82 a $(0.21-3.28)$ & 1.14 a $(0.33-3.84)$ \\
illness (95\% Cl) & & & & \\
\hline
\end{tabular}

* Odds ratio adjusted for: age at index admission, ethnicity, and sex.

a Statistically non-significant, $p=>0.05$

\section{Discussion}

This study indicates that there is an association between use of cannabis by psychotic patients and outcome of psychosis. Those subjects who used cannabis most were associated with more positive (but not negative) symptoms and more continuous illness. Our findings thus support pervious reports $[3,4,12]$.

\subsection{Limitations of the study}

The main limitation of the study is its relatively small sample size. Apart from the group with no cannabis intake at baseline or at follow-up $(n=61)$, the numbers of subjects in the other groups are low ( $n=9,11$ and 15 , respectively). This small sample size did not allow for separate analysis by gender, and the excess of males in the sample could have biased the result. Furthermore, exposure to cannabis was defined broadly, and exposure to cannabis was not subdivided by its extent. Also, the results of the study would have been more meaningful if we could have taken into consideration any association between the timing of the last use of cannabis and the manifestations of symptoms, or if the cannabis use was associated with a particular subset of symptoms. However, the small sample size did not allow for this. 
Similarly, because of the relatively small sample size and infrequency of other drug abuse, we could not perform significant analysis on the possible influence that drugs other than cannabis had on the outcome. The percentage of patients participating in the study who at index admission had a lifetime history of use of a drug other than cannabis more than twice was as follows: opiates $3.4 \%$, cocaine $3.4 \%$, hallucinogens $3.4 \%$, glue $2.5 \%$ and stimulants $5.9 \%$.

Future studies on this subject need to have a sample size big enough to overcome these limitations.

Another limitation of this study is that its design did not include confirmation by laboratory investigations (urine or hair analysis) of the reported cannabis use. However, Martin et al. [15] showed that information on use of soft drugs given by patients is generally reliable, and certainly in London the use of cannabis is acceptable in many social circles.

\subsection{Clinical implications}

Our study shows that psychotic patients who continue to use cannabis are at risk of having more positive symptoms and a more continuous course of illness. We cannot disprove the possibility that patients were using cannabis as a self-treatment for their psychotic symptoms, and thus they were using more cannabis because they had more positive symptoms. However, recent studies which have asked psychotic patients about their motives for taking cannabis have found little empirical evidence that the drug is taken for positive psychotic symptoms or for relief of side-effects [24]. It is also possible that it is the lifestyle associated with increase in severity of psychotic illness, such as unemployment and hospitalization that results in the persistence of cannabis intake but again there is no direct evidence of this.

However, an alternative is that the presence of positive symptoms is secondary to the continued cannabis use. D'Souza [6] has shown in experimental studies that cannabis can induce psychotic symptoms (including visual and auditory hallucinations, delusions and thought disorder) in normal volunteers and in schizophrenic patients, but that the latter are more vulnerable. THC acts in cannabinoid receptors in the brain. Not only is there a close relationship between the cannabinoid and dopamine system but also there is evidence implicating the cannabinoid stsytem in schizophrenia [13]. This could be because THC increases the presynaptic release of dopamine in the nucleus accumbens and prefrontal cortex $[9,20,25]$.

Further research in this area is required, because if an association between cannabis use and poor outcome of psychosis is eventually proven, it will have very important 
clinical implications. In the meantime, from the evidence from this and other studies, we consider it wise to discourage cannabis use by patients suffering from Psychosis.

\section{References}

1. Andreasson S, Alleback P, Engstrom A, Rydberg U. Cannabis and schizophrenia: a longitudinal study of Swedish conscripts. Lancet 1987;2:1483-6.

2. Arseneault L, Cannon M, Poulton R, Murray R, Caspi A, Moffitt T. Cannabis use in adolescence and risk for adult psychosis: longitudinal prospective study. BMJ 2002;325:1212-3.

3. Caspari D. Cannabis and schizophrenia: results of a follow-up study. Eur Arch Psychiatry Clin Neurosci 1999;249(1):45-9.

4. Degenhardt L, Hall W. The association between psychosis and prob lematic drug use among Australian adults. Psychol Med 2001;31:659-68.

5. Dixon L, Haas G, Weiden PJ, Sweeney J, Frances AJ. Drug abuse in schizophrenic patients: clinical correlates and reasons for use. Am J Psychiatry 1991;148(2):224-30.

6. D'Souza C. In: McDonald C, Schulze K, Murray RM, Wright P, Dunitz M, editors. 'Gone to pot': pharmacological evidence supporting the contribution of cannabinoid receptor function to psychosis. Schizophrenia: challenging the orthodox. 2004 p. 127-36.

7. Duke PJ, Pantelis C, McPhillips MA, Barnes TRE. Comorbid non- alcohol substance misuse in people with schizophrenia. Br J Psychia- try 2001;179:509-13.

8. Fowler IL, Carr VJ, Carter NT, Lewin TJ. Patterns of current and lifetime substance use in schizophrenia. Schizophr Bull 1998;24(3):443-55.

9. Gardner EL, Lowinson JH. Marijuana's interaction with brain reward systems: update 1991. Pharmacol Biochem Behav 1991;40:571-80.

10. lager AC, Kirch DG, Wyatt RJ. A negative symptom rating scale. Psychiatry Res 1985;16:27-36.

11. Khantzian EJ. The self-medication hypothesis of substance use disorders: a reconsideration and recent applications. Harv Rev Psy- chiatry 1997;4:231-44.

12. Kovasznay B, Fleischer J, Tanenberg-Karant M, Jandorf L, Miller AD, Bromet E. Substance use disorder and the early course of illness in schizophrenia and affective psychosis. Schizophr Bull 1997;23(2):195-201.

13. Leroy S, Griffon N, Bourdel MC, Olie JP, Poirier MF, Krebs MO. Schizophrenia and the cannabinoid receptor type 1 (CB1): association study using a single-base polymorphism in coding exon 1 . Am J Med Genet 2001;105(8):749-52.

14. Linszen DH, Dingemans PM, Lenior MA. Cannabis abuse and the course of recent-onset schizophrenic disorders. Arch Gen Psychiatry 1994;51:273-9.

15. Martin GW, Wilkinson A, Kapur BM. Validation of self-reported cannabis use by urine analysis. Addict Behav 1988;13:147-50.

16. Mathers DC, Ghodse AH. Cannabis and psychotic illness. Br J Psychiatry 1992;161:648-53.

17. McGuffin P, Farmer A, Harvey I. A poly-diagnostic application of operational criteria in psychotic illness: development and reliability of the OPCRIT system. Arch Gen Psychiatry 1991;48:764-70.

18. Menezes P, Johnson S, Thornicroft G, Marshall J, Prosser D, Bebbington D, et al. Drug and alcohol problems among individuals with severe mental illness in South London. $\mathrm{Br} J$ Psychiatry 1996;168:612-9.

19. Mueser KT, Yarnold PR, Rosenberg SD, et al. Substance use disorder in hospitalised severely mentally ill psychiatric patients: prevalence, correlates, and subgroups. Schizophr Bull 2000;26:179-92.

20. Patel V, Borysenko M, Kumar MS. Effects of delta THC on brain and plasma cathecolamine levels as measured by HPLC. Brain Res Bull 1985;14:85-90. 
21. Peralta V, Cuesta MJ. Influence of cannabis abuse on schizophrenic psychopathology. Acta Psychiatr Scand 1992;85:127-30.

22. Rolfe M, Tang CM, Sabally S, Todd JE, Sam EB, Hstib NJB. Psychosis and cannabis abuse in The Gambia. A case-control study. Br J Psychiatry 1993;163:798-801.

23. Schneier FR, Siris SG. A review of psychoactive substance use and abuse in schizophrenia. Patterns of drug choice. J Nerv Ment Dis 1987;175(11):641-52.

24. Spencer CR, Castle D, Michie PT. Motivations that maintain substance use among individuals with psychotic disorders. Schizophr Bull 2002;28:233-47.

25. Tanda G, Pontieri FE, Di Chiara G. Cannabinoid and heroin activation of mesolimbic dopamine transmission by a common u1 opioid receptor mechanism. Science 1997;276:2048-50.

26. Van Os J, Bak M, Hannsen M, Biji RV, Graaf R, Verdoux H. Cannabis use and psychosis: a longitudinal population-based study. Am J Epi- demiol 2002;156(4):319-27.

27. Van Os J, Fahy $\mathrm{T}$, Jones $\mathrm{P}$, et al. Increased intra-cerebral CSF spaces predict unemployment and negative symptoms in psychotic illness: a prospective study. Br J Psychiatry 1995;166:750-9.

28. Van Os J, Fahy T, Jones P, et al. Psychopathological syndromes in the functional psychoses: associations with course and outcome. Psychol Med 1996;26:161-76.

29. Wing JK, Cooper JE, Sartorius N. The measurement and classification of psychiatric symptoms. Cambridge: Cambridge University Press; 1974.

30. World Health Organization. WHO Coordinated Multicenter Study on the Course and Outcome of Schizophrenia. Geneva: WHO; 1992. 


\section{Chapter 8}

Cannabis Use and Age of Admission to a Psychiatric Unit for First Episode of Psychosis; a Whole Population Based Study

Dr. Anton Grech MD MSc (Lond) FRCPsych (UK), Dr. Nigel Camilleri MD MRCPsych (UK), DCP (Ire), Dr. Rachel Taylor East MD MSc(Lond).

(this paper has been submitted for publication) 


\begin{abstract}
Background: Research has implicated that cannabis has an aetiological role in psychosis, and thus one can hypothesize that it can hasten the age of onset of patients with psychosis who use cannabis.

Aim: The aim of this study is to assess the possible influence of cannabis on the age of onset of patients with first episode of psychotic illness admitted to a psychiatric unit in the Maltese Islands.

Methods and Sample: This study is a one year prospective study that includes all ICD-10 first episode psychosis patients admitted to a psychiatric hospital in the Maltese Islands. Age of admission to hospital was used as proxy for age of onset of psychosis. Use of cannabis prior to admission was ascertained by urine testing.

Results: The mean age of admission to hospital for first onset psychosis for patients whose urine was positive to cannabis was 24.63 years old, and for patients whose urine was negative to cannabis was 44.63 years old. This difference was statistically significant, Mann Whitney $\mathrm{p}=0.001$.

Conclusion: The results indicate that cannabis use can result into an earlier age of onset of psychotic illness. Considering the very widespread use of cannabis, and that earlier age of onset of psychosis is associated with worse prognosis, this issue needs to be addressed further.
\end{abstract}

Declaration of Interest: None 


\section{Introduction}

Malta is an archipelago in the Mediterranean Sea, with a population of approximately half a million people. There are three National Health Service units that offer treatment for psychiatric patients. The largest is Mount Carmel Hospital, with around 600 beds. Smaller units exist within two general hospitals: Mater Dei Hospital (main island) and in Gozo General Hospital (sister island Gozo). There is also a private hospital that occasionally admits patients with mental illness as well.

Several case- control studies have shown that patients with schizophrenia are more likely to use cannabis than other psychiatric patients or normal controls (1 - 4). In 1987 Andreasson et al. (5) published a seminal paper of a follow-up study on a cohort of 45,570 Swedish conscripts. In this cohort the relative risk for schizophrenia among high consumers of cannabis was six times more than in non-users of cannabis. Similar results were replicated in other follow-up studies $(6-9)$. Thus one can conclude that it is very possible that cannabis can have an aetiological role in the development of schizophrenia.

Due to this aetiological role, one can thus hypothesize that cannabis use can hasten the onset of psychotic illness, and so patients with schizophrenia who abuse cannabis have an earlier age of onset than those who do not. Four studies conducted on patients with first episode of psychosis concluded that patients with psychosis who abuse cannabis have an earlier age of onset of illness compared to those who do not $(10-12)$. Sugranyes et al., (13) conducted a study on 116 patients with first episode psychosis and subsequent diagnosis of schizophrenia (after a 12-month follow-up). Their findings showed that cannabis use was significantly associated with a decrease in age of first antipsychotic treatment, and that this correlated with frequency of cannabis use.

Malta is a small country and thus it lends itself well to epidemiological studies that are based on the whole population. We thus chose the Maltese Archipelago to test if the findings of the studies that show that cannabis is associated with an earlier age of onset of psychosis are replicated in a study based on the whole population of a country. 


\section{Subjects and Methods}

\subsection{Sample}

The study design used was a prospective cross-sectional study. The inclusion criteria for this study were all patients with a first episode of psychosis admitted to a psychiatric ward at any of the three government hospitals between $1^{\text {st }}$ May 2007 and $30^{\text {th }}$ April 2008. In Malta there is only one non government hospital that admits patients with mental illness. Admissions for psychosis in this unit are very rare, and during the year of study there were no admissions of patients that fulfilled the inclusion criteria of the study. Participations included persons of all age, sex and ethnical background that were permanently resident in Malta. Tourists and illegal immigrants not living in the community were not included.

\subsection{Clinical Assessment of the patient sample}

At admission the senior doctor established if this person suffered from a psychosis. After the patient was seen by the consultant psychiatrist and multidisciplinary team (MDT) the diagnosis was confirmed or dismissed. Only people with a diagnosis of psychosis by the MDT were included in the study.

\subsection{Age of Onset of Psychosis}

Age of admission to hospital was used as proxy for age of onset of psychosis.

\subsection{Assessment of Cannabis Use}

Use or otherwise of cannabis by the patients prior to the admission was ascertained by means of urine testing within the first few days of admission.

\subsection{Data Protection}

All patients were invited to participate in the study, and were free to decline. Informed consent was given. They were informed that all data collected would be anonymous and confidential and that this study would not negatively or positively effect the treatment they received in hospital.

This study was approved by the relevant hospital authorities.

\subsection{Statistics}

All data was imputed into Microsoft Excel and analysed using SPSS. 


\section{Results}

During the year of study there were 100 patients (Males=55, Females=45) with first episode of psychosis who were permanently resident in Malta and were admitted in one of all the in-patient psychiatric units of the Government Hospitals.

All patients were asked to provide urine for analysis to ascertain the use or not of cannabis prior to the admission. 83 patients (Males=39, Females=36), accepted to have their urine analysed. Patients who refused urine testing were 10 males and 7 females. The mean age of the patients accepting urine testing was 42 years, and the mean age of patients refusing urine testing was 29 years. This difference was statistically significant, Man Whitney $p=0.047$. The difference in sex between the patients who refused and did not refuse urine testing was not statistically different.

The mean age of admission of patients who resulted positive for cannabis in urine testing was 24.63 years, and the mean age of admission of patients who resulted negative for cannabis in urine testing was 44.63 years. The difference was statistically significant, Mann Whitney $\mathrm{p}=0.001$.

The difference in sex distribution within the group of patients who were positive to cannabis in urine testing was not statistically different from that of patients who where negative to cannabis in urine testing; Fisher's exact test, p 2 sided=0.279, p 1 sided $=0.194$.

\section{Discussion}

This study replicated the result of previous studies that showed an association between cannabis use and earlier onset of psychosis.

There can be various reasons for this association. The association could be coincidental. Cannabis is used more in the younger generations. So patients who start suffering from psychosis at an earlier age, have a greater chance that they would have been using cannabis than those who start suffering from psychosis at an older age. Another reason could be because males tend to use more illicit drugs than females and also tend to have an earlier age of onset of psychotic illness than females. The fact that in this study the difference in sex distribution within the group of patients who were positive to cannabis in urine testing was not statistically different from that of patients who where negative to cannabis in urine testing, indicates that the association found in this study between cannabis use and earlier age of onset of psychosis could not be due to this bias. 
It is also possible that the association between cannabis use and earlier age of onset of cannabis is because cannabis use precipitates psychosis in vulnerable individuals or that it could be the sole causative factor of psychotic illness in certain individuals. That cannabis use can precipitate psychotic illness in vulnerable individuals is supported by the knowledge that cannabis can cause psychotic like symptoms (14-15). Also, epidemiological studies have suggested that it is possible that persons who used cannabis prior to psychosis, would have never developed psychotic illness if they have not used cannabis $(9,16)$.

All the possible causes discussed above are not mutually exclusive, and it is possible that the reason for the association is some form of combination of the above factors.

\section{Validity and Limitations}

One of the main strengths of this study is that it based on the whole population of a country.

Since urine analysis was used to assess cannabis use by the subjects, the information about use of cannabis is very accurate and not subject to any bias.

It is very difficult to ascertain the exact time of the onset of psychosis. Thus we decided to use a proxy measure for onset of psychosis, which is the age of hospitalization for age of onset of psychosis. This can create a bias towards patients with insidious onset having their illness reported as starting at a later age than those with acute onset. This is because patients with acute onset of psychosis generally are admitted closer to the onset of their psychosis than those with a more insidious onset.

17 out of the 100 patients who fulfilled the inclusion criteria for the study refused to have their urine tested for use of cannabis. Those had a statistically significant younger age than those who did not refuse. There can be many reasons why patients refused to have their urine tested. Clinical experience in Malta shows that since in Malta smoking cannabis is illegal, patients who use cannabis are extremely reluctant to divulge this information. In fact it is common clinical practice that those who refuse to provide urine samples, are considered that most probably they would have used illicit drugs prior to the admission. So it is likely that a significant number of those who refused to have their urine tested in the study would have been positive for cannabis. Considering that those who refused urine testing were younger 
than those who agreed to have their urine tested, the bias that their refusal to participate in the study might have caused most probably is against not in favour of the hypothesis of the study that cannabis use results in an earlier ago of onset of psychosis.

Our study used a population that were referred as in-patients to hospital, thus excluding all those suffering from a form of psychotic illness that are either not treated or treated in the community only. This can result in an ecological fallacy in the study, but since in Malta there are no community mental services that cater for patients with psychosis, we can confidently say that it is very improbable that a patient with psychosis in Malta is not admitted to hospital.

Data was solely collected from medical files without actually interviewing the respective MDT or patient's themselves.

\section{Clinical Implications}

The younger generations are using cannabis more than before. This study shows that there is an association between cannabis use and an earlier age of onset of psychosis. Early age of onset of psychosis is associated with worse prognosis. Thus it is very important that the nature of the association between cannabis use and earlier age of onset of psychosis is studied more in depth.

\section{Acknowledgments:}

We would like to thank Dr. Neville Calleja MD MSc, for his input with statistical data.

\section{References}

Grech, A., Takei,N., Murray, R., Comparison of cannabis use in psychotic patients and controls in London and Malta 1998; Schizophr Res, 29: 22.

Schneier, F., R., \& Siris, S.G., A review of psychoactive substance use and abuse in schizophrenia: patterns of drug choice. 1987; Journal of Nervous and Mental Disease, 175: 641-652.

Smith, J. \& Huckler, S. Schizophrenia and substance abuse. 1994; Br J Psychiatry, 165: 13-21.

Warner ,R., Taylor, D., Wright, J., Sloat, A., Springett, G., Arnold,S., Weinberg, H. Substance use among the mentally ill: prevalence, reasons for use, and effects on illness. 1994; American Journal of Orthopsychiatry. 64: 30-39.

Andreasson, S., Allebeck, P., Engstorm, A., Rydberg,U. Cannabis and schizophrenia. A longitudinal study of Swedish Conscripts. 1987; Lancet, 2: 1483-1486.

Arseneault, L., Cannon, M., Poulton, R., Murray, R., Caspi, A., Moffit, T.E., Cannabis use in adolescence and risk for adult psychosis: longitudinal prospective study. 2002; British Medical Journal, 325: 12121213. 
Fergusson, D.M., Horwood, L.J., Swain-Campbell, N.R., Cannabis dependence and psychotic symptoms in young people. Psychol Med, 2003; 33: 15-21.

Henquet, C., Krabbbendam, L., Spauwen, J., Kaplan, C., Lieb, R., Mittchen, H.U., Van Os, J., Prospective cohort study of cannabis use, predisposition for psychosis, and psychotic symptoms in young people. British Medical Journal, 2005; 330: 11-14.

Van Os, J., Bak, M., Hanssen,M., Bijl, R.V.,de graaf, R., Verdoux, H., Cannabis use and psychosis: a longitudinal population based study. American Journal of Epidemiology, 2002; 156: 319-327.

Compton, M.T., Kelley, M.E., Ramsay, E.C., Makenya, P., Goulding, S.M., Esterberg, M.L., Stewart,T.,Walker,E.F., Association of Pre-Onset Cannabis, Alcohol, and Tobacco Use with Age at Onset of Prodrome and Age at Onset of Psychosis in First-Episode Patients. Am J Psychiatry, 2009; 166: 12511257.

Gonzalez-Pinto, A., Vega,P., Ibanez, B., Mosquera, F., Barbeito,S., Gutierrez,M., Ruiz de Azua,S., Vieta,E., Impact of cannabis and other drugs on age of onset of psychosis. J Clin Psychiatry, 2008; 69(8): 1210-6.

Veen N.D., Selten J., van der Tweel,I., Feller,W.G., Hoek,H.W., Kahn,R.S., Cannabis Use and Age at Onset of Schizophrenia. Am J Psychiatry, 2004; 161: 501-506.

Sugranyes, G., Flamarique, I., Parellada, E., Baeza, I., Goti, J., Fernandez-Egea E., Bernardo M., Cannabis use and age of diagnosis of schizophrenia. European Psychiatry, 2009; 24(5): 282-286.

Hall, W., Solowij,N., Adverse effects of cannabis. Lancet, 1998; 352: 1611-1616

Murray, R.M., Morrison, P.D., Henquet, C., Di Forti, M., Cannabis, the mind and society, the harsh realities. Neuroscience, 2007; 8: 885-895.

Zammit, S., Allebeck, P., Andreasson, S., Lundberg, I., Lewis, G., Self reported cannabis use as a risk factor for schizophrenia in Swedish conscripts of 1969: historical cohort study. British Medical Journal, 2002; 325: 1199-1201. 
Chapter 9

Discussion 
The importance of genetic factors in the aetiology of schizophrenia is shown by the high heritability estimates associated with this condition. But the importance of nongenetic factors in its aetiology was highlighted by recent studies that have also shown that there are significant variations in the incidence of schizophrenia in different places and in different subpopulations, and that these variations are associated with high attributable fractions (March et al., 2008, McGrath et al., 2004). Many persons are exposed to the putatuive environmental factors in the aetiology of schizphrenia, e.g. cannabis. But it is only a few of those exposed to these environmental factors that develop the illness. Thus, there must be some mechanism that results in vulnerable subgroups that are more sensitive to the schizophrnia causing effect of particualr environmental factors. This sensitivity in certain idividuals to the psychosis inducing effect to environmental risk factors may be mediated via genetic factors. Studies have supported this concept (Van Os et al., 2008). So, the way forward in understanding further the aetiology of this illness is both genetic and nongenetic studies, and finding an efficient way of integrating both approaches in the same studies.

All the studies in this thesis have focused on genetic or nongenetic factors of psychosis. The genetic studies focused on finding endophenotypes for schizophrenia and the nongenetic studies focused on some of the environmental exposures that potentially can contribute to the development of schizophrenia, namely: prenatal exposure to influenza, cannabis, exposure to urban living and low social class. In this section I will summarize and discuss the main findings of the studies presented here. I will then discuss how these results might contribute to the development of further research on the interaction between gene and environment in the aetilogy of schizophrenia .

\section{Endophenotypes}

The studies of this thesis have shown that enlarged lateral ventricles are potential endophenotypes. Together with enlarged third ventricles and hippocampal volume reduction, enlarged lateral ventricles are the structural brain changes most commonly associated with schizophrenia (Nelson et al., 1998, Shenton et al., 2001, Wright et al., 2000, Gur al., 2007).

The studies of this thesis did not show that whole brain volume, volume of cerebellum, volume of temporal lobe, volume of third ventricles, loss of frontooccipital torque and correlations between volume of whole brain or volume of different brain structures and results of neuropsychological tests are potential endophenotypic markers. 
The study 'Brain Volumes in Familial and Non-Familial Schizophrenic Probands and Their Unaffected Relatives' (McDonald et al., 2002) showed that lateral ventricle enlargment correlated with the likelihood of carrying susceptibility genes. This mirrored the results of previous studies (Weinberger et al., 1981, De Lisi et al., 1986, Sharma et al., 1998). Patients with schizophrenia, both those with a family history of schizophrenia and with no family history of schizophrenia, had enlarged lateral ventricles when compared to controls. There was no difference in lateral ventricular size between the two sets of patients. But there were interesting findings in the group of relatives of patients with schizophrenia. These findings were largely contributed by males. Relatives of patients in families multiply affected with schizophrenia had enlarged lateral ventricles, while relatives of patients with no family history of schizophrenia did not have enlarged lateral ventricle. The relatives who were presumed to transmit the genes of schizophrenia had similar enalrged lateral ventricles to that of patients with szhizophrenia. These findings can be interpreted that ventricular enlargement in males was associated with increased genetic risk, and thus being marker of genetic liabilty for schizophrenia and potential endophentypic marker. This study did not show similar findings as regards to the volume of whole brain, cerebellum, temporal lobes and third ventricle. Thus it did not show that these structures are potential endophenotypic markers. A very interesting finding in this study was also that patients with family history of schizophrenia, i.e. the subgroup in the study likely to have more genes prediposing to schizophrenia, that had obstetric complications had larger right lateral ventricles than their relatives and than the control group. This was not found in patients with schizophrenia who do not have a family history of the illness. This finding is an good example of the possible gene-environment interactions this thesis is about, since one can hypothesize that having genes for schizophrenai makes you part of a vulnerable subgroup in which obsteric complications can cause enlarged ventricles.

In the study 'Normal cerebral assymetry in familal and non-familal schizophrenic probands and their unaffected relatives' (Chapple at al., 2004) both probands with a diagnosis of schizophrenia and their relatives had larger right than left frontal regions, and larger left than right occipitoparietal region. This showed the presence of the normal pattern of cerebral assymetry, known as front-occipital torque in both patients with schizophrenia and their relatives, and thus these findings did not support the loss of this torque as a potential endophenotypic marker of schizophrenia.

In the study 'The Relationship Between Volumetric Brain Changes and Cognitive Function: A Family Study on Schizophrenia' (Toulopoulou et al., 2004) there are interesting findings on correlations between whole brain and structures of brain volumes and results of neuropsychological tests. There was a correlation between whole brain volume and intelligence. This was in patients with schizophrenia, in 
their healthy relatives and in controls. There was also in all these three groups a correlation between IQ and volume of hippocampus. All measures of IQ correlated with right hippocampal volume, and verbal IQ was also associated with left hippocampus. There was also an association between delayed recall of verbal memory and the volume of the cerebellum. All these results supported results of previous studies. The only difference from the patients with schizophrenia to the others (controls and healthy relatives), was that there were correlations between left hippocampal volume and estimated full-scale IQ and performance IQ in healthy controls and in healthy relatives of patients with schizophrenia, but not in the patients. But in terms of search for endophenotypic markers, this study did not contribute. The only result unique to the group of the relatives was that there was an association between visual memory (immediate and delayed recall) and volume of left hippocampus and cerebellum. But these results were nullified when for the left hippocampus intelligence was considered as a covariate in the analysis, and when in the case of the cerebellum intelligence and verbal memory were also considered as covariates in the analysis.

\section{Prenatal Exposure to Influenza}

The study 'Maternal exposure to influenza and paranoid schizophrenia' (Grech et al., 1997) did not support the hypothesis that there is an association between in utero exposure to influenza and paranoid schizophrenia. This finding is in line to what recent comprehensive evaluations of the studies on this subject have shown (Selten et al., 2009). Crude analysis in the study showed that an increase in exposure to influenza during the fifth month of gestation was accompanied with an increase in the proportion of patients with paranoid schizophrenia. But when allowance was made for sex, seasonality and birth period, this association was lost.

\section{Urbanicity and Social Class}

The study in this thesis that focused on the possible role of Urbanicity and Social Class in the aetiology of psychosis is 'Socio-economic status and population density risk factors for psychosis: prospective incidence study in the Maltese Islands'. This study replicated results of previous studies that lower social class and exposure to urban living are associated with psychosis (Eaton 1974, Takei et al., 1995, Marcelis et al., 1998, Eaton et al., 2000, Schelin et al., 2000, Allardyce et al., 2001, Sundquist et al.,2004, Kirkbride et al., 2006, Susser et al., 2006). In this study, incidence of psychosis was statistically significant highest in the region of Malta with most residents in the lowest socio economic group. The second highest incidence of psycho- 
sis was in the region of Malta that has the highest population density. The main advantage of this study was that it was a whole population based study.

\section{Cannabis}

The two studies on cannabis presented in the thesis support the notion that cannabis has a potential role in the alteration of psychotic illness.

In the study 'Cannabis use and outcome of recent onset psychosis' (Grech et al., 2005) after a 4-year follow up period, patients with psychosis of recent onset who persisted in use cannabis had more positive (but not negative) symptoms and more continuous illness. This supports the findings of other studies that show that cannabis use can modulate negatively the course of psychotic illness (Pencer et al., 2005, Caspari 1999, Degenhardt et al., 2007, Gonzalez-Pinto et al., 2009, Martinez-Arevalo et al., 1994, Linszen at al., 1994, Stirling et al., 2005, Hides et al., 2006).

In the study 'Cannabis Use and Age of Admission to a Psychiatric Unit for First Episode of Psychosis; a Whole Population Based Study', the mean age of first admission to hospital for psychosis in patients whose urine at admission was positive to cannabis was significantly less than those whose urine at admission was negative to cannabis. This supports the results of previous studies that cannabis use can result in earlier age of onset of psychotic illness, as shown by a recent systemic metaanalysis (Large et al., 2011).

\section{Further Development of Research}

A brief summary of the results of the studies presented in this thesis is:

\section{A. Negative Findings:}

1. There is no evidence that whole brain volume, volume of cerebellum, volume of temporal lobe, volume of third ventricle, loss of fronto-occipital torque and correlations between volume of whole brain or volume of different brain structures and results of neuropsychological tests are potential endophenotypic markers,

2. There is no association between prenatal exposure to influenza and the development of schizophrenia.

\section{B. Positive Findings:}

1. Enlarged Lateral Ventricles are potential endophenotypic markers,

2. Cannabis Use has a potential modulating effect of psychotic illness since its use results into earlier age of onset of psychosis and worse outcome of psychosis of recent onset, 
3. Lower Socioeconomic Status and Urban Living are associated with higher incidence of psychosis,

4. Patients with family history of schizophrenia that had obstetric complications had larger right lateral ventricle than their relatives and than the control group. This was not found in patients with schizophrenia who do not have a family history of the illness.

These positive findings support results of other studies that are discussed in the Introduction of the Thesis. The significance of the combination of the above results is that they highlight several genetic and nongenetic aspects in the development of schizophrenia. As stated above, the way forward in the research on the aetiology of schizophrenia, are studies that in their design they assess the interaction between genes and environment. Studying the gene environment interaction is very complex. This complexity is increased further by the possibility of not only gene environment interactions but also by the possibilities of gene gene interactions and environment environment interactions in the same process leading to the development of psychotic illness.

Due to this complexity, there are various ways how one can study these interactions. While it can be not that difficult to identify a way of measuring the environmental exposure, it may prove to be more difficult to measure the genetic component. The genetic component can be measured by direct measures (molecular genetics) or indirect measures. Indirect measures of genetic risk include being a relative (family studies), or a twin (twin studies) of a patient with schizophrenia. While findings of studies using direct measures of genetic risks have their advantages, mainly that they are more specific and thus their results are more proximal to the actual mechanisms of the aetiology of the illness, studies using the indirect measures still have their importance and can contribute further. The advantages of the studies using the indirect measure of genetic risk are mainly that they are well validated and that the genetic risk in them represents the net genetic effect, including also gene gene interactions. There are several ways how this type of studies can be improved to give more significant results. Such ways can include: (a) by better definition of the environmental risk (e.g. its timing or severity), (b) by including different levels of genetic risk (e.g. including more second and their degree relatives, or twin studies including extended family members.), and/or (c) by better characterization of the phenotype. For better characterization of the phenotype in this type of studies perhaps one can use the approach of using endophenotypic markers. Then, the further knowledge we have from such studies can be used for developing more efficient studies using the direct genetic risk of assessment. 
Thus, a possible improvement on previous studies on the interaction between gene and environment in the aetiology of schizophrenia is family studies including second and third degree relatives, that have better characterization of the phenotype. The potential of such studies has been partly shown by the finding of the study presented in this thesis, 'Brain Volumes in Familial and Non-Familial Schizophrenic Probands and Their Unaffected Relatives' (McDonald et al., 2002), in which it was shown that it is possible that there is some form of interaction between genetic risk for schizophrenia, obstetric complications and enlarged ventricles.

Better characterization of the phenotype can be done by use of endophenotypes. Enlarged lateral ventricles are commonly associated with schizophrenia and the study 'Brain Volumes in Familial and Non-Familial Schizophrenic Probands and Their Unaffected Relatives' (McDonald et al., 2002) showed that they have the potential of endophenotypic markers. But at this stage in research, despite the findings of the study presented, it is too early to state with confidence that 'Enlarged Lateral Ventricles' is a definite endophenotype for schizophrenia. This is because endophenotypes need to be heritable, and research on the heritability of the lateral ventricles of normal twins, so far has shown contrasting results. Some studies showed high heritability of the lateral ventricles (Pfefferbaum et al., 2000, Reveley et al., 1984), while other studies showed that the heritability of the lateral ventricles is low (Baare et al., 2001, Wright et al., 2002). So further studies are required to clear the issue of the lateral ventricles' heritability, before one can suggest their definite use as endophenotypes.

Other than the use of endophenotypes, the other important step for the improvement of the family studies proposed, would be the better definition of the environmental risk factors. One can take the examples of urbanicity and cannabis use that the studies presented in this thesis have shown an association with psychosis.

Urbanicity is most probably a proxy measure of some environmental risk factor or factors that are so far unidentified, which are themselves interacting with the genes and not urbanicity per se. Research has shown that there are other factors, that are more prevalent in urban living and that lead to 'social maladjustment', that are potentially causing the association between schizophrenia and urbanicity (Van Os et al., 2000; Zammit S. et al., 2010). Such factors include single parent family, single marital status and residential instability. So the suggested family studies will be better if the environmental risk is defined as one of these factors rather than using the wide term of urbanicity in terms of population density as was used in the studies of this thesis. 
As regards Cannabis, the studies I presented in this thesis have collapsed cannabis used by all participants in the studies as being of similar content and potency. But cannabis has several constituents, the two principal constituents being delta- 9 tetrahydrocanabinol (THC) and cannabidiol (CBD). THC is the main psychoactive ingredient, and CBD does not induce hallucinations and delusions. Cannabis that is available in the streets consists of different types, with different properties. For example cannabis resin (in the streets known as 'hash'), has less THC, than simsemilla type of cannabis (in the streets known as 'skunk') (Di Forti et al., 2009). So presumably they have different type or degree of involvement in the psychogenetic role that they can play. Thus, for better definition of cannabis as an environmental risk factor for schizophrenia, these differences need to be taken into consideration.

\section{References}

Allardyce, J., Boydell, J., Van Os, J., Morrison, G., Castle, D., Murray, R.M., McCreadie, R.G. (2001) Comparison of the incidence of schizophrenia in rural Dumfries and Galloway and urban Camberwell. Br J Psychiatry,179: 335-9.

Baare, W.F., Hulsoff Pol, H.E., Boosman, D.I., Posthuma, D., de Gesus, E.J., Schnack, H.G., van Oel, C.J., Kahn, R.S., (2001) Quantitative genetic modeling of variation in human brain morphology, Cerebral Cortex , 11: 816-824.

Caspari, D. (1999) Cannabis and schizophrenia: results of a follow-up study. Eur Arch Psychiatry Clin Neurosci, 249(1): 45-49.

Chapple, B., Grech, A., Sham, P., Toulopoulou, T., Walshe, M., Schulze, K., Morgan, K., Murray, R. M., \& McDonald, C. (2004). Normal cerebral asymmetry in familial and non-familial schizophrenic probands and their unaffected relatives. Schizophrenia Research, 67(1), 33-40

Degenhardt, L., Tennant, C., Gilmour, S., Schofield, D., Nash, L., Hall, W., McKay, D., (2007). The temporal dynamics of relationships between cannabis, psychosis and depression among young adults with psychotic disorders: findings from a 10-month prospective study. Psychol Med, 37: 1-8.

De Lisi, L.E.,Goldin, L.R., Hamovit, J.R., Maxwell, M.E., Kurtz, D., Gershon, E.S., (1986) A family study of the association of increased ventricular size with schizophrenia. Arch Gen Psychiatry, 43: 148-153.

di Forti, M., Dazzan, P., Mondelli, V., Russo, M., Butt, M., Still, S., Powell, J., Murray, R.M., (2009) Highpotency cannabis and risk of psychosis. Br J Psychiatry,195: 488-491.

Eaton, W.W., (1974) Residence, social class and schizophrenia. J Health Soc Behav, 15: 289-99.

Eaton, W.W., Mortensen, P.B., Frydenber, M., (2000) Obstetric factors, urbanization and psychosis. Schizophr Res, 43:117-23.

Gonzalez-Pinto, A., Alberich, S., Barbeito, S., Gutierraz, M., Vega,P., Ibanez, B.,Karim Haidar, M., Vieta,E., Arang,C., (2009) Cannabis and First-Episode Psychosis: Different Long-term Outcomes Depending on Continued or Discontinued Use. Schizophrenia Bullettin 37, 631-639.

Grech, A., Takei, N., \& Murray, R. M. (1997). Maternal exposure to influenza and paranoid schizophrenia. Schizophrenia Research, 26(2-3), 121-125

Grech, A., Van Os, J., Jones, P. B., Lewis, S. W., \& Murray, R. M. (2005). Cannabis use and outcome of recent onset psychosis. European Psychiatry, 20(4), 349-353

Gur, R.E., Keshavan, M.S, Lawrie, S.M. (2007) Deconstructing psychosis with human brain imaging. Schizophr Bull, 33 (4): 921-931.

Hides, L., Dawe, S., Kavanagh, D.J.,Young, R.M., (2006) Psychotic symptoms and cannabis relapse in recent-onset psychosis. Br J Psychiatry,189: 137-143. 
Kirkbride, J.B., Fearon, P., Morgan,C., Dazzan, P., Morgan, K., Tarrant, J., Lloyd, T., Holloway, J., Hutchinson,G., Leff, J.P., Mallett, R.M., Harrison, G.L., Murray, R.M., Jones, P.B. (2006) Heterogenity in incidence rates of schizophrenia and other psychotic disorders : findings from the 3-centre AESOP Study. Arch Gen Psychiatry, 63(3):250-8.

Linszen D.H., Dingemans P.M., Lenoir M.E., (1994) Cannabis abuse and the course of recent -onset schizophrenic disorders. Arch Gen Psychiatry, 51 (4), 273-279.

Large, M., Shrma, S., Compton, M.T., Slade,T., Nielssen ,O. (2011) Cannabis Use and Earlier Onset of Psychosis: A Systematic Meta-analysis. Arch Gen Psychiatry, 2011;68(6):555-561.

March,D., Hatch,S.L., Morgan,C., Kirkbride,B.,Bresenahan,M.,Fearon,P.,Susser,E. (2008) Psychosis and Place. Epidemiol Rev, 30: 84-100.

Marcelis, M., Navarro-Mateu, F., Murray, R., Selten, J.P., Van Os, J. (1998) Urbanization and psychosis: a study of 1942-1978 birth cohorts in The Netherlands. Psychol Med, 28(4):871-9.

Martinez-Arevalo, M.J., Calcedo-Ordonez, A., Varo-Prieto, J.R., (1994) Cannabis consumption as a prognostic factor in schizophrenia. Br J Psychiatry,164: 679-81.

McDonald, C., Grech, A., Touopoulou, T., Schulze, K., Chapple, B., Sham, P., Walshe, M., Sharma, T., Sigmundsson, T., Chitnis, X., \& Murray, R. M. (2002). Brain volumes in familial and non-familial schizophrenic probands and their unaffected relatives. American journal of medical genetics, 114(6), 616-625

McGrath,J., Saha,S., Welham,J., El Saadi,O., MacCauley,C., Chant,D. (2004) A systemic review of the incidence of schizophrenia: the distribution of rates and the influence of sex, urbanicity, migrant status and methodology. BMC Med. Apr 28: $2: 13$.

Nelson, M.D., Saykin, A.J., Flashman, L.A., Riordan, H.J., (1998) Hippocampal volume reduction in schizophrenia as assessed by magnetic resonance imaging- A meta-analytic study. Arch Gen Psychiatry, 55 : 434-440.

Pencer, A., Addington, J., Addington, D. (2005) Outcome of first episode of psychosis in adolescence: a 2year follow-up. Psychiatry Res, 133: 35-43.

Pfefferbaum, A., Sullivan, E.V., Swan, G.E., Carmelli, D., (2000) Brain structure in men remains highly heritable in the seventh and eighth decades of life. Neurobiology of Aging, 21: 56-74.

Revely, A.M., Revely, M.A., Chitkara, B., Clifford, C., (1984) The genetic basis of cerebral ventricular volume. Psychiatry Research, 13: 261-266.

Schelin,E., Munk-Jorgensen,P. Olesen,A.,Gerlach,H., (2000) Regional differences in schizophrenia incidence in Denmark. Acta Psychiatr Scand, 101:293-9.

Selten,J.P., Frissen,A., Lensvelt-Mulders,G., Morgan,V.A. (2009) Schizophrenia and 1957 pandemic of influenza: meta-analysis. Schizophr Bull, 36(2):219-228.

Sharma,T., Lancater, E., Lee,D., Lewis,S., Sigmundsson.,T., Takei,N., Gurling, H., Barta,P., Pearlson, G., Murray, R.M., (1998) Brain changes in schizophrenia, Volumetric MRI study of families multiply affected with schizophrenia. The Maudsley Family Study 5. Br J Psychiatry, 173: 132-138.

Shenton, M.E., Dickey, C.C., Frumin, M., McCarley, R.W., (2001) A review of MRI findings in schizophrenia. Schizophr Res, 49: 1-52.

Stirling, J., Lewis, S., Hopkins, R., White, C., (2005). Cannabis use prior to first onset psychosis predicts spared neurocognition at 10-year follow-up. Schizophr Res,75: 135-137.

Sundquist,K., Frank,G.,Sundquist,J., (2004) Urbanisation and incidence of psychosis and depression. Br J Psychiatry,184:293-8.

Susser, E., Schwartz, S., Morabia, A., Bromet,E.J. (2006) Psychiatric epidemiology: searching for the causes of mental disorders. Oxford University Press; New York

Takei, N., Sham,P. ,O’Callaghan, E., (1995) Schizophrenia: increased risk associated with winter birth and city birth- a case-control study in 12 regions within England and Wales. J Epidemiol Community Health, 49: 106-7.

Toulopoulou, T., Grech, A., Morris, R. G., Schulze, K., McDonald, C., Chapple, B., Rabe-Hesketh, S., \& Murray, R. M. (2004). The relationship between volumetric brain changes and cognitive function: A family study on schizophrenia. Biological Psychiatry, 56(6), 447-453 
van Os, J., Driessen, G., Gunther, N., Delespaul, P., (2000) Neighbourhood variation in incidence of schizophrenia. Evidence for person-environment interaction. Br J Psychiatry, 176: 243-248.

van Os, J., Rutten, B.P., Poulton,R., (2008) Gene-environment interactions in schizophrenia: review of epidemiological findings and future directions. Schizophr. Bull, 34: 1066-1082.

Weinberger, D.R., DeLisi, L.E., Neophytides, A.N., Wyatt, R.J., (1981) Familial aspects of CT scan abnormalities in choronic schizophrenic patients. Psychiatry Res, 4: 65-71.

Wright, I.C., Rabe-Hesketh, S., Woodruff, P.W.R., David, A.S., Murray, R.M., Bullmore, E.T., (2000)Metaanalysis of regional brain volumes in schizophrenia. Am J Psychiatry, 157: 16-25.

Wright, I.C., Sham, P., Murray, R.M., Weinberger, D. R., Bullmore, E.T. (2002) Genetic contribution to regional variability in human brain structure: methods and preliminary results. Neuroimage, 17: 256-271.

Zammit, S., Lewsi, G., Rasbash, J., Dolma, C., Gustaffson, J.E., Allebeck, P., (2010) Individuals, schools, and neighborhood: a multilevel longitudinal study of variation in incidence of psychotic disorders. Arch Gen Psychiatry, 67: 914-922. 
Chapter 10

Summary 
Schizophrenia is a severe mental illness, and despite the fact that a lot of research has been dedicated to identifying its aetiology, what exactly causes schizophrenia is still unknown. But from research findings so far, one can confidently say that in the aetiology of schizophrenia there are both genetic and environmental factors. This thesis is on the aetiology of schizophrenia, and thus it contains studies both on genetic and non genetic factors, and suggests a possible model of how the interaction between them in the aetiology of schizophrenia is studied further. 'Chapter 1 ' is a General Introduction to the thesis. 'Chapters 2, 3 and 4', focus on the genetic component of schizophrenia, and are family studies. 'Chapters 5, 6, 7 and 8' are studies on nongentic factors in the aetiology of schizophrenia, and 'Chapter 9' is a General Discussion.

'Chapter 1 ' starts with a short overview of the literature that supports the genetic element in the aetiology of schizophrenia. It then presents the notion of the use of 'Endophenotypes'. It defines what 'Endophenotypes' are, and the possible advantages of their use instead of clinically defined schizophrenia in genetic studies. It presents literature that shows that in schizophrenia there are structural brain abnormalities and neuropsychological impairments, and thus their potential to be used as 'Endophenotypes' of schizophrenia. 'Chapter 1'continues with literature review of studies on the possible roles prenatal exposure to Influenza, Urbanicity, Social Class and Cannabis in the development of schizophrenia. This chapter then concludes with a summary of the studies presented in this thesis.

In the studies presented in 'Chapter 2 and 3' we examined structural brain changes found in patients with schizophrenia and their relatives. These two studies were designed to provide a gradient of genetic risk for schizophrenia in first degree relatives of probands who have a diagnosis of schizophrenia.

In the study of 'Chapter 2' we examined if the structural brain changes found in patients with schizophrenia and their relatives are due to genetic factors or obstetric complications. Brain structures studied were: whole brain, lateral ventricles, third ventricle, cerebellum and temporal lobes. We studied two sets of families. One set consisted of probands with a diagnosis of schizophrenia of families multiply affected by schizophrenia and their unaffected relatives. The other set consisted of families with no other affected individual with schizophrenia. Controls were also used. This study showed that lateral ventricle enlargement correlated with the likelihood of carrying susceptibility genes for schizophrenia, and thus highlighting the potential of lateral ventricles being used in studies as 'Endophenotypes' of schizophrenia.

The study presented in 'Chapter 3', is a family study with the same design as the study presented in 'Chapter 2' and focused on if the reported loss of the normal fronto-occipital asymmetry in patients with schizophrenia and in their non-affected relatives could be associated with genetic susceptibility. The result of this study did not find any association between the loss of this torque and genetic susceptibility 
for schizophrenia, and thus it did not support its use as a potential 'Endophenotype' of schizophrenia.

The study of 'Chapter 4' assessed if the neuropsychological deficits found in schizophrenia can constitute a familial, probably genetic, risk for schizophrenia. The study consisted of a family study where we examined the correlation between structure and function of the brain, and if this correlation had particular characteristics in patients with schizophrenia or their relatives. Neuropsychological assessments were done by an extensive battery of tests, and the brain structures measured by MRI were for whole brain, prefrontal region, lateral ventricles, third ventricles, temporal lobes, hippocampi and cerebellum. This study had interesting findings on correlations between whole brain and structures of brain volumes and results of neuropsychological tests. But in terms of search for endophenotypic markers, all findings were negative.

The study of 'Chapter 5' studied if the proportion of persons with a diagnosis of paranoid schizophrenia would increase with an increase in the level of influenza exposure during gestation. The number of deaths attributed to influenza was used as a proxy measure of the prevalence of influenza, and the exposure months (i.e. the fifth month prior to birth) were divided into quartiles of increasing exposure to influenza according to the frequency of these deaths. Crude analysis in the study showed that an increase in exposure to influenza during the fifth month of gestation was accompanied with an increase in the proportion of persons with a diagnosis of paranoid schizophrenia. But when allowance was made for sex, seasonality and birth period, this association was lost.

'Chapter 6 ' is a whole population prospective cross sectional study based in the Maltese Islands. All patients with first onset psychosis admitted to one of the psychiatric units in the Maltese islands during a one year period were included in the study. This study replicated results of previous studies that lower social class and exposure to urban living are associated with psychosis.

'Chapters 7' is a study on the influence of cannabis use on outcome of recent onset psychosis. It is a 4-year follow up study of a cohort of patients in South London with psychosis who had onset within 5 years of index admission. The patients followed-up were divided into four groups according to duration of cannabis use, taking index admission as reference point. The patients in this study who continued to use cannabis had more positive (but not negative) symptoms and more continuous illness.

'Chapter 8 ' is a whole population based study conducted in the Maltese Islands on patients with first episode psychosis. The aim of this study was to asses if cannabis can hasten the age of onset of patients with psychosis, and thus implying that it has an aetiological role. The results of this study showed that the mean age of first admission to hospital for psychosis in patients whose urine at admission was posi- 
tive to cannabis was significantly less than those whose urine at admission was negative to cannabis.

'Chapter 9' is a discussion which highlights and integrates the results of the studies presented in this thesis. There is discussion on how according to the studies presented in the thesis enlarged lateral ventricles are the only potential 'Endophenotype' of schizophrenia out of all the structural brain abnormalities and neuropsychological deficits studied, and that further research to confirm this is required. The negative and positive findings of the nongenetic studies in the thesis are also discussed. In the last section of this chapter I discuss a possible better model than previous ones, to be used for studying the interaction between genes and environment in the aetiology of schizophrenia. How the findings of the studies presented in this thesis can help in further research, by means of this model, is also discussed. 


\section{Acknowledgments}

First and foremost, I wish to thank Maastricht University, which gave me the possibility to defend this thesis to obtain the degree of Doctor, and in particular my promotor Prof. Jim van Os. Since I have met him at the Institute of Psychiatry when I was a junior doctor he has consistently provided me with sound advice and genuine friendship in abundance. From the University of Maastricht I also wish to thank Elsa Misdom for her persistent help during the preparation of this thesis. I wish thank all the participants in the studies presented in this thesis, because without them these studies would have never materialized. Colleagues and close friends both in London and Malta were instrumental in making working for this thesis a pleasurable experience. A final special thanks goes to my wife Marla, who was my rock throughout the whole process. 



\section{Curriculum vitae}

Dr. Anton Grech was born on 16 November 1967 in Gozo, Malta. He is married to Marla nee Vassallo, and they have three children. He graduated as Doctor of Medicine from the University of Malta in 1992. He became a Member of the Royal college of Psychiatrists, UK, in 1997, and he became a Fellow of the same college in 2011. In 1999 he obtained an M.Sc. in Psychiatry from King's College, University of London. He trained and worked at the Maudsley Hospital in London, between 1994 and 1998. During 1998 he was also a Clinical-Academic Lecturer in the Department of Psychiatry, Institute of Psychiatry, King's College, University of London. Between 1999 and 2002 he was Honorary Researcher within the same Department. In 1999 he proceeded to Malta, where he was Senior Registrar in Psychiatry until 2003, when he was appointed Consultant Psychiatrist with a special interest in Addictions and Neuropsychiatry. In 2000 he was appointed Lecturer in Department of Psychiatry of the Faculty of Medicine and Surgery of the University of Malta, and in 2008 he was appointed as Senior Lecturer within the same Department. In 2011 he was appointed as Senior Research Fellow in the Bedfordshire Centre for Mental Health Research in association with the University of Cambridge, United Kingdom. In 2011 he was also appointed as Clinical Chairman of the Department of Psychiatry in the Ministry of Health, Malta. His main research is on the aetiology of schizophrenia, and it was based at the Institute of Psychiatry London and at the University of Malta. He has published in international psychiatric journals, and presented and chaired in international psychiatric conferences. In 2008 he was chosen as one of the 30 European Scientists to be featured in the book 'Portraits of Science; Scientists of Tomorrow', published by the European Federation of Pharmaceutical Industries and Associations, to commemorate its 30 th anniversary. In Malta he is a member of various national boards and commissions. He believes a lot in using the media to educate on mental health, and for the last years in Malta he conducted radio and TV programmes on issues related to mental health. 